\title{
From seeking health to finding healths : the politics of large-scale cooperation in nutrition science
}

Citation for published version (APA):

Penders, B. (2008). From seeking health to finding healths : the politics of large-scale cooperation in nutrition science. [Doctoral Thesis, Maastricht University]. Datawyse / Universitaire Pers Maastricht. https://doi.org/10.26481/dis.20081001bp

Document status and date:

Published: 01/01/2008

DOI:

10.26481/dis.20081001bp

Document Version:

Publisher's PDF, also known as Version of record

\section{Please check the document version of this publication:}

- A submitted manuscript is the version of the article upon submission and before peer-review. There can be important differences between the submitted version and the official published version of record.

People interested in the research are advised to contact the author for the final version of the publication, or visit the DOI to the publisher's website.

- The final author version and the galley proof are versions of the publication after peer review.

- The final published version features the final layout of the paper including the volume, issue and page numbers.

Link to publication

\footnotetext{
General rights rights.

- You may freely distribute the URL identifying the publication in the public portal. please follow below link for the End User Agreement:

www.umlib.nl/taverne-license

Take down policy

If you believe that this document breaches copyright please contact us at:

repository@maastrichtuniversity.nl

providing details and we will investigate your claim.
}

Copyright and moral rights for the publications made accessible in the public portal are retained by the authors and/or other copyright owners and it is a condition of accessing publications that users recognise and abide by the legal requirements associated with these

- Users may download and print one copy of any publication from the public portal for the purpose of private study or research.

- You may not further distribute the material or use it for any profit-making activity or commercial gain

If the publication is distributed under the terms of Article $25 \mathrm{fa}$ of the Dutch Copyright Act, indicated by the "Taverne" license above, 


\section{FROM SEEKING HEALTH TO FINDING HEALTHS}

The politics of large-scale cooperation in nutrition science

\section{BART PENDERS}


(C) Copyright Bart Penders, Maastricht 2008

ISBN 978-90-5278-735-0

Cover Design and Layout by Bart Penders

Printed by Datawyse Maastricht

Universitaire Pers Maastricht 


\section{FROM SEEKING HEALTH TO FINDING HEALTHS}

The politics of large-scale cooperation in nutrition science

\section{PROEFSCHRIFT}

ter verkrijging van de graad van doctor aan de Universiteit Maastricht, op gezag van de Rector Magnificus, Prof. mr. G.P.M.F. Mols, volgens het besluit van het College van Decanen, in het openbaar te verdedigen op woensdag 1 oktober 2008 om 14.00 uur

door

Bart Penders

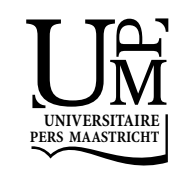




\section{Promotores}

Prof. dr. R. Vos

Prof. dr. K. Horstman

\section{Beoordelingscommissie}

Prof. dr. ir. W.E. Bijker

Prof. dr. M.J.J.A.A. Korthals

Prof. dr. E.C.M. Mariman

Prof. dr. W.H.M. Saris

Prof. dr. P.A.Th.J. Werrij
(Universiteit Maastricht \& Technische

Universiteit Eindhoven) (voorzitter)

(Wageningen Universiteit)

(Universiteit Maastricht \& DSM)

(Wageningen Universiteit \& Radboud

Universiteit Nijmegen) 


\section{CONTENTS}

PREFACE

\section{Chapter 1}

MAKING KNOWLEDGE AND NORMS IN LARGE-SCALE SCIENCE: THE CASE OF NUTRIGENOMICS

1.1. Big Science on the agenda 17

1.2. Size is not the issue 19

1.3. Entangled science on the agenda 23

1.4. Solving big problems 28

1.5. Politics of problem solving 30

1.6. Nutrigenomics: the case of contemporary nutrition science $\quad 32$

1.7. Structure of the book 35

\section{Chapter 2}

NAVIGATING LARGE-SCALE NUTRIGENOMIC RESEARCH PRACTICE

2.1. Studying large-scale science 38

2.2. Entering and charting the complex field of nutrigenomics 41

2.3. Particularities of ethnography 44

2.3.1. The outsider as insider 45

2.3.2. Two narratives on interaction 46

2.4. Understanding interaction as reciprocal sensitisation 49

\section{Chapter 3}

MAKING LARGE-SCALE NUTRIGENOMICS WORK

3.1. The birth of the Gut Health programme 54

$\begin{array}{ll}\text { 3.2. From paper to practice } & 61\end{array}$

3.3. Doability in large-scale science 66

3.4. Food industry as a modular adhesive 70

3.5. Sizing up science to achieve doability? 75 3.6. Health and nutrition: making them doable; making
them molecular 


\section{Chapter 4}

WALKING THE LINE BETWEEN LAB AND

COMPUTATION IN NUTRITION SCIENCE

4.1. Disciplines and interdisciplinarity 84

4.2. From paradigms to styles of science 85

4.3. Bittersweet cooperation between 'wet' and 'dry' $\quad 90$

4.4. The power of maps 94

4.5. Bridging and redrawing the boundary 99

4.6. Multiple healths from multiple styles 103

\section{Chapter 5}

PERSONALISED NUTRITION: IS IT DOABLE? 107

5.1. The promises of personalised nutrition 108

5.2. The doability of personalised nutrition 111

5.3. Individual and group nutrition: an inconsistency? 115

$\begin{array}{ll}\text { 5.4. Why doability matters to ELSI } & 119\end{array}$

\section{Chapter 6}

THE POLITICS OF LARGE-SCALE NUTRITION SCIENCE 125

6.1. Learning from large-scale nutrigenomic research 126

6.1.1. A network of doabilities 126

6.1.2. The size and entanglement of science 132

6.2. Towards a molecularisation of health? 136

6.3. Doability to nutrigenomicists and ELSI researchers 139

$\begin{array}{ll}\text { NOTES } & 141\end{array}$

Notes to the preface $\quad 141$

Notes to chapter $1 \quad 141$

Notes to chapter $2 \quad 145$

Notes to chapter $3 \quad 149$

Notes to chapter $4 \quad 151$

Notes to chapter 5

Notes to chapter $6 \quad 157$ 
REFERENCES

ENGLISH SUMMARY

181

NEDERLANDSE SAMENVATTING

185

CURRICULUM VITAE

189

LIST OF PUBLICATIONS

191 


\section{PREFACE}

I am holding a serum bottle, a small one. I just filled it and put a rubber plug in it. At my left are twenty identical bottles, filled with the exact same medium and at my right lies a little pile of aluminium cylinders, caps. Using a special tool, I can apply them to the neck of the serum bottle and partially over the rubber plug. One by one I add one of these caps to all of the small glass bottles. The aluminium seal is meant to restrain the rubber plug, to prevent them from popping out of the bottles, when the internal pressure rises over the pressure of the surrounding air. When all the bottles are closed and capped, I reach under the desk and grab two steel cages. The wall in front of me is covered by tubes, pipes, clocks and displays in various colours. I put the two cages in front of me and take a pair of safety goggles from the adjacent wall, lock the cages and shift a panel of safety glass down. All these safety precautions are taken, because at a high pressure, serum bottles could explode. Subsequently, I take ten of the tubes from the wall of the gas station and attach needles to the ends of them. These are long needles, just long enough for them, when stabbed into the rubber plug, to enter the air phase inside. I hit the switches and gas is pumped into the bottles. When twice the normal pressure is achieved, I turn on the vacuum pump to pull all of the gas out again. Then I shut the pump down, and switch the gas on again. I fill and empty the gas in the bottle five times, to make sure as little oxygen as possible is left in the bottle, even in the liquid at the bottom. Subsequently I remove all the needles from the bottles and shut the gas station down. My bottles are ready for autoclaving and culturing (Regensburg, Germany; 2001).

Three years later, I am standing next to a laboratory bench, looking at a $\mathrm{PhD}$ student performing these actions, albeit a bit differently. She is culturing bacteria is the exact same serum bottles I used before, slowly pressing the needle as it penetrates the serum bottle to make sure it doesn't break and expose the 
culture to so horrible a thing as oxygen. She is very proficient at it, has done it many times before; possibly, even probably, more often than I did. A few minutes earlier, she asked me to cap her serum bottles. When she observed me doing so, and saw the pace at which I did so, she grew aware that this was not my first time (Netherlands; 2004) ${ }^{1}$.

In the immediate beginning it was odd, observing and describing a research practice of which I had been a part for quite some time. I have been trained as a biologist, a microbiologist to be exact. I have worked and lived in microbiological laboratories for a few years. I have conducted experiments and I have seen them succeed and fail. I have felt the frustration of redoing the same experiment over and over again (e.g. my first MSc thesis lists 997 manual PCR reactions in an appendix, over a course of 9 months). I never managed to publish a research paper, but did manage to get into the acknowledgements of two ${ }^{2}$. It was not because of a lack of interest in biology that I moved into science and technology studies (STS). On the contrary, biology, microbiology and genetics continue to fascinate me to this day. Equally fascinating, I find the contexts in which they exist, whether social, political, financial or otherwise, which motivates my transition from biology to STS.

My background in biology has had implications for the way this study has been set up, for the way in which I have interacted with the scientists who have been the object of this study, for the journals I have selected to present my findings in, the conferences I have attended and much more. It enabled a higher degree of immersion in the research practice, via participating in some experiments during periods of observation, of via the participation in discussions at conferences or in journals. In contrast, it also meant a higher risk of 'going native'.

These particularities make the book that lies before you, as well as the study it represents, neither better, nor worse, than would have been the case if I had a different disciplinary background. It does make it different, gives it a different flavour. For instance, in chapter 2, I will present some relevant methodological issues that reflect my disciplinary background. Nevertheless, for the most part the relationship between object and subject and the way it has been influenced and the consequences this has had, remains a question of methodological and theoretical relevance which has not received due attention. I will continue to address this matter for the coming years and I am grateful that Maastricht University, and especially Klasien Horstman and Rein Vos, have given me the opportunity to do so. 
Four centuries ago, John Donne wrote that 'no man is an island' 3 . He referred to the interconnectedness of human beings; the realisation that they do not exist in isolation from the people around them, and the world they live in. Donne's words equally apply to the academic world and its inhabitants, whether scientists or scholars. In this ethnographic analysis of large-scale scientific research, one can observe very much the same. Laboratories do not exist independent of one another, nor do the people, materials and knowledge in them. Although from time to time, it may seem that way. Not only is this part of the topic of the book that lies before you (if you want to find out how all of this turns out, you will have to start reading the rest of the book, something you will undoubtedly do very soon) but it also refers to the countless others (both people and material) that contributed their share to the completion of this book. Writing a book or a $\mathrm{PhD}$ thesis is a hefty task, to say the least, and those who have given aid, should not go unnamed.

I would like to thank the Societal Component of Genomics research programme (MCG) of the Netherlands Organisation for Scientific Research (NWO), as well as Maastricht University for providing the funding (MCG grant number 050-032-011, to be precise) and material requirements for bringing this $\mathrm{PhD}$ trajectory to an end. Briefly sticking to the institutional level, I would like to thank the research school Science, Technology and Modern Culture (WTMC) for providing an excellent forum for discussion, exchange of thoughts and as a network for getting to the relevant actors in the field of Science and Technology Studies. I doubt whether I would have been fully able to make the transition from biology to STS (if you do not have a clue what I am talking about, you should perhaps better first read the curriculum vitae), if it weren't for WTMC.

Within WTMC, a number of people deserve additional thanks. Paul Wouters, Annemiek Nelis, Sally Wyatt and Els Rommes deserve a lot of credit for 'moulding' my thoughts and my writing. It was via WTMC, that I met other PhD students with whom I talked, discussed and from whom I learned many (shady) skills. Many of them I met over and over again at the relevant conferences, meetings, colloquia and parties all over Europe. There are far too many of them to mention all of them, but Niki Vermeulen, Rens Vandeberg, Wouter Boon, Dougi Robinson and Govert Valkenburg most certainly deserve to see their name in print here.

Nutrigenomics is a happy hunting ground for social scientists as much as it is for nutrition scientists or geneticists; so naturally, I was not the only $\mathrm{PhD}$ student addressing the issue. Rens Vandeberg at Utrecht University, Amber Ronteltap, Laura Bouwman and Rixt Komduur at Wageningen University have been my fellow happy hunters. Although our object of study, nutrigenomics, overlapped, 
we disagreed as much as we agreed with each other about the questions to ask and the answers to give. I hope our conversations were as fruitful to you, as they were to me and I wish all of you the best with the completion of your theses.

Perhaps most of all, I would like to thank all the nutritionists, geneticists, medical doctors, bioinformaticians, statisticians, microbiologists, molecular biologists, dieticians, policymakers, directors, industry representatives, $R \& D$ scientists and other researchers combined under the oversimplified heading of nutrigenomicists. In the book, many of their names, but not all of them, are anonimised and I will thus not mention their names here. Out of all these, some deserve even higher praise for allowing and enabling me to walk around in their labs for weeks at a time and patiently answering endless questions. On an institutional level, the European Nutrigenomics Organisation (NuGO) and the IOP 'An integrated genomics approach towards gut health and nutrition' (Gut Health) deserve equal praise.

I love to travel and writing this book has been the best excuse for doing some extensive traveling over the last years. Destinations ranging from London, Cardiff, Tuscany, Mallorca, and Krakow to Canada and New Zealand have contributed to this book almost as much as they have contributed to my spirits. One foreign adventure, however, needs to be mentioned in more detail. With some support of the Societal Component of Genomics research programme by means of a travel grant, I was able to stay at the Institut für Wissenschaftund Technikforschung of the University of Bielefeld, Germany, and the local graduate school (GK) in the spring of 2007. I would like to thank Peter Weingart and Alexandra Wiebke, because for the most part, they made it happen. Carsten Reinhardt, Vivien Behrens, David Kaldewey, Nico Koppo, Fran Osrecki, Hürrem Tezcan and Cornelis Menke, thanks for discussions during colloquia, lunches and in the pub. I was glad to have served and to continue to serve as an adhesive between WTMC and the GK. We will meet again!

Out of all the colleagues at the Unit of Health Ethics \& Philosophy and later at the Department of Health, Ethics \& Society (which is, as you will have guessed, the same group of people, in the same building, the same offices and on the same chairs), some have to be mentioned in particular. Patricia Jaspers and Josy Ubachs-Moust, you were my roommates. Although the bulk of our conservations dealt with trivia and gossip, I cannot help but believe that some cross-pollination has occurred between the three of us (Patricia, you have entered Science and Technology Studies, and Josy, you have started to include fancy pictures in your papers, what more need I say?). After sharing a room for so long a time, how could it have been otherwise? The two of you were, however, not my first roomies. That is an honor that falls upon Ivo van Hilvoorde and Laurens Landeweerd. Both Ivo and Laurens have moved on from Maastricht, but we will 
keep in touch. Of course, I need to mention a small group of enthusiastic colleagues devoted to Science and Technology Studies, especially directed at genetics and genetic technology and its implications and effects, at our department. Anne van Cromvoirt, Fleur Parabirsing, Els Geelen, Mechteld-Hanna Derksen, Erik Aarden and Ine van Hoyweghen have supported me from the very beginning. We discussed ideas, work, texts, more work, papers, manuscripts, approaches, even more work, methods, styles and techniques. Sometimes we dropped the guise of collegial caution, respect and friendliness, but only for the greater good. I believe, and I hope you do so as well, that all our work improved from it. Some of you have not reached the finish line, whether by choice or circumstance and the others are very close to that finish line (except for Ine, who has taught us where the finish line is and how to cross it). Ine, thanks for being one of my paranimphs as well. I am confident that all of you will do well, now and in the future - you were, are and will continue to be my brothers and sisters as much as my colleagues.

Where there are children, there are at least two parents. Maastricht is no exception to this rule. I have a lot to thank to Rein Vos and Klasien Horstman. Their roles shifted from parents and teachers to coaches and colleagues and during each of these stages I have learned both the craft and art of doing what it is that we do. Thank you for granting me the time to live through a partial biology-to-STS transition and making sure things went approximately the way they should have. I could not have done it without you. At the department, many others have contributed to my wellbeing, as well as to the quality of my work. I would like to mention the 'AIO soupers', our private text discussion cult (including traditions and rituals), for enduring my texts and comments on the texts of others; Rob Houtepen and Arno Müller for late night discussions in the department kitchen; Annelien Bredenoord for continuously reminding me of the existence of ethics and every single individual at the Health, Ethics \& Society department for contribution to the $\mathrm{PhD}$ experience and simply being there. Furthermore, I would like to thank the manuscript committee, Wiebe Bijker, Wim Saris, Edwin Mariman, Michiel Korthals and Fons Werrij, for being willing to form the committee, waiting patiently until the manuscript arrived (with a bit of delay) and subsequently reading and approving it, as well as offering some constructive criticism.

Neither time nor careers halt at the publication of a thesis. There is life after a PhD. So, thank you, Annemiek Nelis and Hub Zwart, for offering me a position which enables me to continue the journey which I started over four years ago. I intend to keep sailing on (you will have to read chapter 2 to 'get' this). Hub, not only do you deserve thanks for this recent fact, but you also were one of the first people who have guided me onto the path which I am traveling now: the interaction between society and biology (The circle is completed...). 
Nevertheless, I will not fully leave the nest and will share the research position in Nijmegen with one in Maastricht, combining a continuation of my research in different contexts (in Nijmegen) with a methodological and theoretical reflection on the subject (in Maastricht).

Furthermore, I would like to thank the Netherlands Organisation for Scientific Research (NWO), the School for Primary Care and Public Health Research (Caphri) and the research school Science, Technology and Modern Culture (WTMC) for financial contributions to the printing of this thesis. Furthermore, the sole reason this thesis does not contain a lot more spelling and grammar mistakes than currently is the case, is because of Vincent Limburg's careful and meticulous proof reading and corrections. Thank you a lot Vincent!

Finally, there is a select and very exclusive group of people, whose contributions to this book is rather limited, but their contribution to the process of finishing it cannot be exaggerated. Sam, thanks for acting as paranimph. You said yes without knowing what it was and without knowing the world which it is part of, but also without even a second thought. I guess that is what brothers do: support without questioning. Parents do so equally well: so, mum and dad, thanks for your unwavering trust, support and belief. Finally, Audrey you have been kept waiting until the end of this preface, as you have been kept waiting far too often over the last years. There are no words to describe you and your part in all this, at least none that would do justice to everything you said and did. I will try nonetheless, but not now and not here. 


\title{
CHAPTER ONE
}

\section{MAKING KNOWLEDGE AND NORMS IN LARGE- SCALE SCIENCE: THE CASE OF NUTRIGENOMICS ${ }^{4}$}

\begin{abstract}
The time may be approaching when a [study of] the problems which science and technology have introduced into the life of the nation and of the world will not only be possible but may even seem sufficiently interesting and imposing to stimulate a major study of these things. Let us hope so, for our future security and welfare may depend upon it, Lyman Chalkley (1945, p. 292).
\end{abstract}

ating and preparing various foods, as well as writing about them, have been
part of daily life within living memory. Furthermore, improving upon the
processes of preparing and increased understanding of what can be eaten
have not escaped the attention of scholars and scientists in nearly every period in
history, as did the normative, moral and social issues surrounding food and food
production (Zwart, 2000). As the sciences grew and changed over the years, so
did nutrition science. Nutrition science remained a small but respectable field
with a highly interdisciplinary methodology, even ranging across the boundary
between the natural and social sciences. Lately, however, nutrition science is,
according to the nutrition scientists, undergoing yet another transformation.
Schneider distinghuises three phases in the evolution of nutrition science.
After going through a phase in which nutrition was analysed in terms of the
single entity of 'nutriment', a period of analytical chemical research followed, 
in turn followed by a third period of biological research ${ }^{5}$ (Schneider, 1977). In this biological period, the completion of the sequence of the human genome (International Human Genome Sequencing Consortium, 2001; Venter et al., 2001) added a genetic perspective to nutrition science (Müller and Kersten, 2003), creating a new branch of nutrition science inquiry: nutrigenomics, that is combining knowledge about the human genome with that of nutrition. Simultaneously, nutrition science has gone through a period of exponential growth. For example, one of the European funded nutrigenomics research projects reports a research budget of over 150 million Euros (combining EU funding and local research budgets for a duration of 6 years; 2004-2009), resulting in nutrition science being referred to as 'Big Science' (van Ommen, 2005).

Building Big Nutrition Science requires the assembly of a lot of technology, a lot of scientists in a lot of laboratories all working together to address research problems collectively. In such an assembly knowledge about nutrition is made, research problems are (hopefully) solved but also, very importantly, ideas about what 'good' or healthy nutrition is, which genes are the 'good' ones but also which experiments are the right ones to answer the questions, change. With these norms, advice about what to eat, or not to eat and how to approach such questions changes, for alongside biomedicine, nutrition science has, from the very beginning, been as prescriptive as it has been descriptive. Alongside descriptions of nutritional content and dietary impact on health, suggestions and regulations are assembled for individual and public health improvement. Whereas, since Foucault, biomedicine has been analysed from a political perspective countless times, comparable studies with respect to nutrition science continue to remain underrepresented - one of the motivations which has resulted in this book.

Because of its newly acquired large-scale character, its rapid ascent in the hierarchy of sciences ${ }^{6}$, its interdisciplinary character, its prominent coexistence inside and outside of academia, its interwoven technical and normative nature and other important features which will be discussed in detail in this book, present nutrition science is a prime candidate for the scientific study of contemporary, large-scale research practices. Issues that feature prominently in social and political debates, such as individuality and the balancing of the public and private good, feature prominently in nutrition science. So do key social and individual motivators such as health and pleasure, displaying the overlap of descriptive and prescriptive practices in nutrition science.

Against this background, this book will ask the question: How does large scale nutrition science work? Contained within this central question are two derivative questions. The first one asks how 'big' nutrition science is able to construct its problems and solutions and how it gets 'things to work'. How much work and what kind of work does it take? What happens to the character of the 
problem in the process? The second one deals with the evolution of new norms which are equally important in the working of a scientific practice. It studies nutrigenomics as a normative practice, involving normative work. In particular, how do notions of health and individuality interact with the notion of nutrition in this particular field, how do these conceptualisations co-evolve with knowledge production in nutrition science and what are the political effects of these processes. What norms for health or nutrition are being shaped? What normative effects can be identified?

In this chapter I will describe how large-scale science was put on the public agenda and subsequently discussed, starting with the introduction of the notion of 'Big Science' in the 1960s and continuing with the 'New Production of Knowledge' and 'Triple Helix' approaches in the 1990s. I will review the most important critiques on these three approaches and I will argue for an increased focus on the normative work in science. I will conclude the chapter with a brief description of two nutrition science research programmes that will feature prominently throughout this book and a short overview of what the reader can expect in the following chapters.

\subsection{BIG SCIENCE ON THE AGENDA}

Examining the role of science in World War II, Lyman Chalkley commented in a 1945 issue of Science on rethinking the post-war relationship between science and society, especially, but not exclusively, in the US. Chalkley suggested, in the spirit of his time, to isolate science from 'corrupting' social influences. However, in the early 1960s the policy view evolved to re-embed science in society, in an attempt to steer and further its merits ${ }^{7}$. In this decade already, Bob Dylan knew that 'the times, they are a-changin'. The title of his song is also the title of a commentary published in Nature in 2002 (Patrinos and Drell). These authors address the controversies regarding the human genome draft sequences published a year earlier and other genomes that were sequenced in that year, including rice, elaborating the theme of the complex relationship between public and private arrangements in Big Science. Scientists notice that science is changing. For instance, Gannon (2006) argues that 'the changes that are taking place now are the result of [a] recognition that the old ways are no longer good enough'; the German Chancellor, Angela Merkel, writes editorials for Science Magazine (Merkel, 2006); scientists are advised to take media studies (Nature Opinion, 2006) and leading journals regularly discuss national and international science budgets and policy ${ }^{8}$. 'Science today' remarkably contrasts the image of scientists conducting their studies free from influences of society and government. That the 
relationship between science and society or science and government cannot be described in such terms has been clear for a very long time now. How exactly it should be framed remains unclear.

When referring to science, a number of endeavours over the last decades has grasped public attention because of their spectacular character. Most prominently are the Apollo project, the Hubble Space Telescope project and the Human Genome Project. Every single one of them has taken many years to come to completion and has cost billions of euros or dollars. Are these three projects different from previous scientific efforts? And if so, how are they different, and why? Max Planck said that each new unit of knowledge costs more then the previous one, because 'the easy answers come first' ${ }^{\text {' }}$. Donald Kennedy continues this line of thought, stating that 'we are [thus] committed to asking more expensive questions that are also more difficult' (Kennedy, 2005). Are more difficult and more expensive the sole determinants of such large scientific endeavours? When reviewing the discussions that address the character of contemporary science it is not solely its material cost and the difficulty of its questions that are noted. Nishimuro suggests that 'whereas historically, science and technology have changed society, society now is likely to want to change science and technology, or at least change their course' (Leshner, 2005). In Nature, an editorial tells us that 'biologists and their institutions are increasingly confronted with the challenges of working in major collaborations' (Nature Editorial, 2003). Here it is identified that next to changing relations between science, industry and society, a changing relationship with the government is developing (e.g. Dalton, 2005). Furthermore, it is identified that science is organised in larger units of collaborations (e.g. Check, 2004) - often spanning multiple disciplines and specialisations (e.g. Knight, 2002; Nature Editorial, 2002) - as well as devoting substantial time and resources to related 'non-scientific' issues, such as communication (e.g. Augenbraun, 2005) and ethics (e.g. Annas and Elias, 2004). The costs and technical problems are not the only prominent matters of concern: 'softer' issues, including communication and values come to the fore as well.

The character of science and scientific change has been addressed systematically before. In the early sixties the physicist Weinberg knew that the times were a-changin' - at least as far as the practice of conducting science was concerned. He coined the catchy phrase 'Big Science' to describe 'new' largescale scientific projects. To him, it was a change that was there to stay (Weinberg, 1961). In the Encyclopaedia Britannica, the entry 'Big Science', lists projects like Apollo, Hubble Space Telescope and the Human Genome Project as key examples (Dennis, 2006). The examples Weinberg uses in his paper are what he calls 'the monuments of Big Science: the huge rockets, the high-energy accelerators [and] the high-flux research reactors', the tools of physics and 
astronomy - the scientific champions of his time. Not long afterwards, one of the earlier works that systematically reviewed changes in scientific practice - again, mostly but not exclusively, physics and astronomy - appeared: 'Little Science, Big Science', by Derek de Solla Price (1965). In his work, he unleashed the scientific method on science itself and by doing so he started a new field, currently known as scientometrics. He approached science from a new perspective, which meant to him that the amount of money, the number of scientists and their training mattered. Throughout his analyses, he posed a new question. Not about the size or shape of science, but about the hidden qualities of its character: a question that in the end he was largely unable to answer. Over thirty years later, two new 'schools' of science studies scholars took up this question. These are the 'New Production of Knowledge' and the 'Triple Helix'.

I will first discuss the topic of 'Big Science', particularly with the help of the work of De Solla Price, who was one of the principal authors to start to address the notion that science has both quantitatively and qualitative changed and shifted over time. Then I will move forward to two new approaches addressing the character of contemporary science which coexist at the present time: the 'New Production of Knowledge' and the 'Triple Helix'.

\subsection{SIZE IS NOT THE ISSUE}

Derek de Solla Price listed and discussed changes and shifts in science in a series of lectures, published as 'Little Science, Big Science' (1965). A later version included a number of additional essays (De Solla Price, 1986). In his illuminating work he confronted the world with many graphs and calculations demonstrating steady and exponential growth of science through the ages, contrasting the history with the immediacy of science ${ }^{10}$. In the foreword to the later volume 'Little Science, Big Science and Beyond', Robert Merton and Eugene Garfield praised De Solla Price as 'the father of scientometrics' (Merton and Garfield, 1986, p. vii). In his earlier work, much of his argument was indeed supported by the claim of using measuring methods of science, in his own words: "why not turn the tools of science on science itself?' (De Solla Price, 1986, p. xv). In later papers and essays, De Solla Price used a wider methodology, including also more qualitative approaches. These essays are included in the later 'And Beyond' volume, in which De Solla Price discussed - while reviewing the size of science - its distribution, internal interaction and social and political properties, as well as the role of technology. While the terminology used to distinguish Little and Big 
Science had been coined by Weinberg (1961), not by De Solla Price, he continued to use it. However, using both the qualitative and quantitative methodologies, he continually pointed out its limitations.

For instance, he argued that the change from little to big was a 'remarkably' gradual shift (De Solla Price, 1986, p. 3), although the results of this gradual shifts are such that we are cannot help being dazzled when we look at it:

The large scale character of modern science, new and shining and allpowerful, is so apparent that the happy term "Big Science" has been coined to describe it. Big Science is so new that many of us can remember its beginnings. Big Science is so large that many of us begin to worry about the sheer mass of the monster we have created. Big Science is so different from the former state of affairs that we look back, perhaps nostalgically, at Little Science that was once our way of life (p. 2).

Even though the title of his book may hint otherwise, it is not merely the size of science De Solla Price is interested in. He argues that growth is a trait that can be found in science throughout the ages. Because of the exponential growth he demonstrates, it becomes ever more apparent that the growth of science is not a new phenomenon. Most of all, it is not adequate to classify contemporary science as something different:

If we are to distinguish the present phase as something new, something different, from the perception of a burgeoning science that was common to Maxwell, to Franklin, and to Newton, then we cannot rest our case on the rate of growth alone (p.13).

However, that does not mean that size and growth rates are traits of no significance - perhaps better ignored. Not at all, according to De Solla Price, size is one of the traits - among many others - that make science what it is today. He does demonstrate, however, that growth rates cannot be used as the sole explanation for the transition from Little Science to Big Science. He demonstrates that the growth science has exhibited in history is rather constant, but that it will create some problems in the near future. One of the striking consequences of the uninhibited exponential growth of science would be a scientific population that exceeds the total human population, as well as a scientific budget that exceeds the combined gross national products of all nations in the world. Derived from these and other observations, De Solla Price hypothesises that perhaps the pressure contemporary and future societies will place upon scientific growth - reducing that growth - may be one of the factors that define contemporary science. He argues that along with its size, the nature of science as such changed and continues to change. It is this fundamental transformation that he considered as important as issues of scale. As 
a historian of science, most of De Solla Price's argument is set in the past - but it extends into his time, the 1960s. Reading 'Little Science, Big Science', it is nonetheless recognisable that early 21 st century science can be substituted for 1960s science with little injury to the argument.

In 'Rethinking Big Science', fourty years after the publication of 'Little Science, Big Science', Westfall argues that perhaps the use of the terminology of 'Big Science' furthers the temptation that understanding the phenomenon hinges on understanding the size, or the 'bigness' of science. She refers to the term largescale science - as Weinberg (1961) originally did - but she distinguishes between modest, mezzo and grand large-scale science, contesting that Big Science needs to be big (Westfall, 2003). She expresses her discomfort with the term 'Big Science' quoting Galison: 'My view is this: as an analytic term, 'big physics" ${ }^{11}$ is about as helpful to the historian of science as 'big building' would be to an historian of architecture' (Westfall, 2003).

Westfall (2003), Smith and Tatarewicz (1994) and others have not only criticised the focus on size, but have taken up research projects directed at largescale research programmes and their specific functionality striving to break themselves free from the values that have become attached to 'Big Science' during the last half century. They have researched, amongst other things, heavyion-physics and space telescopes, not from a perspective of size, but from a perspective of systems of technologies, institutions and social networks. They approach 'Big Science' using a more comprehensive framework derived from the history of science and technology and the social studies of science and technology, enabling them to look into the myriad of activities, strategies, processes, and goals connected to large-scale science projects.

This new approach moved Big Science away from issues of scale, away from 'bigness', and towards a system or network of interwoven technologies, socialities, institutions or organisations. When the size of science is not the issue, but the character of scientific practice, then the prefix 'Big' does not suit the purpose of grasping the nature of modern science. De Solla Price offered numerous historical examples of huge national and international efforts from the time that science was generally considered exclusively 'Little' (De Solla Price, 1965). Furthermore, Westfall argues that large-scale science can be rather modest in size (Westfall, 2003). This leads to the conclusion that the distinction between 'Little' and 'Big' Science does not overlap with the distinction between 'old' and 'new' science. The size of science cannot exclusively define the character of contemporary science.

Next to the quantitative changes in scientific practice, De Solla Price describes a number of qualitative changes in scientific practice. Most importantly this includes the intensification of collaboration in science, that is, the generation of 
invisible colleges - 'virtual' communities of collaborators. These small, tight and highly international cooperative communities of top-level scientists would retain personal and social relationships in a world of overabundance of information and literature (De Solla Price, 1986, p. 85). His argument was not only descriptive, but also normative. While he pleaded for scientists to become politically active and responsible, and that scientists, given their increasing ties with the state are capable to do so. Throughout the whole book, he elaborates his point that science cannot continue as it has done throughout history and needs to pursue new role. What should distinguish contemporary science from 'old' science is not primarily size, but a qualitative difference ${ }^{12}$ : the growth of science will result in societal pressure to counter such an unsustainable growth and consequently, the voices of politics and society will resonate ever louder within science and scientific practice $^{13}$.

So far, I have primarily reviewed and discussed the use of Big Science as an analytical concept in the study of science. However, there is a normative dimension to 'Big Science', a matter of concern equally relevant and interesting to the practitioners of 'Big Science', as well as those who study it. Capshew and Rader list 'a number of Big Sciences': Big Science as a pathology, Big Science as a scientific phenomenon, Big Science as an instrument, Big Science as industrial production, Big Science as an ethical problem, Big Science as politics, Big Science as an institution, Big Science as culture, and 'wrap up' their listing with Big Science as a way of life (Capshew and Rader, 1992). Furthermore, the vocabulary of 'Big science' has become increasingly widespread and is very deliberately being used to accomplish political goals. However, the rhetoric used, cuts both ways. Those in favour of 'Big Science' frame this kind of science as the future of the scientific enterprise, whereas those opposing 'Big Science' rhetorically construct it as a 'pathological condition, afflicting the otherwise healthy organism of science proper' (Capshew and Rader, 1992).

Big Science is not a given - nor an explanation - of the workings of contemporary science. It is part of it and after half a century, it is still in need of further explanation, that is, to 'come to a better understanding how science is made big and how Big Science is made' (Capshew and Rader, 1992). While the quantitative study of science and scientific communities was performed under the banner of scientometrics, the study of the qualitative changes in science was being conducted under the heading of science studies or the social studies of science. While 'Big Science' continued to be debated, it was until the 1990s that alternative theories emerged. Two groups of scholars again addressed the particularities of the practice, community and organisation of contemporary science. It started out with the publication of 'The New Production of Knowledge'. The dynamics of science and research in contemporary societies' (Gibbons et al., 1994), a book that 
swiftly acquired the status of a citation classic, as 'Little Science, Big Science' did before. Shortly afterwards, a second line of thought was coined in a paper on 'the Triple Helix of University-Industry-Government relationships' (Etzkowitz and Leydesdorff, 1995).

Scientists themselves also recognised changes in society and science and their relationship in the last decade. Not did they discuss the role of commercial parties in science, but also the knowledge produced, science funding and policy, and science communication:

[T] he man on the street realized that scientific and technological progress increasingly affects his life - and not always positively. Accordingly - and justifiably - non-scientists began to demand that scientists revealed more about what they actually do. And as scientists needed more money for their work, this was also in their interest. [...] In the past decade, other changes have taken place that undermine authoritative voices in all spheres of life and that now require a different approach by scientists. [...] Crass capitalistic attitudes led to the attempt to introduce GMOs surreptitiously. Their reasoned defence of the technology made scientists in this field, and by extrapolation all scientists, suddenly appear to be in the pockets of industry. It was a bad outcome and signalled the need for a new strategy (Gannon, 2006).

The scientists themselves called out for a new strategy, an alternative conceptualisation of the relationship between science, academia and commercial partners.

\subsection{ENTANGLED SCIENCE ON THE AGENDA}

With their book 'The New Production of Knowledge. The Dynamic of Science and Research in Contemporary Societies' (Gibbons et al., 1994), first published in 1994, Michael Gibbons, Helga Nowotny, Peter Scott and their colleagues have addressed the particularities of contemporary science. Discussions about the size of science that featured very prominently in the works of 'Big Science' are not absent from their argument, but Gibbons, Nowowtny and Scott chose to focus on the qualitative differences between the 'old' and the 'new' practices of 'doing science' which they identified as 'generally accepted to be significant' and which are said to 'have given rise to new discourses of science and research' (Nowotny et al., 2003).

Firstly, Gibbons et al. identify a trend towards a 'steering' of research priorities. This trend can subsequently be observed on three levels of organisation, namely the supranational level, the national level, and the system level. Secondly, 
Gibbons et al. observe a trend towards the commercialisation of research, with respect to research funding as well as research products (e.g. intellectual property) and express a worry about the consequent restrictions on the circulation of research findings and subsequent options for refutation and control. Thirdly, they observe a trend towards the accountability of science, 'driving' research to some sort of national or international 'significance'. This exposes scientific practice to a process of assessment of this significance (Nowotny et al., 2003).

Gibbons et al. argue that as a response to these trends, scientific practices have fundamentally changed, which they propose to call a shift from 'the old paradigm of scientific discovery' to 'the new paradigm of knowledge production'. With this distinction they introduced the terms 'Mode 1' and 'Mode 2' science. In 1994, they hoped that 'a more felicitous term will eventually be found' (Gibbons et al., 1994). However, through the extensive number of comments on their work ${ }^{14}$ and their subsequent efforts to further develop the argument in a number of papers (e.g. Nowotny et al., 2003) and a new book (Nowotny et al., 2001) the Mode 1 vs. Mode 2 vocabulary has become rather widespread.

Mode 1 should be considered as the traditional production of knowledge, whereas Mode 2 is the alternative, the new production of knowledge that incorporates - or at the very least considers - the trends Gibbons et al. observe. They propose a number of qualitative differences between Modes 1 and 2 of knowledge production, starting with the context in which scientific knowledge is produced. Firstly, Mode 2 knowledge is produced in a context of application, which encompasses the 'total environment in which scientific problems arise, methodologies are developed, outcomes are disseminated and uses are defined' (Nowotny et al., 2003). Furthermore, Mode 2 knowledge production is a transdisciplinary process and consequently, Gibbons et al. argue that it is supported by individual or group expertise and tacit knowledge more than by traditional research products. Thirdly, via a transformation of the dynamics of research communities, the number and diversity of sites at which knowledge is produced have increased. This part of the argument has been expanded through the introduction of the concept of the agora: a problem-generating and problem-solving environment in which the contextualisation of knowledge production takes place. The agora can be considered as an institute or a building, this is not necessarily so; it does not even need to be a geographical location ${ }^{15}$. Fourthly, Mode 2 knowledge is not the product of an impartial, objective survey of nature, but the result of an active process, which Gibbons et al. choose to call a 'conversation' between researchers and research subjects. As a result, Mode 2 knowledge is highly reflexive. Finally, given the alternative and diverse organisation of Mode 2 knowledge production, it is unclear how to define the quality of research process and product, resulting 
in multiple co-existing definitions of 'quality'. Consequently, Mode 2 knowledge requires alternative forms of quality control (Gibbons et al., 1994; Nowotny et al., 2001, 2003).

The debate concerning Mode 1 versus Mode 2 science and the implications of such shifts and changes is ongoing. According to the initiators, 'closure [...] is neither possible, nor desirable' (Nowotny et al., 2003). So, this book can be considered as an attempt to stretch and add to the debate on contemporary science in which Mode 2 is one of the theoretical frameworks attempting to further understanding on the subject, specifically with respect to the coevolving production of knowledge and norms, focussing norms as they feature in contemporary nutrition science such as health and individuality.

Initiated at approximately the same time, a different approach was developed to cope with the particularities of contemporary science. In a series of papers, including special issues of the journals Science and Public Policy and Minerva the 'triple helix' model was presented to the science studies and science policy communities. In full: the triple helix of university-industry-government relations (Etzkowitz and Leydesdorff, 1998a) or the triple helix of innovation (Etzkowitz and Leydesdorff, 1998b) was proposed as a model to help understand and analyse changes in knowledge production, innovation and science. The triple helix papers are not classified as a citation classic, but they are firmly rooted in the scholarly community. through the aforementioned papers and most notably, six international conferences were organised between 1996 and 2007, exclusively devoted to the triple helix ${ }^{16}$.

Etzkowitz and Leydesdorff, the principle authors putting forward the triple helix model, argue that the boundaries between the university, industry and government have become unclear and remain to exist in a state of flux. Each of these three social spheres is actively working to construct, maintain and expand ties with the other ones (Etzkowitz and Leydesdorff, 1998a). Furthermore, the authors argue that a normative change is taking place in science, replacing disinterestedness by the capitalisation of knowledge. They follow up Marx's outline of science-based economic development, as he predicted the growth of science-based industry. They suggest it has expanded from a bilateral mode between science and industry towards a trilateral mode, including the sphere of government. These trilateral relationships operate at regional, national and international levels. Hence, Etzkowitz and Leydesdorff suggest that a 'spiral model of innovation is required to capture the evolution of multiple linkages at different stages of the capitalisation of knowledge' (Etzkowitz and Leydesdorff, 1998a). This trilateral spiral is conceptualised as a triple helix, in which the three strings in the helix represent the social spheres of academia, industry and government whereas the concept of the helix points out their intricate entanglement. 
In a state of such intense entanglement with government and industry, the positions of academia and of science itself have changed. The 'classic' linear model of innovation from basic science, through applied research to product development is under great pressure. Etzkowitz and Leydesdorff argue that the model cannot work anymore, since views on the use and goals of science have changed (Etzkowitz and Leydesdorff, 1998a). On top of the cultural and military legitimations - Etzkowitz and Leydesdorff call these 'traditional' - they identify a new way of legitimation: 'the future legitimation for scientific research that will keep funding at a high level is that it is the basis for economic growth ${ }^{17}$ (Etzkowitz and Leydesdorff, 1998a; Leydesdorff and Etzkowitz, 2001).

In such complex networks feedback between various institutions has a profound impact on societies and their infrastructure, rearranging the basis of that network. Etzkowitz and Leydesdorff argue that the trinity of academia, industry and government are said to exist in a state of 'endless transition', a state of affairs that may be analysed via the 'triple helix' model, in which the

[s]ciences innovate all domains of social and economic life and the innovative environments feedback on the innovating agencies. The [resulting] transitions are expected to be complex, asynchronous, and asymmetrical. (Etzkowitz and Leydesdorff, 1998a).

Within the field of science dynamics, the triple helix model started to qualitatively identify the changing relationships between science, industry and government at the various organisational and institutional levels. As the project progressed, the model obtained a mathematical base including a number of quantitative indicators (e.g. Leydesdorff and Meyer, 2006). The multidimensional character of the triple helix thesis developed into a number of identifiable selection environments, such as wealth generation, novelty production and public control (Leydesdorff and Meyer, 2006), operating upon each other in a multidimensional space, requiring the use of quantitative tools such as geometrics and statistics. Thus, the triple helix as a heuristic in the analysis of academiaindustry-government relationships combines qualitative and quantitative modes of enquiry. The triple helix most of all is concerned with innovation systems, and perhaps less with science in general. However, processes of innovation in various shapes and grades are not to be ignored when addressing the issue of how science works in society (O'Malley et al., 2002).

The two new approaches to contemporary science and scientific practice in addition to the approach started by De Solla Price as sketched above, demonstrate that science as a large-scale public-private enterprise remains to be a fruitful subject for research (Tuunainen, 2002). These approaches did not develop independent of each other. In fact, Gibbons et al. quote De Solla Price in the 
first chapter of their first book and Etzkowitz and Leydesdorff in turn, regularly refer to Gibbons et al. in their numerous papers ${ }^{18}$. Scholars involved in the use and further development and discussion of any of these conceptualisations of the 'present state of the art of science' are tributary to each other. In their paper on shifts in quality control, Hemlin and Rasmussen even group both Mode 2 and the Triple Helix under the headings of 'new organisational forms' or 'bodies in triple helix-mode 2 activities' (Hemlin and Rasmussen, 2006). However, the arguments and claims of both approaches cannot be juxtaposed easily. 'The New Production of Knowledge' and the 'Triple Helix' have been compared, contested and critiqued on several occasions. I will limit myself to the main critique relevant to the argument in this book ${ }^{19}$.

Perhaps one of the main critiques deals with the co-production of knowledge, in both the 'Triple Helix' and 'The New Production of Knowledge'. While 'The New Production of Knowledge' appears to be more sensitive to the normative implications of contemporary scientific practices, the 'Triple Helix' is less so. Mehta attempts to remedy this by suggesting that 'The triple helix of state, university and industry is missing an essential fourth helix, the public' $(2002)^{20}$. The suggestion has not been taken up and as far as the 'Triple Helix' is concerned, most normative and moral issues are left unaddressed. The naivety which speaks from such a position is eloquently summarized in a specific modification of the 'Triple Helix' thesis. It is the 'triple felix', partly meant as a critique, partly as a parody. It proposes a possible scenario for the process and outcome of the ménage-à-trois of university-industry-government as the proverbial 'cats in the sack' ${ }^{21}$. One can imagine that in this sack, both the process of scientific innovation and the accompanying norms and social and political entities that arise alongside them, can result in a struggle; the catfight which can be observed in the cartoon. Similarly, but to a lesser extent, an insufficient or inconsequent focus on the normative dimension of knowledge production is identified with respect to the 'New Production of Knowledge'. For instance, Harbers identifies two views on societal relevance in the Mode 2 literature, which are, he argues, wrongfully interwoven. The first addresses knowledge as a tool in global competitiveness and as such it is market directed; the second addresses knowledge as 'input for and object of the public good'. The tools for economic and societal innovation and the respective norms accompanying both forms of innovation are not necessarily in balance. He argues that the norms economisation and democratisation are regularly at odds (Harbers, 2002). Similarly, Kunneman argues that normative issues and especially moral considerations lack from 'Mode 2', and therefore proposes 'Mode 3'. The Mode 3 knowledge, he argues for, is 'based on the living environment: knowledge of life skills and of morally weighted insights into a worthwhile future, clearly distinguished from the problem solving industrial 
knowledge', thus incorporating moral considerations alongside scientific ones (van der Graaf, 2005; Kunneman, 2005). An alternative version of Mode 3 has also been suggested by Hinterberger, to include not only intellectual activities but also to incorporate 'bodies, hearts [and] feelings' (Hinterberger, 2005).

Contrary to the 'Triple Helix', the 'New Production of Knowledge' has been critiqued for its lack of well documented empirical studies. In his comparison, Shinn argues that 'the intellectual structures of the Triple Helix and the New Production of Knowledge differ significantly'. According to Shinn, 'Mode 2' is empirically underdeveloped and 'the six authors have not embarked on confirming empirical projects; neither have colleagues come up with corroborating data' ${ }^{22}$ (Shinn, 2002; also Heilbron, 2003). Nowotny et al. agree with this observation admitting that ' $[\mathrm{b}] \mathrm{oth}$ the New Production of Knowledge and Re-thinking Science were written as reflective essays rather then empirical studies' (Nowotny et al., 2003). In contrast, the Triple Helix puts empirical material in a central position. However, its theoretical message 'is not intelligible to many in the audience' because of the complex mathematical formulations (Shinn, 2002). In this book, I will combine a dense empirical approach with a focus on the normative 'side' for large-scale science, filling the open space the 'Triple Helix' and 'The New Production of Knowledge' left at this intersection.

In conclusion and given the main question of this book, to find out how large-scale science is made to 'work', it is imperative to properly navigate the concrete practice of large-scale science and to address the co-construction of knowledge and norms in contemporary nutrition science. In the following sections, I will briefly explain why these two topics, the empirical and the normative, are so important and worthwhile to be addressed. In the following section, I will introduce some examples of the ambitions of large-scale science and ideas on why it is thought to work, whereas section 1.5 will critique these assumptions via a focus on some of the norms which are actively included in large-scale science and provide suggestions for the study and interpretation of normative and political effects of large-scale nutrition science.

\subsection{SOLVING BIG PROBLEMS}

Large-scale science is assembled to address problems which are thought to be so complex, that they require a large-scale cooperative approach. Placing a man on the moon is without a doubt a complex undertaking, as is building a space telescope or finding a cure for cancer. The Apollo project lies in the past, the Hubble space telescope is still out there, while cancer remains one of the pressing biomedical problems of our day. An example which aligns very much with the 
topic of this book is the Human Genome Project. The HGP is one of the largest, most expensive and interdisciplinary programmes of the recent past. In the late eighties and early nineties, the Department of Energy and the National Institutes of Health decided that when enough money would be spent, enough effort would be invested, and enough patience would be exerted, it should be possible to sequence the entire genome of a human being. A similar line of thought existed at the start of many more large-scale projects: enough money, enough effort and a healthy dose of patience are basically all which lies in between the current situation and the solution to the research problem, whether the latter is a to put a human being on the moon to develop, a hydrogen bomb or to sequence a human genome.

Money, effort and patience are not enough as research in the context of either the 'New Production of Knowledge' or the 'Triple Helix' models has shown: there is a need for cooperation, both between disciplines within science and between science and other institutions, such as the government and industry. Besides a lot of money, a lot of effort and a lot of patience, it is necessary to add, for instance, a lot of cooperation to make large scale science work.

Science and Technology studies have demonstrated how hard it is to make a fact (Latour and Woolgar, 1986 [1979]). Considering that hard work is very important, it is worthwhile to know how it is done, how a fact is made or how a problem is solved. Joan Fujimura has beautifully demonstrated in her study of cancer research how research problems are addressed, how they are reformulated so that they can be solved and the amount of work it takes (Fujimura, 1987, 1996). A critique of Fujimura's was that it was mainly conducted in a single laboratory. Therefore we should ask what this means for large-scale science. If in a single lab, solving a problem is so hard, how much harder is solving a problem in a highly interdisciplinary, highly cooperative and geographically widespread field such as nutrigenomics? Does it require just more work or also different work? In chapter three, I will expand on the study of Fujimura, in order to demonstrate that it does indeed take a lot of work which, in such a complex setting creates a number of issues particular to large-scale science but also that the notion of doability can help us to understand the normative dimension of problem solving. At the end of the book, in the final chapter, we will return to the question whether a lot of money, a lot of effort, and a lot of patience suffice to solve the big problem, but also whether cooperation as a strategy necessarily results in more problems being solved or problems being solved more efficiently, easily or swiftly.

Problem solving is not our sole concern here. The solving of a problem does not solely result in a solved problem, but also in a changed context and content of that problem, in terms of the material, but also in terms of its normativity. We need to take a close look at how and why norms change. 


\subsection{POLITICS OF PROBLEM SOLVING}

Having the sequence of the human genome readily available would, according to some, result in the understanding of man, the eradication of disease and the promotion of health for all human beings. Motivations like these were part of the reason to set up such a large-scale initiative. Over time, as the sequencing effort continued, these aspirations were continuously reassessed and rephrased. However, the idea, or hope, that large-scale research programmes will add to our health has remained. Stem cell initiatives, genomic research programmes, biotechnological initiatives and many other large-scale projects in the life sciences all share a goal of improving our health: a normative, a political goal.

Doing science, with health in mind as a goal, does have major consequences. Producing facts and finding solutions for complex research problems is very hard, yet in this process of creating facts and solving problems, norms are rearticulated. Science continuously produces a variety of norms, not only for what counts as 'proper science', but also norms for what counts as proper health for a certain person, what the right things are to eat, which lifestyles are healthy and therefore preferable, and which kind of risk should be considered normal, slightly elevated or highly dangerous. This process of norm construction in combination with the practice of solving scientific problems will be the subject of the following chapters. Thus, it will be shown that creating norms is not an innocent act but instead that creating or changing norms is an active (re)construction, for instance through inclusion or exclusion, of our social and physical surroundings (Bowker and Star, 1999).

Issues concerning the co-production of norms and knowledge have been addressed in a subset of literature focusing particularly on the biopolitics of scientific practices. Here, biopolitics is the politics of life, living matter and living beings and their health. A thorough analysis of the practice of contemporary nutrition science does not halt at a description of the ways in which knowledge is produced, but should also reflect the normative and social issues it encompasses. As a part of the process of knowledge production, as well as in the knowledge that is produced, norms and values exist which spring from both science and society as they interact. Especially the norm for health, as it has been intricately connected with nutrition and individuality, lies at the heart of biopolitical ${ }^{23}$ existence. As a result, the biopolitical consequences of the description of large-scale nutrition science cannot and should not be ignored.

The notion of biopolitics originates from Foucault and is currently widely used by a group of scholars who can collectively be designated neo-Foucaultian. 
One of its prominent members is Nicholas Rose, who refers biopolitics as the 'politics of life itself'. Biopolitics is the active and deliberate political influence on and intervention in the birth, death and health of a population and its members. While radical political enterprises, such as eugenics (Lemke, 2005) or full-scale war (Marks, 2006), also fit this conceptualisation, most biopolitics is far more subtle, up to a level where it may not be observed at all: science and the norms it produces exert a very subtle, but very real influence on how people live and live together via a process of normalisation and disciplining. Furthermore, it is not exclusively a 'politics of political organs', of governments and nation-states. It is above all a hidden politics of science, performed by the construction and reconstruction of what is considered normal' and 'pathological' by the sciences. According to Foucault, politics and governance span from a politics of the self: a governing of the self through choice and self-control to the politics or government of others, and guidance, a 'politics of the soft touch'. It encompasses the rights of the individual and the population as a 'resource for the state' (Greco, 2004, p. 3 ), thus strategically coordinating forces and power relations (Lazzarato, 2002). It debates the range of our (biological, social and cultural) freedom and results, in life becoming a strategic enterprise (Novas and Rose, 2000, p. 487).

In the 'master biopolitical binarism of normal and pathological' (Katz and Marshall, 2004), health corresponds to the normal situation. In this dichotomy, a preferred 'movement' towards the normal situation exists, which has been described as a disciplining effect. Nearly every individual desires to be healthy, as opposed to diseased. Our daily lives have been disciplined to fit this desire, refraining from behaviour that clearly invokes the unhealthy, such as smoking, and seeking out behaviour that invokes health, such as exercise and hygiene. Deviant behaviour is immediately 'punished' by personal guilt and even further by the possibility of social monitoring. Not only individual behaviour and individual bodies have been and continue to be disciplined this way, society at large has been reshaped into both source and object of normalisation and disciplining, through the 'spatialisation of medicine upon the individual body' (Rose, 2007b). To Foucault, the ultimate example of this reshaping could be observed in the clinic where the individual patient grew into the centre of attention more and more (Foucault, 1986a).

This entire process of governing life, health and wellbeing has been called 'the politics of life itself'(Rose, 2001), or 'biopolitics'. The life sciences and clinical medicine, as Rose argues, are intricately bound to the rise of biopolitics. These sciences not only produce knowledge about human beings, human populations, behaviour and health. Through the production of knowledge they determine what is normal, and connect certain norms for specific individual physiological traits, such as blood pressure, or statistical population traits, such as birth counts, as 
well as the values that accompany them. Unsurprisingly, as a theoretical notion biopolitics has gained large popularity with respect to the field of public health. Public health, according to Lupton (1995), 'is a form of medicine, social medicine, which directs its professional attention towards the health of populations, aggregated bodies [...]' (p. 2). And although the relationship between medicine and health and nutrition and health are not the same, the notion of biopolitics is very useful in the review of the role of health in nutrigenomics. For we all eat, and apparently we do so, to remain healthy. The national and international initiatives to properly feed the populations of their respective nations are the nutritional counterparts of the large public health initiatives. More recently, the focus has shifted from making sure everybody has enough food of proper quality, to making sure people do not eat too much. Malnutrition and under-nutrition have been replaced by over-nutrition and obesity, yet the trend towards health remains unchanged. Furthermore, nutrition and food production have been analysed from a Foucaultian perspective before (Zwart, 2005a) ${ }^{24}$ and even Foucault wrote on the subject ${ }^{25}$ (Foucault, 1986b). Arguably, nutrition or diet is of more consequence to our daily lives than biomedicine or public health initiatives, since the penetration of food and drink into society is very deep. Both, however, feed the need for health. Public health and public health nutrition have been institutionalised in national nutrition advice centres and policies ${ }^{26}$. Such political entities control, advise and guide individuals towards a set normal for health, but nonetheless do not take responsibility for their actual health status. Individuals are expected, through internalisation of the normal, to govern themselves, to exhibit selfdiscipline in order to 'reach' the defined normal and bear the consequences of their decisions (Lemke, 2001).

Large-scale biomedical and nutrition scientific practices can be interpreted in terms of biopolitics. The construction of problems, solutions and facts cannot be separated from the construction of new norms. Together, they define the face of nutrition science. Exactly which problems and norms and how they interact, however, has largely remained unclear. Biopolitical theorising has come up with two suggestions for this interaction. Firstly, health may molecularise, or secondly, it may be solely based upon risk (Rose, 2007b). Whether this is the case in contemporary nutrition science is at the heart of this book. When seeking to understand health, what norm(s) for health do we end up with and what do they do? The following chapters address both how large-scale science is made to work, as well as the normative and political effects of this process. 


\subsection{NUTRIGENOMICS: THE CASE OF CONTEMPORARY NUTRITION SCIENCE}

Nutrition science has a lot to offer as an exemplar for contemporary large-scale scientific practices ${ }^{27}$. In this book, the question addressed is 'how does largescale science work?'. Also very important are the political effects of 'making it work', the norms which are constructed alongside the facts and how these norms may work out. Nutrition science offers us a clear window on both: difficult and complex research problems, which are tackled by hard-working scientists in cooperative and large teams, as well as the goal of increasing our health via optimising nutrition. To enable a detailed description of how nutrition science works with respect to the construction of problems, as well as the simultaneous production of new norms, two research programmes have been selected the main sites for empirical research. In the course of the following chapters of this book the reader will become increasingly familiar with these programmes. Here, I will give a very short introduction to both programmes.

The analysed programmes are centred on a recent development in nutrition science, namely the large-scale production of genetic knowledge, also known as genomics. In the case of nutrition science, it is named nutrigenomics, nutritional genomics, or less often nutrinomics (Arab, 2004). I will use the term nutrigenomics throughout this book. The first research programme, Gut Health ${ }^{28}$, is a multimillion Euro project consisting of a number of(Dutch) academic partners, who closely cooperate with several (multinational) commercial partners. These commercial partners are not solely spectators, but are actively engaged in the financial and scientific management of the entire programme. Funding for Gut Health partially originates from these commercial partners, but for the most part, the project is funded by the Dutch Ministry of Economic Affairs, as an attempt to stimulate commercial and economic, as well as scientific growth and innovation. The Ministry of Economic Affairs directs its science funding strategically: 'Using [these] research programmes, the government wishes to increase the access of commerce to academia and improve and intensify contacts between commerce and academia' (SenterNovem, 2006). Gut Health is a programme that mobilises state-of-the-art technologies and scientific insights in the field of genetics. Scientists, as well as the commercial representatives, involved in Gut Health go to great lengths explaining why this particular nutrition science project and nutrition science in general is of the utmost importance to contemporary society. The projects goals, strategies and methodologies are contextualised using terms such as obesity - the increasing body weights of the inhabitants of the first world - and starvation - the lack of proper nutrition in the third world. So, next to increased innovation in the Netherlands, there is the promise of health to the 
world. Because of the envisioned change they are thought to invoke in society, a lot of attention has been given - and significant funding has been redirected - to research on the social consequences of this programme. Social sciences and the humanities have been actively persuaded to shed their light on the developments in contemporary genetics.

The second large-scale research programme I will be referring to on a regular basis throughout the rest of this book is NuGO: the European Nutrigenomics Organisation $^{29}$. NuGO is a European collaboration of more than 20 academic institutions, funded by the European Framework Programme 6. It is mainly an academic initiative, but its meetings are crowded with industry representatives and over time, EU funding will decline and NuGO is expected to generate its own

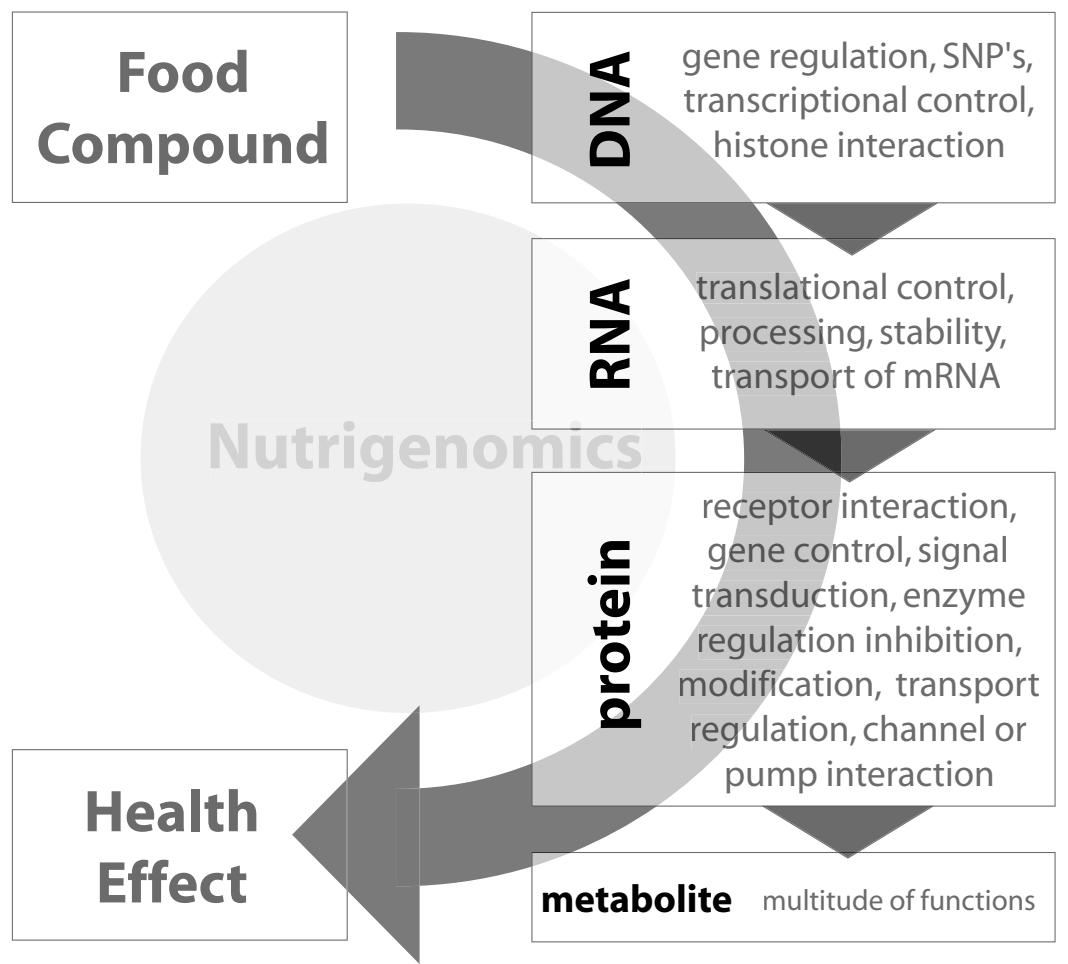

Figure 1.1. Simply Nutrigenomics. This figure is based upon Van Ommen (2004) and shows the envisioned relationship between a food compound and a health effort via the molecular intermediaries of DNA, RNA, proteins and metabolites. The study of nutrigenomics aims to research the workings of all these intermediaries in order to understand the relationship between as many food compounds as possible, and the health effects that may result from them, as well as health effects that may result from adding them to, or removing them from, the diet (SNP $=$ Single Nucleotide Polymorphism). 
financial foundation. At the moment, $\mathrm{NuGO}$ has its own EU 'police officer' 30 checking up on them, on behalf of the 'people of Europe'. The Europe-wide collaboration $\mathrm{NuGO}$ is supported by a EU collaboration grant of approximately 20 million Euro - not counting the member institute or department funding, the total of which may be as high as 150 million Euro (van Ommen, 2005) - and thus could safely be designated 'big'. While NuGO is primarily directed at nutrients and gene expressions, social scientists have their place in $\mathrm{NuGO}$ as well, with research directed at Science Communication, as well as Ethical, Legal and Social Issues of Nutrigenomics ${ }^{31}$.

Numerical characteristics, such as the amount of money invested in a research programme, can easily be recognised on paper, but they do not explain or demonstrate how knowledge is produced or science is performed, what scientific insights shaped, or what technological advancements occurred in the process and what normative, political or social entities they are accompanied by. To avoid a reconstruction of text book science, and to facilitate the understanding of the subte mechanisms of problem solving and norm construction, an in depth analysis of the laboratory practice is needed. For this particular reason, I have entered the practice of nutrition science and I have followed its actors, throughout their (and subsequently my) journey through nutrigenomics.

\subsection{STRUCTURE OF THE BOOK}

The following chapters are a report of my journey and of the findings that have resulted from it. How does contemporary large-scale science, and especially nutrition science work, with respect to the problems it studies, the way it approaches and solves them, as well as with respect to the norms that are produced in the process. In the following chapter, the main methodological issues with respect to this question are discussed. How does one approach this research question? These methodological issues are, amongst other things, the choice for an ethnographic approach and for a focus on the concepts of 'health', 'nutrition' and the 'individual' with respect to the case study of nutrigenomics. Furthermore, the main implications of such choices are discussed, which requires a reflection on the position of the researcher in the observed field of science, as well as the position and legitimation of the acquired expertise.

The following three chapters comprise the main empirical part of this book, although empirical material is used throughout all chapters. Chapter 3 shows how the organisation of the Gut Health programme and its research problem interact. It demonstrates that particular parts of the problem, sub-problems, can be constructed into feasible sub-problems. However, this simultaneously influences 
the feasibility of the other sub-problems, as well as the overall research problem. Different actors, as well as the material characteristics of the research setting, interact to 'make it work', resulting in a complex, situated problem structure held together by the shared technologies and the interests of, amongst many, food industry. Chapter 4 continues the line of thought addressing issues of 'making it work', but focuses on the epistemological dimension of the research problem. Specific parts of the overall (umbrella) research problem are not only located in different laboratories and thus at different geographical sites, very often they are confined to a number of different disciplines. Nutrigenomic research practice is characterised by the involvement of a large number of differences, yet a specific disciplinary and methodological boundary is particularly relevant to genomic research practice: the boundary between biology and computation. Chapter 4 will focus on this boundary. Chapter 5 presents an analysis of apparent inconsistencies between expectations and imaginaries of nutrigenomic research with actual research practice. Via analysing the expectations and the research practices concerned with the notion on the 'personalised' diet, as an exemplar for nutrigenomic research, an apparent inconsistency is resolved. Furthermore, the position of the researchers addressing ethical, legal and social issues is addressed with respect to the continued existence this apparent inconsistency.

Finally, chapter 6 draws together the arguments in the book with respect to the two questions posed at the beginning of this chapter. First, conclusions will be formulated on the level of the character of large-scale scientific research practice. Second, shifts with respect to conceptualisations of health, nutrition and the individual are discussed, as well as the consequences for our understanding of nutrigenomics. Ultimately, this book will present an alternative conceptualisation of research practice to the approaches as suggested in this chapter, 'Big Science', the 'New Production of Knowledge' and the 'Triple Helix'. Simultaneously, it will address issues particularly relevant to the case study of nutrigenomic research practice: the articulation of new norms for health, nutrition and individuality. 
CHAPTER TWO

\title{
NAVIGATING LARGE-SCALE NUTRIGENOMIC RESEARCH PRACTICE ${ }^{32}$
}

\begin{abstract}
If you want to understand what a science is, you should look in the first instance not at its theories or its findings, and certainly not what its apologists say about it; you should look at what the practitioners of it do, Clifford Geertz (1973).
\end{abstract}

\section{$\mathrm{H}$} ow does one find out how large-scale nutrition science works? The advice, uttered by Clifford Geertz listed above, implies that asking scientists afterwards how knowledge has been produced, does not result in satisfactory answers; one should follow up what happens in practice. Latour demonstrates how science, as it proceeds, backgrounds certain aspects of the knowledge production process; that solely studying the product, knowledge, cannot teach the researcher about the complex process that has resulted in this product, the process of knowledge construction. In order to be able to understand science, it is simply not good enough to study products or outcomes only (Latour and Woolgar, 1986 [1979]; Latour, 1987). Dealing with 'unfinished knowledge, that is knowledge in the business of being constituted is the speciality of what is called laboratory studies (Knorr-Cetina, 1995, p.141). Laboratory studies deal with science in action, science as it takes place, as work, as a collective process, thus foregrounding what has been incorporated into knowledge, yet escapes our eye. 
Researchers conducting laboratory studies have entered the laboratory in order to get access to the process of knowledge construction. Bruno Latour, together with Steve Woolgar has conducted one of the first and still most prominent laboratory studies. He has entered the neuro-endocrinology laboratory headed by Roger Guillemins in La Jolla, USA, to study how knowledge was being produced in a laboratory setting. Entering is to be taken literally here, since Latour spent two years inside the lab, observing scientists in their 'natural habitat' (Latour and Woolgar, 1986 [1979]). In a second example ${ }^{33}$, Joan Fujimura has followed cancer geneticists in two oncogene research laboratories in California for three years before writing her socio-historical account of cancer genetics in the US (Fujimura, 1996). In the following chapter, the work of Joan Fujimura will be prominently discussed

\subsection{STUDYING LARGE-SCALE SCIENCE}

One of the key notions in this type of studies, whether in an actual laboratory, or in different settings, is the idea of following the actor. The researcher follows the actor that is to be observed into the lab, inside the lab, around the lab, wherever the actor goes. This actor can be a human actor, a specific scientist or a doctor, but, perhaps counter intuitively, most often the notion of actor is stretched to include non-human actors of interest: science, technologies, specific ideas, notions or apparatuses. This way, the study of science is not restricted to the study of scientific minds, but of the material practice that science is, including its material problems such as performing difficult and complex experiments, handling and interpreting data that apparently make no sense whatsoever, or the cost of specific machinery. For Latour, the actor to follow was the 'fact', whereas Fujimura was 'chasing' the 'proto-oncogene theory'. Following the actor includes a journey of physical following as much as cognitive following. Furthermore, following the actor and observing and reporting are cumbersome tasks - without a doubt. Latour picked a single laboratory as the site for observation, whereas Fujimura restricted herself to two labs, thus both limiting the actual journey undertaken. In this book, research projects are described that are comprised of dozens of laboratories combined, and dozens of additional non-laboratory sites - thus increasing the complexity of following the actor - which deserves some further explanation.

I will use a metaphor to describe the particularities that are part of following the actor in such a complex, large-scale research practice, to coherently describe some of the problems that accompany following nutrition scientists: a sailing journey ${ }^{34}$. This metaphor of sailing goes back to the ages in which explorers knew little of the world and every journey was meant to discover new lands and wealths. 


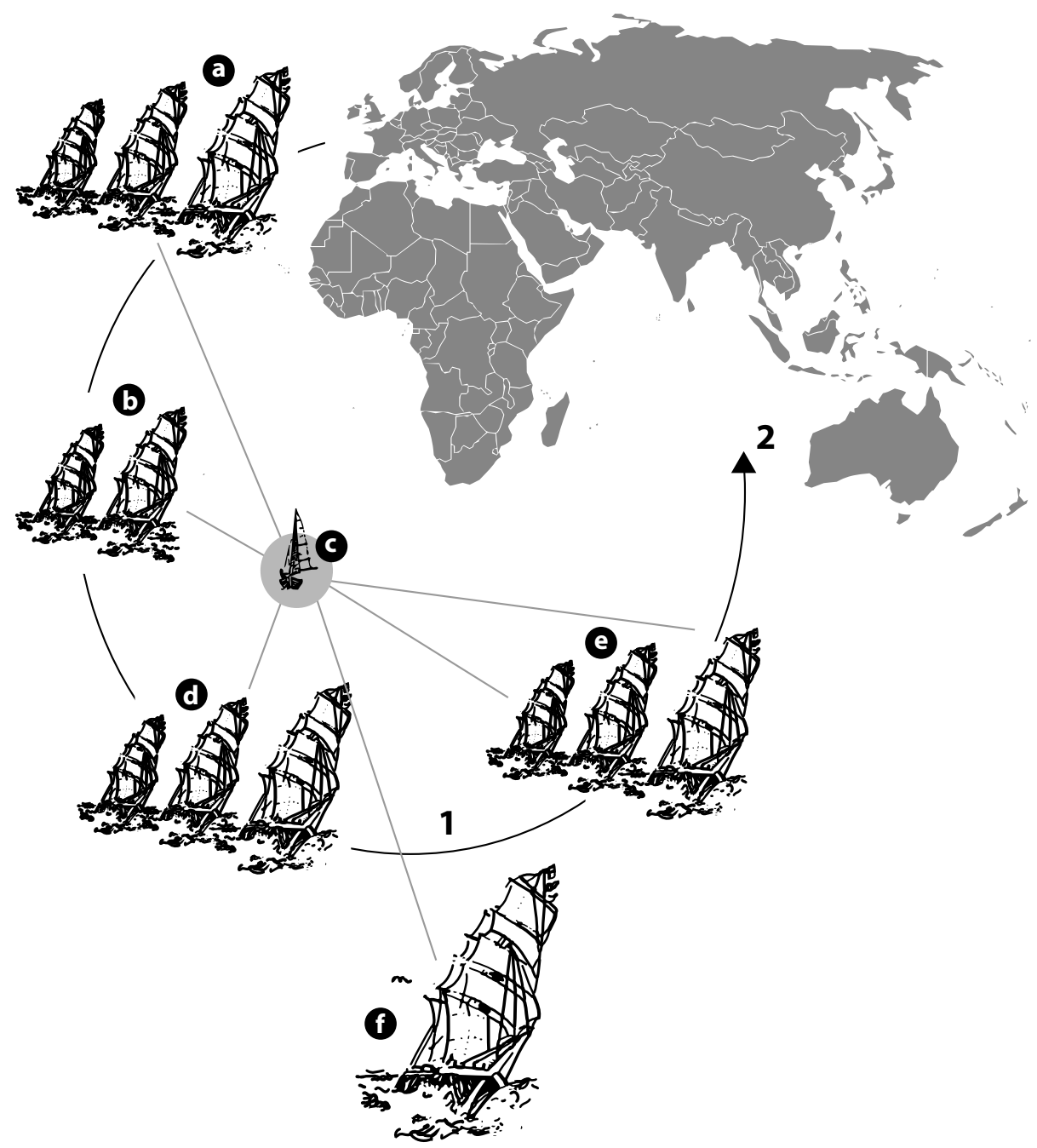

Figure 2.1. Sailing across the troubled waters of large-scale research practices. The image above is a graphical representation of the sailing metaphor used in this chapter. Various large-scale research programmes (for instance, a: the human genome project, b: Gut Health, d: NuGO, e: the human genome diversity project. Obviously, a lot more large-scale research programmes can be identified that are relevant for contemporary nutrition science. The image is merely an abstract representation) can be conceptualised as fleets, navigating the dense 17 century traffic between Europe and the Indies (1), the goal of these programmes (2, in this case, the goal could be conceptualised as 'health'). The single ships represent the programme partners: labs and sometimes food companies. Amidst this melee of ships and fleets, another small vessel is navigating: mine (c). It joins some fleets or ships for a brief time, then leaves and joins other fleets, navigating its way around large-scale science. From time to time, it leaves the main path and joins with an external fleet (f), the domain of science and technology studies. 
Like those travellers, the researcher observes the coastlines, topographies and climates and draws maps of them, while travelling by. Opting for the metaphor of sailing enables the conceptualisation of the relationship between researcher and object of research in two ways.

Firstly, such journeys were not undertaken alone. Such an old sailing vessel was crowded with people, who all existed in some type of a relationship with one another. Equality does not exist between those participating in this adventure, neither between researchers and researchees, nor between those researched. Furthermore, multiple sailing vessels may coexist within a fleet, sharing a goal for the time being, but each with a distinct 'way of doing'. Consider, for instance, the route around Africa between the seafaring nations of England and the Netherlands and their colonies in the East Indies. Ships organise themselves in 'fleets', enabling them to carry more spices, and other goods, as well as for protection. In such a fleet, a structure exists, albeit a situated one, changing and shifting (see figure 2.1). Here, we can recognise the collaborative efforts of different laboratories, sharing a research theme, or even a goal, but nonetheless still doing things 'their way'. The science researcher has to find his place upon entering such a lab. In other words, following the actor is a matter of carefully navigating the waters of large-scale nutrition science, changing boats along the way and covering enormous distances. In the particular case of this research project, this does not solely apply in the metaphorical sense of the word: I have traveled to Italy, Spain, Poland, the UK and New Zealand and various laboratories and conference centres in each of those nations.

Secondly, the ocean changes, it is dynamic and provides dangers to its travellers, shifting and unexpected dangers. Storms come and go, and as they do they are not just the weather, they also determine the state of the ocean, its waves, currents and the ability to traverse it at will. Or, as Martín Cortés describes the watery road: "This road differs from those on land in three ways. The one on land is firm, this unstable. The one on land is quiet, this moving. The one on land is marked, the one on the sea, unknown' ${ }^{35}$. As a sailor, one has to adapt to the circumstances as they present themselves. Furthermore, landmarks are also present when at sea, such as topographies of coastlines as well as stars and star systems. While navigating large-scale science, one continuously has to be sensitive to what is happening on the boat, as well as in the fleet. Most importantly, as an observer, one has to seek out a route through the practice, since staying at a single site, on a single boat, does not reflect the particularities of large-scale cooperation ${ }^{36}$.

If the metaphor is aligned with the actual research practice, a number of practical and reflexive questions come to the fore. Firstly, very practical, which boats are we talking about, and how did the observer get onboard? Phrased differently, how and where have observations taken place, and how were they conducted? 
Part of this question is acquiring entrée, selection of sites for observation and acquiring focus. Secondly, how did the shipmates interact and what did they learn from each other? Phrased differently, what did these observations do to the observer and the observed? This is a reflexive question, diving deeper in the relationship between science research and nutrition scientists. In the following sections these questions will be dealt with, starting with the practical part of observing large-scale science and the implications of ethnography and ending with a reflection on the consequences of opting for such an approach.

\subsection{ENTERING AND CHARTING THE COMPLEX FIELD OF NUTRIGENOMICS}

In order to do laboratory studies, the researcher has to move into the lab and it is exactly there, where my journey through nutrigenomic practice started ${ }^{37}$. To find out how day-to-day nutrigenomic research works, and how nutrigenomics in general is made feasible, I have chosen to enter the field as an ethnographer. This research project, as a part of the Societal Component of Genomic Research ${ }^{38}$, had been designed to fit onto (or into) the 'An integrated genomic approach towards gut health and nutrition' programme and to a limited degree, entrée had been prenegotiated. The pre-negotiation mainly was a formality, since actually coexisting and getting along - both very much required for long lasting productive cooperation - requires trust, which has to be earned, as well as social connections that have to be forged. Both require work and compromise. Formal entrée encompassed the programme meetings, co-organised with chaperone committee meetings and observations in laboratories. However, since the laboratory is the dominion of $\mathrm{PhD}$ students, laboratory technicians and post-docs, and the supervisors who had formally granted access are not found in there, before every period of lab observation, entrée had to be renegotiated, in order for the fieldwork to be productive.

Such negotiations meant making compromises and promises. Amongst other things, this meant that every scientist who wanted to, as well as gene and protein names, would be anonimised. No tape or digital recordings would be made during the observations. Furthermore, to compensate for lost time spent on interaction with the observer, I would help them out in the labs. As a result, in this research 'participant observation' was chosen as the main ethnographic path. Its characteristics are further discussed in the following section.

The main laboratory observational periods lasted for approximately a month ( 4 to 5 weeks at 5 or 4 days a week, respectively) at each of the four selected laboratories. For observation, laboratories D, E, F and G (see figure 3.1) were 
selected, spanning multiple aspects of the programme in terms of focuses and technologies. The enormous amounts of field notes and interview transcripts, as well as documents from within nutrigenomic practice can be organized, managed and coded by means of a computational aid to qualitative data analysis (in this research the computer program QSR NVivo was used). Initially, coding starts out as the clustering and structuring of large amounts of empirical data. Codes are not products or results of data analysis, they are part of it. For instance, as coding continues, the topography of codes, as it slowly grows in the computer program, provides structure. In QSR NVivo, the words topography and structure acquire a new meaning, since codes and texts can be spatially grouped, either as separate sets or intertwined. Whereas in silico this is relatively easy, on paper this would have been an enormous task. Through this initial structure, thought and analysis are guided and connections between codes and empirical sources grow clearer. A second advantage of in silico data analysis, is the flexibility in recoding and restructuring the code topography as insight advances. In silico coding resulted in the use of several hundreds of codes, eventually reduced to approximately 120 codes and subcodes. Considering the amount of text and codes to be managed, opting for a computer program was perhaps the only viable option.

After commencing fieldwork in nutrigenomic practice, I was able to observe how the network I was studying expanded. Scientists from the Gut Health programme travelled between sites of nutrigenomic practice, they visited meetings and conferences, referred to other labs, publications, websites and software. Furthermore, most of them were part of other networks or consortia that somehow were involved in nutrigenomic research. The two main other networks were the Nutrigenomics Consortium, a 20 million Euro Dutch initiative, and NuGO, a 17 million Euro European initiative. Whereas the Nutrigenomics Consortium directed itself, above all other things, to 'fundamental research', $\mathrm{NuGO}$ was directed at facilitating integration and cooperation between nutrigenomic initiatives throughout Europe. Over time, the number of sites at which nutrigenomic practice could be identified, as well as the number of sites that could be accessed, grew exponentially. The latter was possible because a number of the scientists in the Gut Health programme - with whom outstanding relationships had been built - held key positions in both other networks ${ }^{39}$. Observations were mainly expanded towards of European sites of nutrigenomic practice, via $\mathrm{NuGO}$, since observations in the Gut Health programme already provided insight into numerous Dutch sites. As a result, observations were also conducted at numerous conferences and meetings in the Netherlands, Italy, Spain, Poland, the UK and New Zealand, providing opportunities to engage in both formal and informal discussions with nutrigenomic practitioners, as well as to present papers and posters. Finally, interviews were conducted to further 
deepen understanding of nutrigenomic research practice. These interviews were conducted as semi-structured in-depth interviews of all the active researchers in the Gut Health programme ( $\mathrm{n}=20)$, a number of other (food-industry affiliated) members of the Gut Health programme $(\mathrm{n}=5)$, as well as scientists from $\mathrm{NuGO}$ $(n=3)^{40}$ and external experts $(n=3)$. Combined with literature, these interviews and observations form the empirical base of this book.

Describing absolutely everything that happens in the research practice of nutrigenomics is not a practical way of doing ethnography. Ethnographies of scientific practice have been conducted in the past, each with a different focus. Initial laboratory studies dealt with questions on what laboratories (Latour and Woolgar, 1986 [1979]) and scientific practice are about (Latour, 1987; KnorrCetina, 1995), or which roles tacit knowledge has in them (Collins, 1974, 1999). More recent ethnographies have widened the sites at which scientific practice can be observed, which have included court rooms (Lynch and Cole, 2005), insurance firms (Van Hoyweghen, 2007), forensic institutes (Toom, 2006) and many more. One of the key sites for this type of study has been the medical practice (see e.g. Mesman, 2002; Radstake, 2007).

These researchers have selected ever more specific focuses. These range from the construction of specific objects or packaged series of objects and tasks to facilitate cooperation (Star and Griesemer, 1989; Fujimura, 1996), the construction of differences in forensic and evolutionary sciences (M'Charek, 2005a, b) and bodily integrity (Toom, 2006) to the role of risk in insurance practices (Van Hoyweghen, 2004a, b). In each of those cases, the specific focus was decided upon beforehand, but was rearticulated and developed during observation and participation. This is not surprising, since actual insight in which issues can be considered relevant or specific for the practice, requires an understanding of that practice. This understanding is constructed through the initial, undirected, general observations. After a potential focus has been identified, selected and centred upon, observations can be directed towards $\mathrm{it}^{41}$. In this research, a small number of key issues, each of them simultaneously both prominent in nutrigenomic practice and prominent in social debates surrounding nutrigenomics and the relationship between scientific practice and society at large could be identified.

The agenda as well as the research questions were thus adjusted accordingly over time. The key issues, the 'actors to be followed', were the notions of (1) health, (2) food or nutrition and (3) the individual. Not surprisingly, nor coincidentally, these three notions exist on the intersections of all that has been discussed in the previous chapter. Health, or the goal of improving and/or approaching health through nutrition can be said to be an embodiment of the trends towards steerability, accountability and commercialisation, as discussed in 
chapter 1 . The increasingly individualising society has been discussed by Beck and Beck-Gernsheim (2002) and both health and nutrition will be demonstrated not to be immune to such socio-political shifts.

\subsection{PARTICULARITIES OF ETHNOGRAPHY}

Participant observation, as the name suggests, is a method of fieldwork in which the observer actively engages in the daily work that is performed at the sites of observation. It is argued, that through doing, more can be learned from a practice than from merely watching (e.g. Spradley, 1980; Hammersley and Atkinson, 1983; Jorgensen, 1989; Kawulich, 2005). Following Geertz, Gans considers it to be 'the most scientific' of the methods of fieldwork, because 'it is the only one that gets close to people. In addition, it allows researchers to observe what people do, while all the other empirical methods are limited to reporting what people say about what they do' (Gans, 1999, p. 540). However, the observer must be careful not to uncritically adopt the perspective of the observed practitioners, referred to as 'going native' while simultaneously encroaching upon that perspective very closely. This requires an intricate balance of proximity and distance, which can be maintained only by regular retreats from the field, literature reviews and discussion with colleagues outside of the field.

This particular style of research is motivated by the research goals formulated beforehand. Firstly, this is detailed empirical study of nutrigenomic research practice in which a focus would lie upon the normative work in nutrigenomics. Secondly, there also is an openly normative goal which states that the recognition and active (if not reflective) incorporation of normative issues into the daily practice of doing nutrigenomics, is going to change that practice for the better. With respect to the first, empirical research goal, an in depth empirical analysis of nutrigenomic research practice is facilitated by actually becoming a participant in that practice. However, the whole field cannot be spanned by observations only. For that reason, observations were supplemented with interviews, seeking out new norms as they are constructed ${ }^{42}$. It takes a lot of time and effort and a lot of social and communication skills to wander around nutrigenomic practice as freely as possible, trying to identify the issues relevant in contemporary knowledge production. Fieldwork is, and remains, a never-ending story. A description of a practice is never complete, and as a result, the empirical material does not cover everything and thus cannot describe or explain everything ${ }^{43}$. The second normative research goal, attempts to induce change in the nutrigenomic practitioners. This change can only be induced by interaction between the social scientist and the natural scientist. It is important to consider that the type of 
interaction I am referring to here is different from the interaction that is taking place while doing fieldwork, while 'doing' ethnography, required for addressing the first, empirical research goal. That is to say, these two types of interaction can happen at (almost) the same time but they have a different character. They refer to two distinct tasks initially formulated for the observer. The first task is for the observer to be 'allowed to observe the [...] project, but will not intervene with this research practice' (Vos et al., 2002), whereas the second task is 'to analyse and further stimulate the sensitiveness of normative issues with respect to genomics food research and nutrition on an individual as well as institutional level and to stimulate the development of normative orientations of researchers, professionals, consumers and patients' (Vos et al., 2002). This results in the important question whether non-intervention on the one hand and stimulating sensitiveness on the other can co-exist in a research method that thrives on interaction. Therefore, we will look closer at how interaction is shaped, and what it can do.

\subsubsection{The outsider as insider}

To a participant observer, balancing empirical, social and geographical proximity with critical and theoretical distance is a major challenge. Furthermore, it is made increasingly complex because of possible observers' backgrounds, whether the observer originates from a tradition that promotes empirical and social proximity or critical and theoretical distance, matters to a large extent. In this particular case, the former applied, since the observer holds a degree in (molecular) biology. The technologies employed, are partly the same and mostly similar to the ones used in nutrigenomic practice. Where they differed to a significant extent, existing expertise made it possible to quickly grasp and understand them, thus facilitating the degree of participation. The observer, in this case, is a partial insider, not institutionally, but culturally. It has been argued that being an insider unlocks certain empirical and normative aspects of the practice studied, that remain closed to the (cultural) outsider (Pearson, 2001; Radstake and Penders, 2007). However, alongside the advantages that come with being an insider, the disadvantages must be considered as well (see e.g. Bonner and Tolhurst, 2002). Kanuha (2000), for instance, demonstrates the particularities that come with interactions amongst insiders, which have been experienced in this research setting as well:

'Interactions between myself and participants in which they would state 'Well, you know what I mean' or 'I guess I do not have to tell you that', were not uncommon. In addition, the degree and kinds of shared laughter, unfinished phrases or specific terminology represented the 'knowing' and familiar references that characterize interactions between those who share cultural ways [...]' (p. 442-3). 
Being an insider may harm broad openness towards and critical reflection upon a practice which is studied (Labaree, 2002) ${ }^{44}$. Despite the difficulties connected to it, being a nutrigenomicist was only half the work. In order to be able to conduct interviews, following the observations, as well as to be able to analyse the material collected through observations, interviews and literature review, expertise had to be acquired in Science and Technology Studies. Out of fear of 'going native' or 'going observationalist', science researchers have often opted for the position of stranger to the practice (see e.g. Latour and Woolgar, 1986 [1979]; Hess, 2001). However, the position of stranger need not be an advantage, it can be a hurdle (Lynch, 1982) ${ }^{45}$, even to the extent of reaching a cultural schizophrenia. Therefore it was imperative that alongside the time spent at nutrigenomic conferences, meetings and in labs, distance had to be actively maintained by regular withdrawals from the field. These were spent reading a lot of books and papers, talking to colleagues and enlisting in, and following courses in an STS grad school.

\subsubsection{Two narratives on interaction}

One of the main characteristics of the approach taken in this project is the interaction between researcher and researchees. This interaction can mean a lot of things; time spent together in laboratories; emails exchanged; proofreading of draft papers; attending presentations and lectures, but also having lunch; drinking massive amounts of wine at conference dinners and exchanging plenty of laughs. This way, ethnography becomes the 'fine art of hanging around' ${ }^{46}$. Being in a laboratory several days a week exposes personal and professional successes, worries, troubles and problems. When performing experiments together, one gets to share success and failure and the emotions that result from them. This type of interaction is undoubtedly the major advantage of ethnography and simultaneously the researcher's biggest worry.

Let's look at two short first person narratives, two examples each corresponding with a type of interaction. Firstly: imagine me in a white coat, wearing blue plastic shoe covers, standing amidst laboratory equipment and mice cages. I am in the animal testing facility of a Dutch university. Just before entering it, the $\mathrm{PhD}$ student I was working with, explained me what was going to happen. This is the general rehearsal for an actual experiment that is going to happen the next day. Since the experiment involves mice, which are expensive and, because they have been on a special diet for quite some time now, a lot of time, effort and money had been invested in them. The rehearsal is supposed to make sure that the experiment is going to go according to plan. Every glitch encountered in that 
rehearsal is going to have to be removed. During every step of the experiment, the $\mathrm{PhD}$ student and her supervisor, who is also present, explain to me what they are doing and why they are doing it. I have a task appointed to me as well, namely that I will collect the gut from the mice after the technician has removed them, and after the $\mathrm{PhD}$ student has turned them inside out, and put them in a tube with a specialised buffer. I then shake the tube vigorously for 30 seconds, transfer the buffer into a separate tube and add new buffer to the tube with the mouse gut and shake again, all together 7 times. After the rehearsal is done, the tubes with shaken buffer are to be brought to a separate laboratory for analysis. The rehearsal shows that there is not enough time to shake and remove the buffer around the intestines in the time allotted for the experiment. What to do? The experiment was clear to me, and I asked a question in which three alternative strategies were contained, each with consequences for the experiment. I asked whether they would - in order to save time - pool the mice guts, pool the RNA or not pool at all.

W007: 'Yes, that is a good one. If one already pools at the gut level, one can take along more guts with less work. That means that we have to assume that the differences between the various cell types are larger than the differences between the different mice. Yes... we will just have to assume that. Good idea!'.

W007 says to W008: 'Hey [W008], Bart just had a very good suggestion. Listen. If we pool the guts [...], the guts of the mice of a single group, we can do more. And we will just assume that the differences within the cell types are smaller than between the cell types'.

W008: 'I am not so sure of that... if you look at some of the arrays'.

W007: 'It seems like a good strategy to me', Observation, 20040420.

During the rest of the day, the $\mathrm{PhD}$ student (W008) and her supervisor (W007) continued to discuss the advantages and disadvantages of my suggestion. The next morning I was told that they would go with my suggestion.

The second example shows a different type of interaction. Early 2006, I was in New Zealand, attending a local conference on nutrigenomics entitled 'Nutrigenomics, from science to the supermarket'. The programme was very interesting and I read work from nearly all of the speakers. It presented a great opportunity to do observations and plenty of opportunity to talk to those people informally during the breaks, lunches and dinners. Even though it was a natural science conference, I submitted an abstract of my own work, in which I claimed that the goal of personalised nutrition - that is a part of nutrigenomics - is not a very doable one. In the subsequent paper I used empirical material derived from the field itself. Not only was this abstract selected for poster presentation - the intended goal of submission - but it was also selected for oral presentation at the conference. In a field in which posters are the preferred form of presentation, it 
was a rare happening, especially for a submission that was obviously the odd man out. Nonetheless, it provided me with the opportunity to talk to the field, about the field, for twenty minutes ${ }^{47}$. Upon walking into the venue the next morning I was stopped by one of the conference organisers. He said 'At the end of this conference, we have an expert panel on the future of nutrigenomics and personalised nutrition in particular. We want you to be in it. After we heard your presentation we are interested about your position. You represent a different position and a different generation in nutrigenomics ${ }^{38}$. He was right about both. The panel members were mainly nutrigenomicists with a very positive opinion about what nutrigenomics could and should do, and they all had grey hair. The organisers had decided that my argument was relevant enough for their practice, to put it forward once again.

The first type of interaction shows that one can become so familiar with a practice that one reaches a level at which you can even contribute to that practice. It even resulted in an appearance in the 'acknowledgements' of one of the project

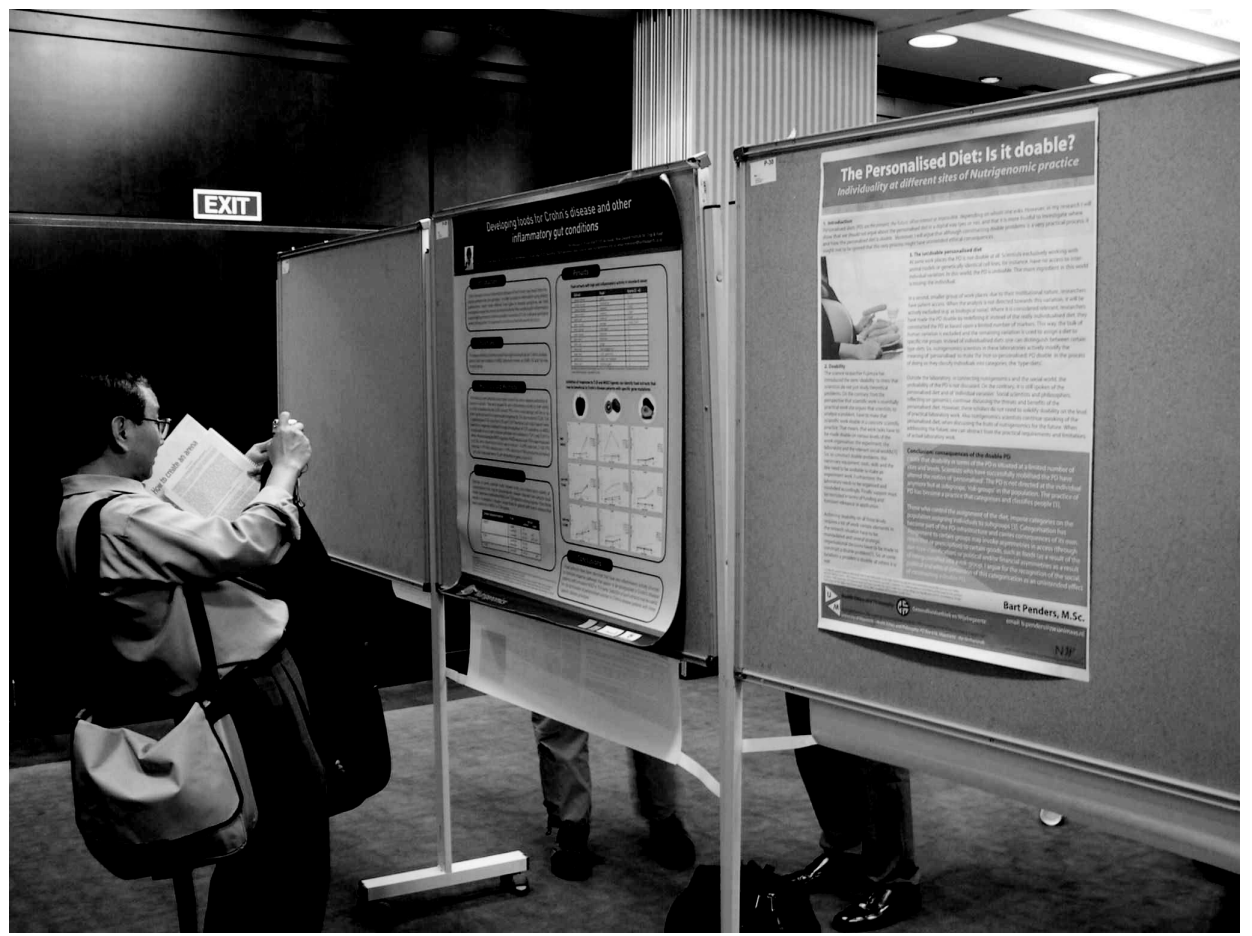

Figure 2.2. Poster Display. Display of the poster 'The personalised diet: Is it doable? Individuality at different places of nutrigenomics practice' (poster on the right) at the 'Personalised Nutrition Conference' 2005 in Palma de Mallorca, Spain. At this conference, as well as at the 'Nutrigenomics, from science to the supermarket' conference in New Zealand, this poster was put up amidst the other nutrigenomics posters. Photograph by Bart Penders, 20051103. 
presentations. The second type of interaction is not solely about acting along with a practice, but about taking a normative stance, while being in a practice. Looking back upon the observer's double task not to intervene and at the same time, to stimulate sensitiveness, the question rises: does an increased preparedness to reflection on normative and ethical issues of nutrigenomics count as intervention? Just 'being there' is enough to count as interference, according to Donna Haraway, since observation means acting inside practices that intervene and interfere in the world: to 'act' in the 'belly of the beast' (Haraway, 1991). Deciding whether both types of interaction were successfully balanced was decided in negotiation with to the field. If too much of a stir was being created, it would most certainly act upon it. The following step was to write down the argument in a concise paper and submit it to a journal in nutrition science, by which it was accepted (see Penders et al., 2007a). These two examples are the first steps in the understanding of such close interaction and possible consequences it may have for the research, the researcher and the object of study.

These two examples obviously demonstrate that in this research, the role of the researcher was not considered to be a 'fly on the wall', trying as hard as possible to be as invisible as possible. To be an invisible observer is simply impossible. Ethnography is all about interaction, actively engaging with the object of study, asking questions, nosing and poking around. As one does research, one is in the business of making a difference instead of merely standing by.

\subsection{UNDERSTANDING INTERACTION AS RECIPROCAL SENSITISATION}

On the boat, in the fleet, or in the lab, the researcher coexists with his object of study, in close proximity and in close contact. This relationship can be described in terms of sensitisation ${ }^{49}$. Drawn from biology, a possible definition would be 'to render an organism sensitive to a serum via a series of exposures'. As a result of the notion of co-travelling, both the STS scholar and his object unavoidably expose themselves to one another. When spending so much time together, on board of our beloved sailing vessel, researchers expose themselves to the field they study, enabling them to see deeper and more clearly into its heart. But it works both ways: at the same time, the actors from the field of study are exposed to the researchers as well.

When revisiting the examples above from the perspective of sensitisation, their differences fade away. I could never have added to the mouse intestine experiment the way I did, had I not been sensitised by the nutrigenomicists to see the world their way. The New Zealand conference organisers would never 
have invited me on their panel, had they not been persuaded to - at least partially - see the world my way. Such cross-fertilisation is something to work with and play with: it has the ability to invoke change. However, it is accompanied by the responsibility to guide sensitisation to a state of mutual benefit. Drawn from biology, sensitization can teach us another lesson. When mutual exposure is not monitored quantitatively and temporally, irritation may occur as a result of it. The idea of sailing together may suggest a relation of equal effect, but practically this is not so ${ }^{50}$. We STS scholars gain entrance to the field through the grace of our objects. So it is us who must be aware of avoiding irritation as a result of exposure, though it may teach us valuable lessons as well. From the perspective of sensitisation, the relation between researcher and object of study is in constant peril. Haraway phrases it like this: '[e]thnography is a method of being at risk' (1997, p. 190). If I were to constantly try to sensitise nutrigenomic professionals - when I say constantly, 'indoctrinate' perhaps would be a better word - that would lead to overkill, an imbalance - irritation - and perhaps even expulsion.

Methodological vocabulary is scattered with terms somehow describing exchange. Terms such as participation, interaction, expertise, saturation and sensitisation all describe aspects of cognitive and normative exchange and are thus all connected. In this particular type of study, participating is very important, since it provided the opportunity to interact on a large scale. Interaction is something that happens between practices, between natural science and social science and between the natural scientist and the social scientist, across boundaries. Sensitisation makes these boundaries easier to cross, in both directions. Finally, sensitisation can lead to interactional expertise, and for some, even contributory expertise ${ }^{51}$. Interactional expertise enables an individual to meaningfully comprehend and engage in debate and discussions in a practice that is not native to him, as if it were so, whereas contributory expertise enables an individual to contribute insight and actually participate to a practice, fully mastering its language, normativity and materiality (Collins and Evans, 2003, 2004; Collins et al., 2006). Collins and Evans argue that a sociologist of science, or an ethnographer, can acquire interactional expertise, but contributory expertise is something that is limited to the practitioners and specialists themselves. Contributory expertise includes interactional expertise, supplemented with amongst other things, technological connoisseurship and technical tacit knowledge. Nonetheless, they argue that some ethnographers may have contributory expertise. However, in that case they will have acquired it prior to their occupation as a sociologist, or the discipline studied is very easy to master (Collins and Evans, 2004). Both expertises cannot be acquired through the reading of papers or books; they can only be acquired through participation, interaction and sensitisation. Here, sensitisation is not something confined to interaction across the boundaries of natural science and 
social science, in this case nutrigenomics and STS. It is something that is part of every interdisciplinary practice, where boundaries are common and various expertises are cultivated simultaneously ${ }^{52}$. Furthermore, it contains elements of a cognitive, as well as a normative recognition and outreach over (disciplinary) boundaries. Acquiring expertise in a practice requires both cognitive, as well as normative adjustments or alignments with respect to the elements of that practice. It requires a lot of work and failure is a real and imminent danger, in which failure means either not being able to invoke sensitisation from interaction, or expertise from sensitisation.

From an analytical methodological point of view, the bidirectional process of sensitisation can be separated into two unidirectional processes. The first of the two examples of interaction, shows that sensitisation from nutrigenomics to STS has clearly succeeded, since the researcher was able to contribute to the particular experiment. Furthermore, the second example shows that sensitisation from STS to nutrigenomics also has the potential of succeeding. However, the text that lies before you is part of that interaction, both the product of sensitisation, as well as aiming for sensitisation, thus adding to the effort made in example two ${ }^{53}$. Furthermore, when there is nothing to add to a description, when interviews or observations do not provide new or additional data, anthropologists or ethnographers speak of saturation. Saturation, when positioned in the framework of sensitisation, is not only the saturation of the empirical data of the researcher. Even when the empirical data is 'saturated', there still is something to be gained, namely the construction of expertise through interaction and sensitisation. Saturation can only then be accomplished, when an acceptable level ${ }^{54}$ of expertise is reached, enabling not only description of a practice, but also action in a practice.

The notion of sensitisation is the link between interaction and the construction of expertise. Thus, it is not just a methodological issue, but also a standing product of the research process. This means that once expertise with respect to a practice has been constructed, participation, interaction and sensitisation have become easier to accomplish ${ }^{55}$. However, in order to be able to continuously reflect upon this practice, an external expertise - in this case in STS - is necessary. Thus, after a careful start, sailing with nutrigenomic professionals has provided an in depth analysis of nutrigenomic practice. The analysis and subsequent insight, however, have not solely been used for value-free description, if such a thing is possible, but have been mobilised for the benefit of acquiring expertise, hence enabling the STS researcher to act in nutrigenomic practice as well as in STS practice, mobilising both expertises interchangeably at will, which is not unlike Pearson arguing that 'it is [...] possible that, if the researcher is a part 
of the researched community, he or she can act as a bridge between the two [...]. The researcher thus acts as both insider and outsider, embodying the resulting tension [and enabling] constant reflexivity' (Pearson, 2001, p. 61).

Sensitisation is, however, not limited to the actions of and reactions to endeavours of single participant observers and their objects of study. It is a perspective, a way of conceptualising relations. A parallel can be drawn on the level of science studies at large, not unlike the notion of 'going native', which can apply not only to individual researchers, but to entire STS oriented research programmes. Sensitisation is part of the interaction of STS with its object of study. As such, it represents the reciprocity science studies so actively seek and ensures that science studies are relevant to their audience: the scientists who live, work and act inside these complex research practices.

From here I continue this journey through large-scale nutrition science, carefully navigating the troubled waters of research practices and problems, norms, values, boundaries and facts, following health, nutrition and individuality wherever they may lead. 
CHAPTER THREE

\section{MAKING LARGE-SCALE NUTRIGENOMICS WORK ${ }^{56}$}

The part $[\ldots]$ is reflected in the whole. The part shines

through.

Theordore Sider (2007)

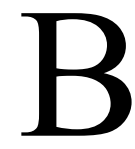

oundaries are central to scientific practice and large-scale scientific practice has a lot of them. How they are relevant in knowledge production, however, is a matter of dispute. Shinn explains a difference in which 'The New Production of Knowledge' and the 'Triple Helix' deal with boundaries in scientific practice. In a comparison between the 'New Production of Knowledge' and the 'Triple Helix', the former has been described as notably de-differentationist (Shinn, 1999, p. 150) or even anti-differentationist (Shinn, 2002 , p. 604), denying boundaries, divisions and demarcations between types of knowledge, social institutions and structures. The 'Triple Helix', however, takes a neo-differentationist approach (Shinn, 2002, p. 606), leaving existing boundaries, divisions and demarcations intact and adding action and interaction up to a level where the demarcated entities are able to take over one another's roles. Shinn argues that 'The New Production of Knowledge' stands alone in the radical anti-differentationist position, because it has no recognisable sociological and theoretical roots (Shinn, 2002). The 'Triple Helix', however, is rooted in Luhmann's systems theory framework - a structuralist approach (Shinn, 1999, 2002). The 'Triple Helix' does not describe a change in structures internal to science, such as disciplines and research fields, whereas 'The New Production of Knowledge' spends a great deal of effort attempting to further transdisciplinarity, 
the ideal of not only crossing, but transcending the boundaries between disciplines, effectively deleting them. Between the positions taken by the 'Triple Helix' and the 'New Production of Knowledge' with respect to the role and importance of boundaries, demarcations and structure, room for manoeuvre exists in terms of description and analysis. Science-internal boundaries cannot be denied, nor ignored and cooperation between social structures, between industry, government and science does not come by itself. Science is part of society. That does not mean that boundaries between them are absent, or that boundaries inside science are absent. Mode 2's argument - that when problems are being suggested by society to science, forging an alliance between them, the face of science will change - is legitimate nonetheless. This change does not remove all boundaries or differentiations, as the 'New Production of Knowledge' suggests, but neither does it leave all of them unaffected, as is hinted at by the 'Triple Helix'. How such processes look like, will be the topic of the remainder of this chapter, a report of a journey that encountered and traversed many a boundary.

The journey through nutrition science practice will start close to home, in the Dutch Gut Health programme. The programme consists of a complex array of geographical and non-geographical sites, resulting in a large complexity. This chapter analyses the role of the boundaries that exist inside such a complex setting. How is it, that despite this complexity, scientific practice continues to thrive? How do experiments relate to the overall goals of a large programme? This chapter will start by introducing the organisational complexity and will continue to demonstrate that the links between sites and the links contained to single sites shape the experimental work conducted and simultaneously constrain it. Scientific practice continues to move on, but as ties are forged to enable it to do so, other ties are unmade or made unlikely.

\subsection{THE BIRTH OF THE GUT HEALTH PROGRAMME}

As always, the beginning of a research programme is not evident. It has to be chosen. Here the process that brought together the people, the laboratories, the equipment, the funding and the research problem(s) that together comprise the Gut Health programme has been chosen as a start. Following a call for programmes, scientists from a number of laboratories proposed a research programme that addressed the relationship between micro-organisms and the human gut. A second group of scientists independently proposed a project that addressed nutrients and the gut: 
[It] started in the chaperone committee, people who had obviously judged the projects. From that [committee] very clear the advice was put forward to merge the two projects... to see whether it was possible to merge the two projects. When such an advice is uttered you obviously know that you can choose not to follow up on it, but chances of your project being funded would grow extremely small. So, for that matter, there quickly was a reason to see whether it was possible to cooperate. At the time, that went rather smoothly... it has been some years now. [Scientist M001] and I contacted each other - remember that we did not know anyone; we didn't even know each other - and we arranged a meeting to get together the teams that were behind each of the project proposals. It took a few rounds [of rewriting] to produce a final proposal that everybody agreed with. But actually, things went rather smoothly, because both groups recognised clear overlaps in the approaches. There were quite some differences, but enough overlap to produce one coherent story and put that into one project proposal. Interview Scientist Z002, 20051124.

The funding body did not want to fund two similar, or perhaps even overlapping, research programmes. Scientist Z002 is clear about the 'stimulus' given by the funding body, to both projects teams, to consider a merger. Diplomatically, the words 'no merger, no funding' were not uttered, but the message was clear. These two teams of scientists, who had never met each other had to work together to get their share of the funding. The chaperone committee scientist Z002 refers to is something all programmes funded from this particular budget from the Ministry of Economic Affairs have as a part of their organisational structure. It consists of a representative from the funding agency, an independent academic (who, in this case, chairs the committee ${ }^{57}$ ) and representatives from industry - in this case mainly food industry. A food company can buy a chair in the committee by contributing to the research project financially (an annual fee) or otherwise (materials, equipment, expertise, etc.). In return, they will be informed about the scientific development of the programme and will have a front row seat in case anything commercially applicable would come out. Not the scientists, but the chaperone committee members and the funding agency decided that the two programme teams had to consider a merger. Scientist Z002 recalls this process as a rather smooth one, but also that it took several rounds to come up with the final product. It took work to produce the definitive proposal - centred on these overlaps.

So what were the overlaps that were identified? Project A wanted to look into the interaction between certain bacteria and the gut. Project B wanted to look into the interaction between certain nutrients and the gut. These nutrients would be amino acids, fatty acids and aflatoxin. When phrased alike, the overlaps may seem rather straightforward - but this was most certainly not the case: 
훙흥 둥 궁

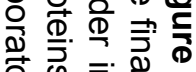

崫

풍. 욤응.

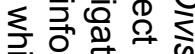

곡 윽 흔 응 옹

उํㅠ 1 응

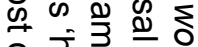

음 을 응 읏

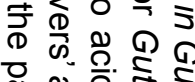

잉 으오

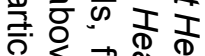

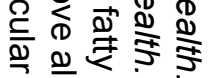

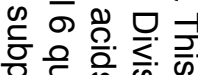

के क

융 ฏ 을 응 응

ब) क व

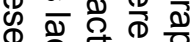

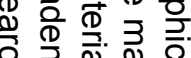

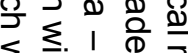

这 1 (

心宁

ᄋ

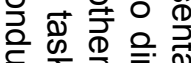

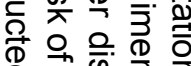

雨 옹 은

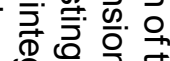
윽 穴. 穴

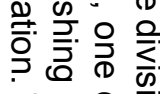
검 호음음

ㅇํ응 욱

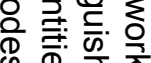

心.

亏.

ป

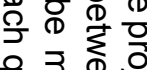

읃

ڤ

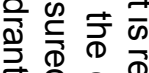

융 음

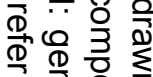

+ 은

穴

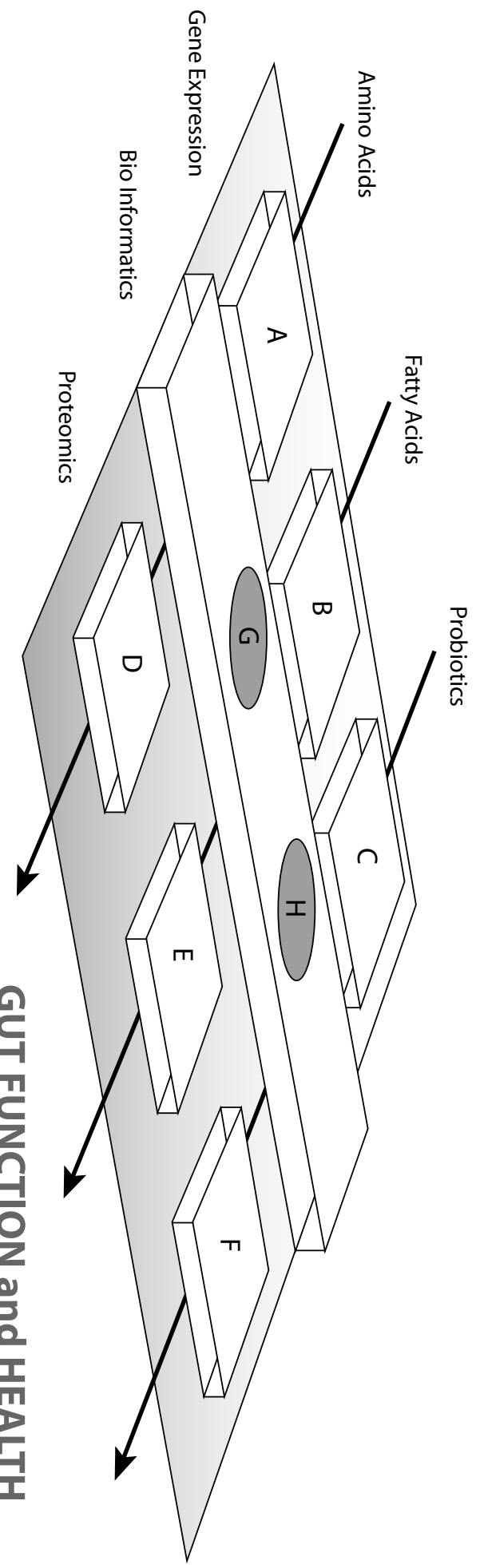


[There are, however,] a number of differences. Amino acids and fatty acids are mostly active in the small intestine and [bacteria-species] more in the large intestine. You are most certainly looking into different things and a number of processes [directing them] will certainly be different. Furthermore, with respect to [species of bacteria] and probiotics in general, it is not very well known what sort of interaction they induce. There are a lot of hypotheses, but there is very little uncircumstantial proof. Interview Scientist Z002, 20051124.

A solution was devised in which the differences were confined to smaller modules in the programme, actively attempting to diffuse them. The scientists involved combined a technological approach - the genomic approach - with the compounds and organisms they wished to research, as well as the models in which they wanted to perform this research into a patchwork of (sub)projects as depicted in figure 3.1 .

Combined, the Gut Health organisational modules work on the umbrella research problem of gut function and health. Defining gut function and health, however, is one hell of a problem. To use the words of scientist W001: 'One cannot research health, for health is everything ${ }^{58}$. Thus, a modular problem structure has been arranged to make research problems 'less uncertain' and 'more doable', by enabling the modules to be restricted to a sub-problem or a small number of subproblems, that makes sense in the context of the umbrella problem (Fujimura, 1987). Furthermore, the sub-problem can be further fragmented into smaller units. An example is shown by means of Table 3.1. It shows a list of experiments and activities that combine into the sub-problem laboratory $\mathrm{D}$ has to face. In order to reach publication IV.1-5, problems II.1-15 and III.1-6 need to be solved, using (among many other things) the tacit knowledge and technological connoisseurship, acquired in I.1-7. In this table, as well as throughout the programme's meetings, all such activities were very much referred to as technological problems.

Scientists working in a module of the programme restrict themselves to the problems they face inside that module. All the problems that go with the other modules are not theirs, thus making their job easier, or easier to oversee. Complementary to this modular structure there is a need for a relation to the umbrella problem and between the modules and the sub-problems, a connection that ties together the sub-problems and the larger research problem. In this particular programme, this tie is twofold. Stated simply, the two dimensions in the module patchwork, being the compounds researched and the entities to be measured, always link a number of sub-problems together. This means that, in the first dimension, measurement of gene expression is done with a technology called micro-arrays and measurement of protein expression is done with $2 \mathrm{~d}$ gel 


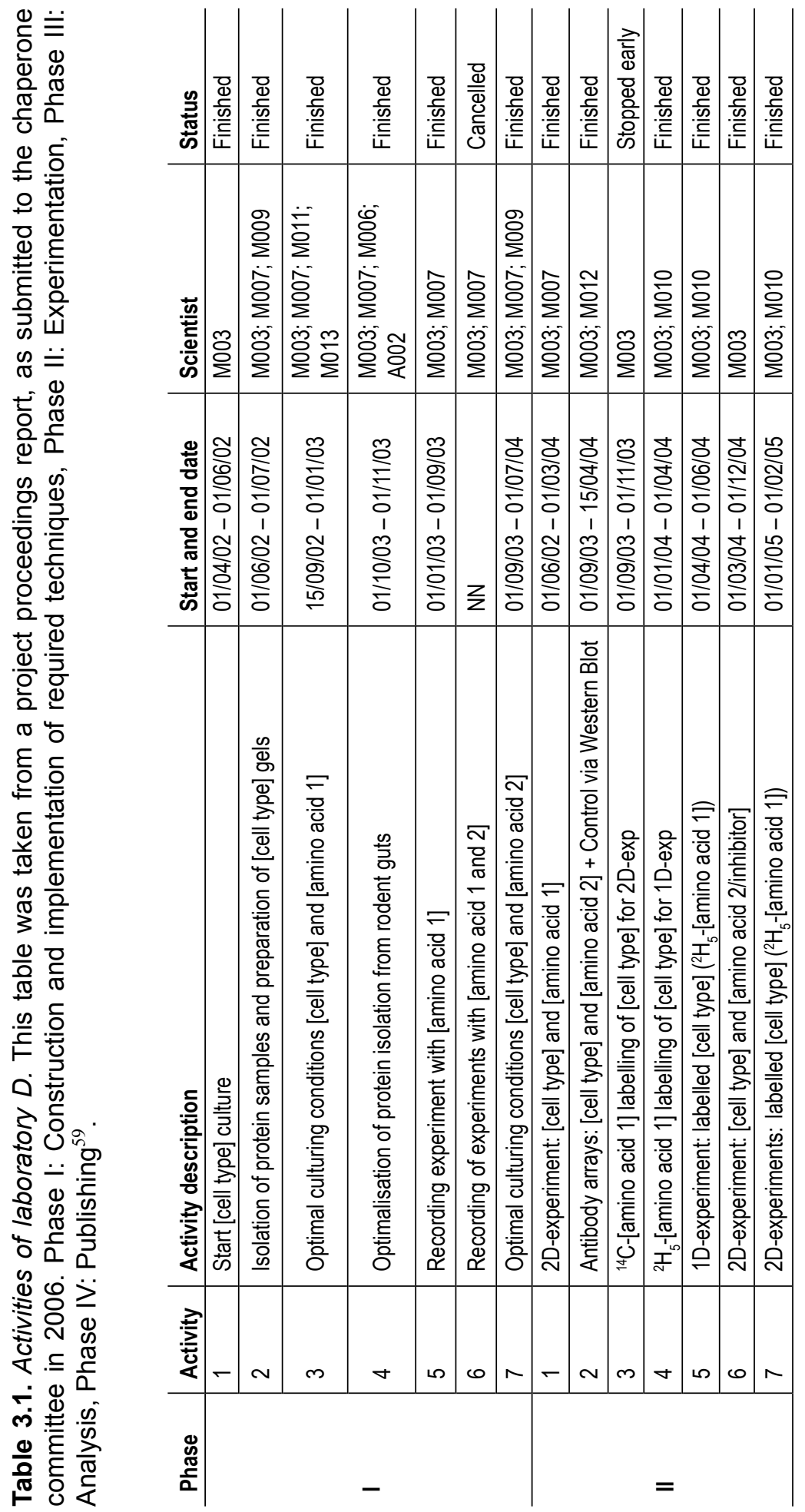




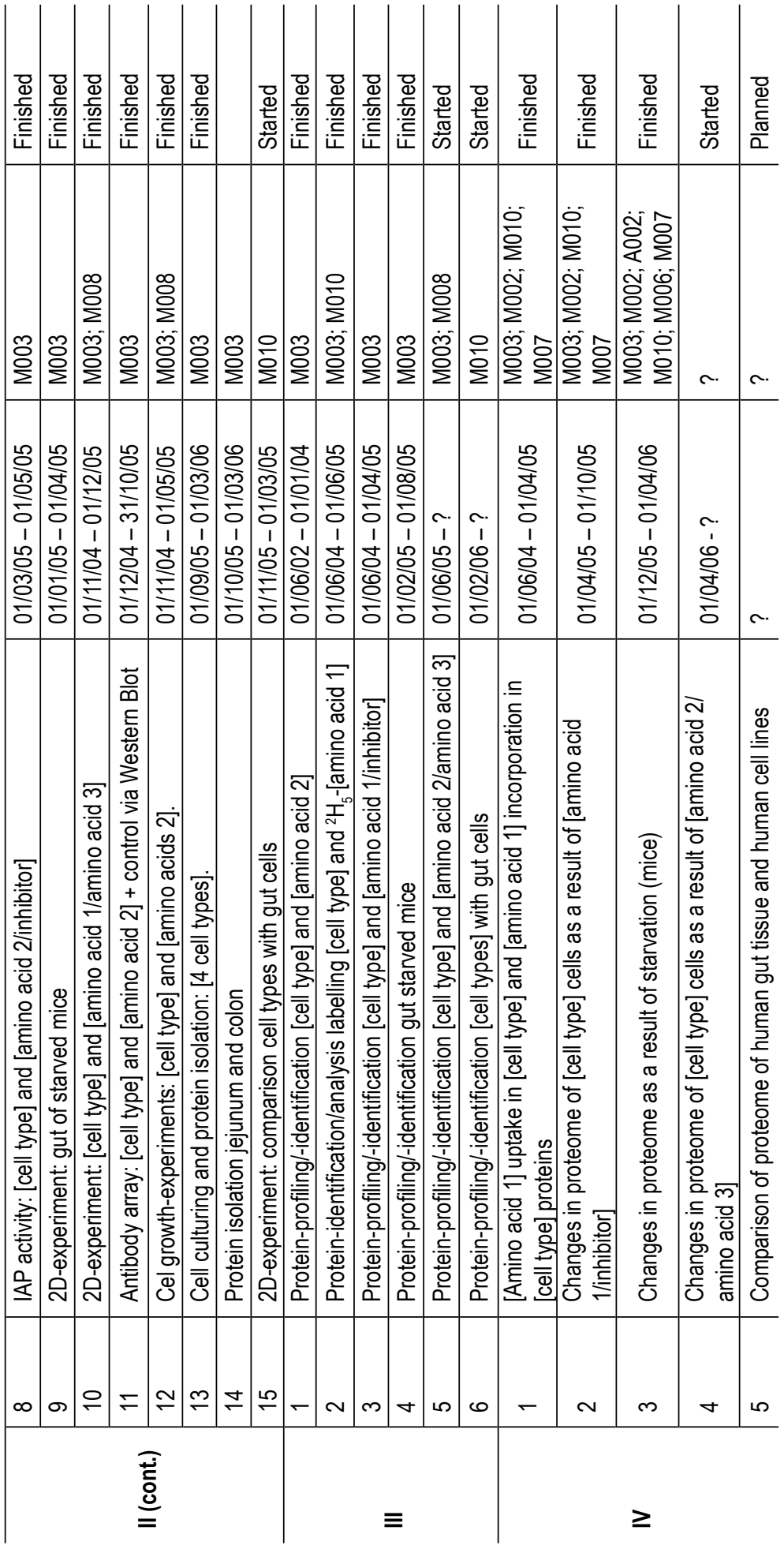


electrophoresis. Modules A, B and C were going to use the micro-arrays, whereas modules D and E would use gel-electrophoresis (among many supporting technologies). The second dimension also provides links, tangible chemicals, nutrients or organisms present in the laboratories. Ideally, laboratory $\mathrm{D}$ for instance, would thus have methodological ties to laboratories $\mathrm{E}$ and $\mathrm{F}$ and at the same time it would share a research subject with laboratory A. Comparable relationships will then exist between all the partners in the programme, mutually linking them under the larger umbrella of gut function and health and thus accounting for the experiments performed.

However, building and maintaining such links requires work. They neither come easy, nor standard. Two partners in the programme were appointed the task to construct and maintain the ties based upon the micro-array technology ${ }^{60}$ :

Within the project team, array production and measurements will be performed at two locations, [B] and [C], both having experience in this area. Both facilities will share the materials and will act as mirror sites. This will guarantee a flexible approach towards all other partners and implement a quality control system, since at regular intervals identical samples will be measured at both locations. Gut Health project proposal.

In doing this work, constructing and maintaining the ties, the positions of the labs in the programme changed. Laboratories B and $\mathrm{C}$ had the experience, the expertise, to build and to use these micro-arrays for the benefit of the Gut Health programme. According to the programme proposal, the programme had 250 thousand Euros to do so. Laboratory B would concentrate on the microarrays directed at the human genome and laboratory $\mathrm{C}$ on the micro-arrays for the bacterial genome, thus partially loosening the ties with lab C. By dividing tasks this way, lab B would build the array for all labs 'doing' gene expression (including lab C) and lab $\mathrm{C}$ was to be the only laboratory using the bacterial array ${ }^{61}$. With respect to the groups 'doing' protein expression, the technology used in that field is more widespread and can be purchased easily from known laboratory suppliers. At least, as far as the $2 \mathrm{~d}$ gel electrophoresis system is concerned. Protein identification, however, is a bit more complicated and the technology may be considered experimental, perhaps even more experimental than in gene expression studies:

The field of proteomics is, from the methodological point of view, still in flux, so that a generally accepted, standard approach remains to be established. In contrast to gene-expression profiling, more than one approach may in fact be necessary to obtain the sought-after information. Gut Health project proposal. 
Although everybody is in some way involved in constructing, managing and maintaining the ties between the programme partners, a larger-than-average portion of this work has been dropped in laboratory B's lap. Despite the design of the programme, as shown in figure 3.1, suggested similar roles for the labs in the network, laboratory $\mathrm{B}$ had been given an apparent key position in establishing and maintaining the programme's modular configuration.

\subsection{FROM PAPER TO PRACTICE}

The modular configuration as depicted in figure 3.1 was predesigned; the picture itself was part of the final programme proposal. Wandering through the laboratories of the Gut Health programme, it could readily be observed that the daily practice of the scientists involved in the programme did not exactly fit the description presented in the programme proposal or other literature pertaining to the programme's organisation ${ }^{62}$. As Gut Health moved from the drawing board into scientific practice, a number of complications and contingencies arose.

One of them was a hurdle that remained after the initial merger that gave rise to Gut Health. Some modules mainly originated from the "micro-organisms and the gut' programme, whereas other modules mainly originated from the 'nutrients and the gut' programme. This has resulted in a situation in which ties that bind some modules are stronger, as well as different, to others. Scientist W008 refers to the consequences of the merger:

To my own daily work it has had no consequences whatsoever. Except for the fact that their work does me no good. That means that I have colleagues in the programme, but they do nothing for me. Interview Scientist W008, 20050531 .

The module scientist W008 is responsible for has not changed significantly to her, after the merger. Furthermore, she does not identify significant ties between several sub-problems:

All of it ... is very unconnected. And I think everybody is aware of that. Yes, it is all very unconnected $\ldots$ because they mainly look at the bacterium, not even at the gut. Interview Scientist W008, 20050531.

Scientist M002 agrees. He looks back upon that merger as 'artificial':

The third branch of the project, of [laboratory $\mathrm{C}$ ], was more of a strategical decision [...]. [Bacteria] can also invoke a health effect, possibly, as can 
nutrients, so we share that. But they remain to be two distinct entry points for the study of gut health. I still think of it as an artificial merger. That is something that can be noticed, of course. Interview Scientist M002, 20051018 .

Scientists from this 'third branch' also identify the lack of ties that bind the modules:

I think that everybody does his own thing, eventually. That includes these meetings and the like. I cannot say that people who work in a different group add something to my subject. Everybody does one's own thing. I am together with [Z003 and Z002] and others have teamed up in other groups. Interview Scientist W006, 20050919.

The modules were envisioned to be different in setup, enabling them to approach different sub-problems. Gut function and health can be perceived as a grand challenge, wisely split up into questions that are not so broad, but approachable, affordable, intelligible and thus: doable. However, not losing track of the umbrella problem requires connections between the sub-problems to keep the programme together. The shared micro-array technology was envisioned to play a large role in 'keeping things together'. When I entered the programme, it had been running for a number of months. The day I first visited the chaperone committee meeting, it was being held at laboratory $\mathrm{C}$ and all the scientists and the commercial representatives had gathered in a meeting room to discuss the proceedings of all the modules. It was there that I learned, that the micro-array which laboratory B was asked to provide, had been abandoned. Looking back upon how that decision was reached, a senior scientist from laboratory B recalls that the decision was motivated both technologically and politically:

[There were a] lot of technological and other reasons. We have indeed started out with cDNA arrays and I think we had that method up and running rather well. At that time, there had been a discussion. I think that, at that point, it was a very political discussion. Other [laboratories] wanted to do their own thing. When that discussion was finished, technology had advanced and the system that we used was not state-of-the-art anymore. We have switched from cDNA arrays to oligo arrays and subsequently to Agilent arrays ourselves. We now see that the Agilent arrays are much better. At the time, when the discussion was going, we tested the Agilent arrays from that time and we decided they were really bad, and so was Affymetrix. That is because this whole shift occurred in a time when there was a huge development in this experimental technology. I think that home made 
arrays currently do not have the quality that these companies can offer. But I think that when we started out, we were better. Interview Scientist W002, 20051108 .

Deciding to abandon the homemade array, meant deciding to sever an important intermodular tie. It presented the Gut Health team with an additional decision to make. Commercially, a number of arrays were and are available. The two major players on the micro-array market are Agilent and Affymetrix, the two array types scientist W002 refers to. They use a different approach for measuring gene expression. Simply put, Agilent compares two samples in two different colors, whereas Affymetrix uses only one color and the comparison has to be done in silico. One of the bioinformaticians explains that his laboratory actively argued for a shift towards commercial arrays. Though unwillingly, the bionformaticians may have tipped the balance between the two major commercial arrays:

From the beginning we have argued that if we want to do bioinformatics, the first thing we need to know is which genes are on the array, including the sequences. This because we do several control analyses on a sequence level. We have continuously argued that if we were going to work with a home made array, we want to know the sequences and not just the names of what is on it. We have argued that it is hard to normalise small arrays and that is why we are little enthusiastic about it. I think that this is something that has seeped through. Following that we have encountered a number of problems with two-color arrays [...]. Because we clearly demonstrated these problems, they will have had an effect in the choice between the two [types of arrays] and influenced the choice of a lot of people who have shifted more strongly in favor of Affymetrix. That was because we had a lot of data from the two-color arrays and could easily demonstrate quality problems. Interview Scientist M004, 20051025.

As we will see, the resulting balance has had major consequences for the other labs in the programme, especially laboratory B.

Parallel to discussions about a choice between arrays within the Gut Health programme, choices had to be made throughout the entire field: everybody in genomics - whether nutrigenomics or other genomics versions - was using arrays. Some were still using their own homemade arrays, whereas others opted for commercial solutions. The parent institutes of laboratories A through $\mathrm{G}$ had to make these decisions as well. Over time, it became increasingly clear that the parent institutes of laboratories A, B and $\mathrm{H}$ had opted for Agilent arrays and the parent institutes of laboratories D, G, E and F had opted for Affymetrix arrays. The logistical burden of committing to an array type is huge, with single devices such as the array reader priced up to 200 thousand euros. The solution institutes 
generally have opted for is to set up Genome Centres. Such a centre is comprised of a single room stuffed with extremely expensive technology and specialised staff to operate this technology. Since others are not allowed to operate the machinery, doing micro-array experiments mainly consists of handing over the samples for analysis and receiving data back in an email message. For a single laboratory it is hardly an option to defy such a choice for a specific array.

After a very short ${ }^{63}$ cooperation with an external micro-array service provider, Gut Health member laboratories followed in the footsteps of the parent institutes because of the availability of the Genome Centres. As a result, no single standardised micro-array existed in the Gut Health member laboratories and especially for laboratory B this had major consequences. The lab was envisioned to be a technology provider at first, but now this role had been taken over by the Genome Centres, pushing the lab towards a substantially less central role in the programme:

Not only would we provide arrays to everybody, but above all, $\mathrm{PhD}$ students would perform experiments in our lab. I think our role in the project has been marginalized. Secondly, we were subsequently required to input a research project of our own, something we didn't have before. We sort of turned from a technology partner into a scientific partner, but classified into a certain part of the original programme proposal. That didn't follow up on the other projects [in this laboratory]. So in the end I am not very satisfied with our role in [Gut Health]. Interview Scientist W002, 20051108.

Furthermore, the other partner working on lipid nutrients in the gut - laboratory $\mathrm{E}$ - chose to focus more on gene expression than protein expression resulting in a shift towards the module of laboratory B. This meant that more laboratories chose to focus on gene expression than on protein expression. Thus, while the modules remained, their content was shifting.

The decision making process surrounding the micro-arry also had effects for the bioinformatics departments. Both bioinformatics laboratories, $\mathrm{G}$ and $\mathrm{H}$ were initially asked to construct a database, connected to the array, laboratory B was providing, in which gene expression data could be entered and compared. However, because of the shit of laboratory B, they saw no use anymore:

There is a d[ata]base and an analysis system available. [It] is very expensive, but it saves a lot of time. Commercial arrays agree well with commercial databases and most groups already have access to these $\mathrm{d}$ [ata]base systems. The time saved can be spent wisely on other matters, such as pathway analysis and data mining. Observation Scientist M004, 20031012. 
The companies providing the micro-arrays, provide bioinformatics tools designed to fit their platforms as well. The database never was constructed, a decision connected to the Gut Health programme being forced to use multiple gene expression platforms:

A central database was envisioned, in which all data would be saved so that everybody in the programme would be able to have access to it. Subsequently, the analysis would be performed altogether. But this has not happened. Everybody started using their own system, as well in terms of [micro-array] platforms as experimental models, mice, humans and cells. Both cannot be compared amongst each other. That database would, if it would have come into being, not have worked. Interview Scientist E001, 20050308 .

Shifts in one module had effects that reached into the other modules. Ultimately, every laboratory had to find its new place in the changed topography of the Gut Health research programme.

The task laboratories $\mathrm{B}, \mathrm{G}$ and $\mathrm{H}$ signed up for in the Gut Health programme was circumvented by buying technology and the connected tools, instead of developing these themselves. Laboratory B reinvented its module in an alternative configuration of the Gut Health programme. So did laboratories G and $\mathrm{H}$, although they did so in their own way. Furthermore, laboratory $\mathrm{H}$ could not find the post-doctoral fellow it was supposed to hire ${ }^{64}$. After quite some time, laboratory H's senior scientist was able to find a candidate suitable for the job. However, scientist $\mathrm{A} 003$ did not have a $\mathrm{PhD}$ and could not be hired as a post-doctoral fellow. Instead, the post-doc position was redesigned to fit A003's profile, changing it from a 3-year post-doctoral position into a 4-year $\mathrm{PhD}$ student position. Scientist A003 was selected based upon his potential and the expertise he could contribute to the programme. Where the construction of the programme database had disappeared as one of the main deliverables, laboratory $\mathrm{H}$ and with it scientist A003 had to find 'something to do'. Now that scientist A003 was employed in a $\mathrm{PhD}$ student position, he was expected to produce a $\mathrm{PhD}$ thesis.

Not only laboratories are affected by shifts in the configuration of the programme, so are individual researchers. For instance, in the Gut Health research programme, bioinformaticians have selected a number of tasks for themselves:

What we do, is to try to project the outcome of $[\ldots]$ an experiment onto existing knowledge, being biological pathways, biological functions and levels [...]. One can throw statistics at [such data] and see what processes are the ones in which things happen, whether one would expect that or not. That's about it. Interview Scientist M004, 20051025. 
The bioinformaticians in the programme have in this way partly adopted the role of bioinformatics consultants, to be approached when in need of bioinformatics advice. The other part is about developing the methods they need to comply with the tasks they set themselves. Both the post-doctoral fellow M005, working in laboratory G, and Scientist A003, working in laboratory H, took both tasks to heart.

I am a PhD student on this position, but was supposed to be a post-doc. He was supposed to do supporting work for the experimental groups and especially micro-array data analysis. [...] We have tried to propose our own research plan, something that was largely non-existent previously. Some sort of a problem-directed approach, we called it. The plan was that over time, during acting as a consultant for the different groups, problems would arise and new bioinformatics would be necessary. Interview Scientist A003, 20051122.

Scientist A003 needed this new bioinformatics to compose a PhD thesis, whereas scientist M005 did not have that need and was able to provide more support to the other laboratories. As a result, both laboratories $\mathrm{G}$ and $\mathrm{H}$ created a role for themselves within the programme, but these roles significantly differed from each other ${ }^{65}$. The processes that resulted in abandoning homemade arrays and homemade databases, led to an alternative configuration of the programme. The modular configuration remains, albeit altered both in terms of intermodular ties, as well as in module content. This configuration arose in concordance with both internal and external contingencies and may, in some ways, be considered robust. As scientist M006 recalls 'almost all of us ended up doing something completely different, but it still worked out ${ }^{96}$.

\subsection{DOABILITY IN LARGE-SCALE SCIENCE}

The relationship between the modules and the whole programme is continuously changing. Through its modular configuration, Gut Health can be said to address a number of issues. Firstly, there is the need to satisfy the wishes of the funding agency, a clear example of which is the combination of nutrient and micro-organism modules into one programme. Secondly, through the act of making gut function and health a modular problem, it limits the number of tasks every single scientist has to oversee. Thirdly, this configuration provides shelter to several laboratories with supposedly complimentary expertise, as well as interested food industry ${ }^{67}$. The previous analysis suggests that these three aspects of Gut Health are part of an emerging configuration to make the large-scale cooperative programme 
doable. Here, doable extends to every possible aspect of the programme, from acquiring the funds down to conducting an experiment. The notion of 'doability' has been extensively discussed before in the context of cancer research (especially Fujimura, 1987; Clarke and Fujimura, 1992; Fujimura, 1996). It started out as an actor category, which developed into a theoretical framework for explaining and understanding decisions on all levels of scientific practice and in numerous social worlds.

Fujimura uses a simple drawing (figure 3.2) to explain the particularities of 'doability'. She distinguishes three levels of 'work', on the experimental level, for instance performing a PCR reaction, the laboratory level, for instance the layout of a laboratory and the machinery that is available, and the social world level, for instance the rules of conduct and the theoretical notions which are part of the discipline the lab is part of. In order for a problem to be doable, all three levels need to be aligned, so that tasks belonging to each of them align. Fujimura adds two observations to this framework, which may seem rather trivial, but they most certainly cannot be ignored when conceptualising problem-solution construction the way she does. Firstly, if scientists have unlimited, or at least abundant resources, constructing doable problems is not as hard as compared to situations of scarcity. In other words, one can buy oneself out of a situation of undoability. Secondly, uncertainties decrease a problem's doability 'because it inhibits researchers' abilities to plan ahead which, in turn, means that much of the work is carried out on an ad hoc basis' (Fujimura, 1987). Scientists will only devote resources, both intellectual and tangible, to problems that are perceived to be doable, or that have the potential of becoming doable. In both cases, decisions will be made to optimise the alignment of tasks within, or that surround a research problem. This is the scientific alternative to the one of the strategic rules of engagement Sun Tzu left us in 'The Art of War': 'Thus it is in war the victorious strategist only seeks battle after the victory has been won' (Giles, 1910).

I will expand upon the alignment, not restricting it to tasks (work) on multiple levels, but also include all 'actants' into this picture, such as reagents, texts and protocols. Fujimura includes these elements into the alignment indirectly, via incorporating the tasks of getting the elements in a research situation together. By directly incorporating all elements in the alignment, the diagram shifts from reflecting a doable problem as solely doable in terms of work, towards a doable research practice. This way, 'doability as alignment' creates a middle ground that leaves room for both materialities (network-centred) and decisions (actorcentred).

Fujimura's model has inspired many following study, including this one, but she has been criticised for not living up to her promise of facilitating understanding throughout laboratories and social worlds: 'Fujimura stresses the importance of 

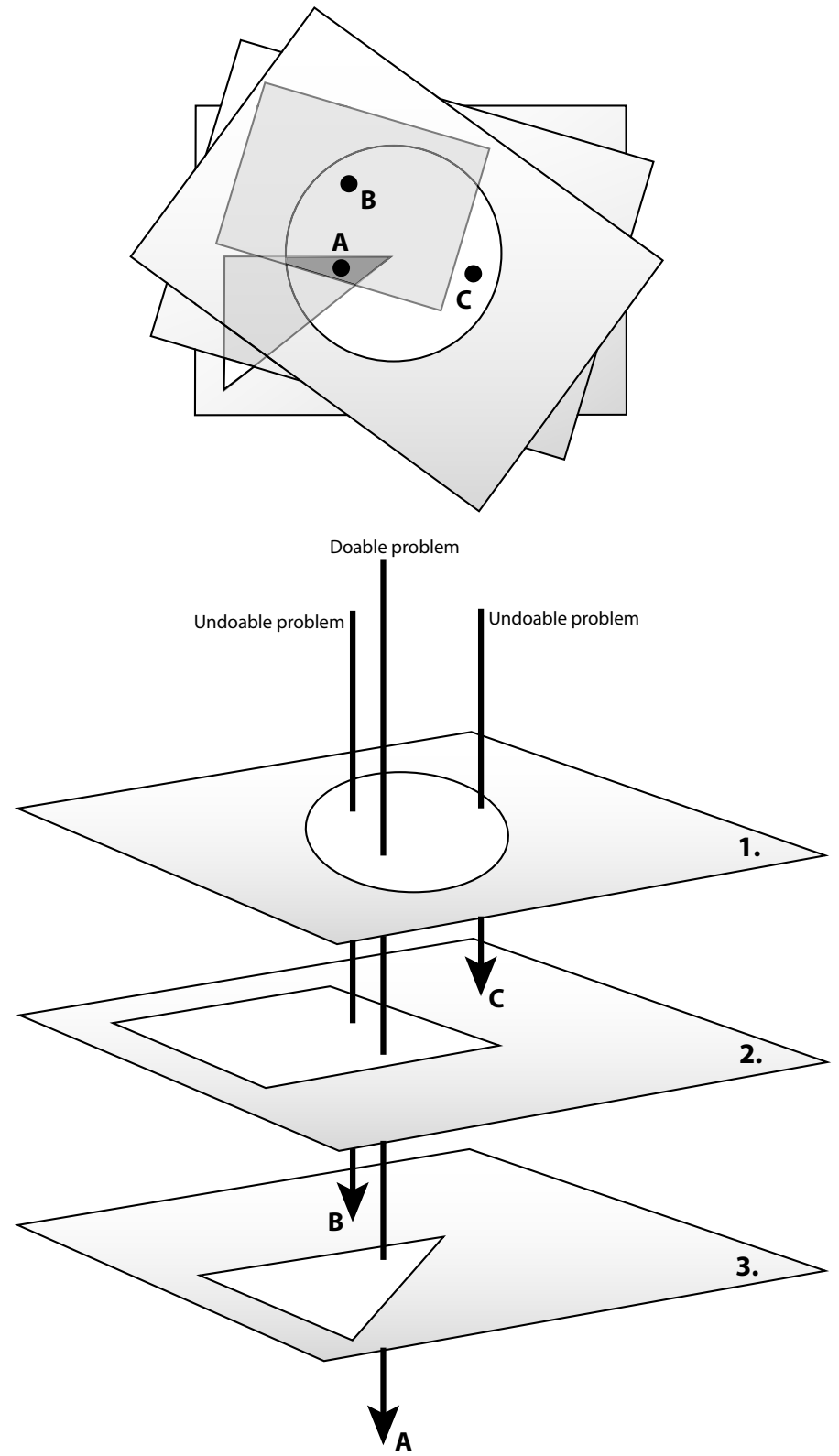

Figure 3.2. Doability as alignment. Redrawn from Fujimura (1987), doability is the situation in which all the actors and elements in the research situation are aligned. The act of pursuing doability and rearticulating the elements in the research situation to reach alignment, can be conceptualised as shuffling and manipulating three layers filled with tasks, until tasks on every level exist in vertical alignment and the doable problem, visualised as an arrow, can traverse all layers. 1. Social world, 2. Laboratory, 3. Experiment, A-C: research problems. Left: side view, right: vertical view. 
a broad 'ecological' approach to science, one which explores numerous social worlds, but her investigations are focused on the single world of a research laboratory' (Löwy, 1998). Palladino agrees and argues that the laboratories Fujimura studies are not loci 'upon which all social action converges' (Palladino, 1998). She may have inadvertably focused upon the laboratory in expense of the other sites of scientific practice and in the process trimmed the notion of doability of much of its value for the analysis of contemporary scientific practice. I will nonetheless show the groundwork Fujimura has invested in 'doability' can be taken beyond a single laboratory and into a world of large-scale research efforts, such as the Gut Health programme.

A research problem such as gut function and health cannot easily be reduced to a single social world, a single laboratory or a single experiment - it is too big and too complex. As a result, the modular configuration of the gut function and health umbrella problem is accompanied by a modular configuration of several 'doabilities'. Just as the sub-problems relate to an umbrella problem, the modular doabilities relate to the doability of the umbrella problem, including intermodular ties, such as shared methodologies, notions and funding. Furthermore, the use of 'doability' as a motivator for decision-making processes may suggest that a 'state of doability' is a homogenous and static state of affairs. Problems may, however, range from potentially doable and barely doable up to clearly doable. This implies that the overall doability of the umbrella problem cannot be visualized as a single three level alignment. I will demonstrate that the doability of Gut Health research practice is more of an intricate web of interconnections all requiring some version of alignment but also operating in smaller subunits.

In the Gut Health programme scientists and industry representatives all together manage this set of local doabilities, changing or circumventing the misalignments they encounter as the programme unfolds itself. Since the scientists act inside a module of the programme, they manage the doability of the sub-problems connected to that module. However, because of the connections between the modules, their actions echo into the adjacent modules. For example, while laboratory B was getting their cDNA micro-array to work, other laboratories chose a different strategy to get their gene expression measurements to work. Their decision to opt for commercial arrays severely affected the work in laboratory B. As scientist W002 explained above, laboratory B finalised their arrays and got them to do what they were supposed to do, from a technological point of view. However, the array never came into action in the programme. Scientist W002 identified the process that resulted in that situation, a 'political discussion' ${ }^{68}$, a discussion in which the programme partners considered arguments relevant, other than scientific and technological. Even though lab B does not use the array they built now, they did so for quite some time. The solution they devised to fit the 
sub-problem of 'reliable gene expression measurement' fulfilled their needs and can be said to have made their problem locally doable. However, this particular solution to the 'reliable gene expression measurement' problem, limited itself to laboratory B.

As mentioned earlier, lab $\mathrm{C}$ and company $\mathrm{X}$ managed to co-conduct an experiment at both sites because at neither of these sites the necessary expertise and technology both were available. By combining expertise and technology, scientists from lab $\mathrm{C}$ and company $\mathrm{X}$ succeeded in performing the experiment. Scientist W006, from lab F, however, was unable to accept the terms and restrictions that came with this cooperation and lab F slowly faded to the background. These terms and restrictions are part of the daily practice of doing science in a commercial environment and are just as important a factor as are all the others in order to approach, and eventually solve, a problem. Even though within a single programme, lab $\mathrm{C}$ and company $\mathrm{X}$ needed two laboratories to get a single experiment running. The process that led to this cooperation was in turn less appreciated by members of laboratory F. In a somewhat different state of affairs, laboratory B managed to get their problem solved in their own lab, a solution that however was not transported to the other programme members. Apparently, what can be made doable or what has been made doable need not be equally so in every laboratory of the programme, nor can doability always be constructed at a single site or laboratory.

Not only does the alignment of tasks differ over time, it also differs across sites and places. Programmes such as Gut Health extend both over time and place, unlike the single-laboratory studies on which Fujimura based her conceptualisation. Fujimura herself hinted at both a temporal and a situated character with respect to the alignment of tasks that results in a doable problem (Fujimura, 1987). Various local doabilities, corresponding to the sub-problems, such a measuring the effects of a certain amino acid on gene expression, as well as the doability of the umbrella problem of gut health and function, coexist within this single programme. Because of the ties that exist between the modules, and the modules and the programme, these doabilities also interact.

\subsection{FOOD INDUSTRY AS A MODULAR ADHESIVE}

An important element in the configuration of the Gut Health programme is the chaperone committee, which holds a number of industry representatives. Their numbers have varied throughout the programme, as they could freely enter or leave the committee. Numbers have been as high as nine companies providing 
representatives to the programme. What do such food industry representatives do? Their role is perceived differently by many of the programme members. Scientist W008 is not sure what the representatives do or should do:

On paper, they are the chaperone committee, so they should guide me into a direction of which they think it is best for the programme, they chaperone. In fact they are some sort of a control institute [within the programme] and as far as I understood it, they should be monitoring whether we take the right path. For as far as they are able to. [However,] I have never received a single comment from any single one of them. Once, over six months ago I was asked the question 'what can we do with this?'. That was after two and a half years of research, the first thing I heard from them. Interview Scientist W008, 20050531.

Scientist W008 identifies the chaperone committee as notably absent from the daily practice of research, and scientist M007 agrees with her:

I have to say that scientifically speaking, I see - and hear - very little influence $[\ldots]$. They fill out some sort of progress monitoring form. I have to say that I find the influence of the companies marginal given that we approached one of them and the response to that was somewhat chilly. That could be improved [...]. I think that science takes a certain path and the companies sit there and listen but do not have a steering role. That is how it appears to me. Interview Scientist M007, 20050621.

Scientist Z003 speculates on the industries motivations:

Currently, the situation is that the industry is present and waits until the names of genes they can patent pop up [...]. Up to this point, nothing interesting has popped up [...]. I think they are very careful in presenting their own data. Understandable, however they can extract more value [from the programme] if they would - in some way. Interview Scientist Z003, 20051124.

To both scientists W008 and M007, the chaperone committee members are more of an audience to the programme than they are participants. This notion of 'being audience' to the programme is something the industry representatives themselves use as well. However, from time to time, they step up and actively participate in the daily practice of Gut Health:

Initially [we were] mostly observers, because the entire methodology had to be developed. Last [meeting] I have explicitly pointed out in which direction the programme would go if [we] were to decide. But we are a 
consortium of companies and scientists who all have their own thoughts on the matter. That is something we have clearly put out on stage. Interview Industry Representative I001, 20050915.

This active involvement is not something that is restricted to the chaperone meetings, which are held every couple of months. For instance, laboratory C has actively cooperated with one of the food industry companies on a specific experiment in which the company opened up their laboratory for Gut Health experimenters:

I have been working closely with [company X] for two years now. I have the idea that it is very useful, and it is an agreeable cooperation, especially the last year. I think we profit from it [...]. It creates a number of possibilities, for example, at [company $\mathrm{X}$ ] they have a lot of experience with tissue culturing and they have looked into the interaction of [bacteria] with human cells. The experiment I would probably come up with as pilot experiments - they have done them already, so I can skip that. That is the advantage. They offer the possibility to perform the experiments [at their labs] for me. And so they did. The experiment was discussed together, decided upon together and constructed together. Ideas were contributed from both sides and the experiment was performed at the [company name] lab. On harvesting day, I went over and helped them, giving me an idea of how things work. I subsequently took the RNA samples over to [laboratory $\mathrm{C}$ ] and did the array work here. Those facilities, [company X] doesn't have, so this type of experiments, these methods, they cannot perform them. That is the added value for them. [They tell me that] when [they] look at the total gene expression pattern, [they] see things comparable to the experiments they performed themselves. Interview Scientist Z003, 20051124.

Laboratory $\mathrm{C}$ is quite content about the interaction between their lab and the food industry laboratory. Scientist W006 from laboratory F was initially also involved in this cooperation. She does not share Z003's positive evaluation:

I have had meetings with [company $\mathrm{X}$ ] and [laboratory $\mathrm{C}$ ], but it actually is more [company $\mathrm{X}$ ] and [laboratory $\mathrm{C}]$. They shut me out a bit [...]. Relations were difficult. It happens that meetings are cancelled, but not several times in a row. I did not think it worked out nicely. They have all these rules and regulations in their laboratory. If you want to do an experiment in their labs, that is very difficult. I'd rather do it here. Certain things just aren't allowed there. Interview Scientist W006, 20050919.

Apparently, comparable initiatives do not yield comparable results for everybody. 
The industrial representatives have interacted selectively with the partners in the programme, thus exposing themselves to issues that are imminent in food industry research and development, for instance the restrictions and regulations scientist W006 refers to. Sometimes food industry representatives have addressed all the programme partners in a chaperone meeting ${ }^{69}$. Via the chaperone committee, food industry was able to introduce the restrictions and interests from their particular type of nutrigenomic practice into the Gut Health programme, thus adding to nutrigenomic practice a commercial perspective and improving upon options for actual implementation and valorisation.

Nevertheless, no single member of the programme, scientist, committee administrator or industry representative, concerns himself with all the aspects of the programme. Senior scientists do not know in detail what is going on in their laboratories, and even less what is going on in the partner laboratories. Industry representatives are often located even further away from daily experimental practice, restricted to the reports made in the chaperone committee meetings and the written progress monitoring forms. Together, they manage the various experimental, laboratorial and social worlds that together constitute the Gut Health programme as well as its context.

When compared to the scientists in the programme, the chaperone committee members have a different role in the programme's configuration. Scientists mainly work in a certain module of the programme, and on a certain sub-problem. Industry representatives, however, are not restricted to a specific module (although they sometimes act in a module) and they address not a sub-problem, but the umbrella problem. Their commitment to the Gut Health programme mostly does not restrict itself to a single or small number of modules:

[Company Y]'s interest goes out to all three product categories. So, proteins, fats and probiotics. One cannot go without the categories [of gene and protein expression], so within all three columns [we are interested in] the whole picture, even though I think that for most people bioinformatics is mostly an appendix. Interview Industry Representative I008, 20050915.

I do not think we have a favorite [module]. One can argue that this is because of our existing business, we sell probiotics... so if anything were to arise from that, it could possible help our existing business. But we also have an extensive programme on bioactive peptides, making the amino acids very interesting. We also sell fatty acids. To us, I think, it is more about the developments we observe. We do not see anything specific to further enhance our existing products. Interview Industry Representative I001, 20050915. 
As a result, next to the material and technological ties that have been forged between the modules of Gut Health, it is the chaperone committee and its members that act as an additional tie, 'holding it together'.

However, not all food industry company are alike, and some have very clear favourite modules to which they devote significantly more time and effort, linking them more closely to them. An example of this is company X, closely working with laboratory $\mathrm{C}$, as shown before:

We were interested from the very beginning [...] together with [laboratories $\mathrm{C}$ and $\mathrm{F}$ ] in gut health in general and specifically [bacteria species] that exist in the gut $[\ldots]$. Our business is nutrition and all of that goes through the gut. Those [bacteria strain] were a model component to us, because we are very much into infant nutrition; with our infant formulas we are able to specifically stimulate [bacteria species] populations in the gut. That explains the connection. Interview Industry Representative I005, 20060125.

In contrast, the $\mathrm{PhD}$ students in the Gut Health programme are tied very much to their own project in their own module, responsible for planning and conducting the experiments and reporting their findings through either presentations or publications, especially directed at the sub-problem that is their responsibility ${ }^{70}$.

Approaching the end of the official duration of the Gut Health programme, company representatives had witnessed struggles, shifts and changes in the organisation and setup of the programme, as well as in the scientific strategies, set up by the individual laboratories. Attempts at making the technology work and making it fit the problems at hand had led to a number of decisions that affected the ways in which technology was used, and the position of the different laboratories in the modular programme configuration, as well as the position of the industrial representatives in the programme and the chaperone committee. At the 2005 chaperone meeting, industry representatives carefully explained their views on the goals and strategies of the programme and the type of knowledge they actively wished to pursue while respecting the technological and organisational struggles the programme had gone through so far and was still going through. They requested more attention to issues relating to the umbrella problem of nutrition interacting with gut health and function, as quotes above have demonstrated. Those issues were the concepts of health and nutrition. Although key notions in the research programme, and more importantly, key notions in the social and financial accountability of the programme, these could not be found in experimental strategies in the laboratories. Health and nutrition existed in the umbrella problem only and were excluded from the sub-problems, to make them more doable. In other words, they put health, as well as food, prominently on the 
agenda of the Gut Health programme again, which still was very much focussed on finding technological solutions for problems arising in the various modules that addressed molecules and cells much more than nutrients and bodies.

\subsection{SIZING UP SCIENCE TO ACHIEVE DOABILITY?}

A strategy to improve the doability of a problem is to expand the network and to increase the number of modules addressing several aspects of the problem, thus increasing the science of scientific practice ${ }^{71}$. Halfway through the Gut Health programme, another (much) bigger consortium came into being as a result of European funding: $\mathrm{NuGO}$, (the European Nutrigenomics Organisation, as introduced in chapter 1). Nearly all members of Gut Health have been members of the NuGO consortium as well. Furthermore, the Dutch research community comprises a large part of the NuGO consortium and scientist M001 argues the work done in the context of Gut Health is at least partly responsible for that: 'As the result of our work, the Netherlands have taken the lead in Europe, for example in NuGO'72. In contrast, Scientist W002 disagrees: 'I do not think it has added anything to NuGO. That has completely passed by [Gut Health]. I do think that [it] was important for Dutch nutrition research' ${ }^{73}$. Whether Gut Health acted inside NuGO might be unclear, NuGO most certainly started to act within the confinements of Gut Health. For instance, at the chaperone meeting 2005 of the Gut Health programme, not only did the industry representatives take the stage, this meeting also was one of the first meetings where NuGO acted upon the agenda inside the ranks of Gut Health as scientist M001 pointed out: 'we focus at the pathways, especially the lipid pathways. Why? Because NuGO does so too ${ }^{74}$.

As the Gut Health programme advanced, technological difficulties standing between the scientists and the sub-problems they were working on decreased, or phrased differently: most sub-problems were constructed doable on an experimental and a laboratory level. At this point, industry representatives readdressed the topic of gut health, forcing the scientists to consider health not only on an abstract level as an opportunity to account for their programme, but also to incorporate it in their problem construction. Health became an issue that had to be considered on multiple levels of problem construction. The process of doable problem construction resulted in an attempt to exclude health from the problem formulation: 
The level of the project at this time is 'what does glutamine do in a cell?'. Statements concerning health, screening, assays and the like have nothing to do with us. Observation Scientist W002, 20050301.

However, the food company representatives did not let go. After all, their interest in the programme was mainly directed at health and they were actively pursuing that knowledge:

We do not ask you to build the high-throughput screening system... but supply us with the knowledge to make it happen! Observation Industry Representative I003, 20050301.

Scientist E001 disagrees with I003. He believes the knowledge I003 is after does not comply (anymore) with the way in which the programme has been shaped. During the ongoing process of problem construction and reconstruction, experiments have been conducted and laboratories have been modelled to make the sub-problems doable. Introducing health into the problem construction process requires a translation and scientist E001 is clear about what is and what is not doable: 'We can measure and we can determine, but we cannot translate. That is an entirely new project ${ }^{75}$. Scientist W001 agrees and connects an issue of scale to the Gut Health programme configuration:

We are a very small project, focused on mechanisms. If you want markers, you will have come across with a lot of money. This is a pioneering project. Observation Scientist W001, 20050301.

It appears that making the various sub-problems more doable, has not made using and measuring health and health claims more doable.

Clarke and Fujimura argue that actively manipulating and articulating the various elements in the research situation lies at the heart of what constructing doable research problems are about (Clarke and Fujimura, 1992). Among many others, health is such an element. In order to construct gut health into a doable research problem, health itself has become subject to manipulation and articulation:

What is health? Scientist W002, 20050301.

800 Genes can be a marker, if clustered right. Can we say, based upon 800 genes that the gut is healthier? Scientist M004, 20050301.

Decide! Decide what health is! Scientist M001, 20050301.

We agree. Decide! [...] To decide what is healthy you have to decide what healthy is. Industry Representative I003, 20050301. 
Scientist W002 points out, that others have taken up this question and that experts from $\mathrm{NuGO}$ were going to gather in the nearby future, to tackle this matter once and for all:

Concerning this discussion about health. At the end of May, a large number of experts will gather in Krakow to address health in nutrigenomics. What health is, and how to deal with it. Organised by NuGO. Observation Scientist W002, 20050301.

It is interesting to see that while the Gut Health network incorporates $\mathrm{NuGO}^{76}$ in an attempt to make researching health more doable, rhetorically, it is attempted to actively externalise the notion of health from the programme: 'In this programme we have decided not to determine what healthy and what diseased is. We solely address normal physiology' ${ }^{77}$. Since the Gut Health programme continued to use health in terms of social and financial accountability and the Gut Health and NuGO scientific practices did significantly overlap, issues related to defining and determining health remained part of Gut Health practice and debate.

The notion of (gut) health as part of a research problem, however, remains problematic. Scientist N002 contrasts the use of health for social accountability with the use of health in doable problem construction. According to her, incorporating health into research practice is "stupid":

I would wish for nutrition science and nutrigenomics to exist as a scientific discipline, which exists because it wants to discover new things, create knowledge and understand connection, like mathematics and physics. But the deliverable 'we will make people healthy and prevent all disease' is stupid. However, eventually we will need to take this path because politics opens the doors to funding only there [...]. I personally feel extremely unpleasant about these promises. Interview Scientist N002, 20051211.

Ultimately, gut health and function, as an umbrella problem, has not become more doable. Contrastingly, all the sub-problems, most of which had been of a technical nature have been made doable. $\mathrm{PhD}$ theses have been and are being completed, papers have been and still are being published, and scientific careers have been crafted from the Gut Health programme as PhD students advance into academia and food industry. Despite all this, the main aim, gut health and function has not (yet) become a doable research problem. Also, expanding the number of sites, via the inclusion of NuGO has not improved upon the situation. However, the processes that constructed various doable sub-problems and have gathered 
support from $\mathrm{NuGO}$ in order to incorporate health into scientific practice have also had their effect on the notion of health itself and its relation with nutrition: they have become subject to manipulation and articulation.

\subsection{HEALTH AND NUTRITION: MAKING THEM DOABLE; MAKING THEM MOLECULAR}

The funding tender from which Gut Health drew its budget, was solely meant for funding genomic science programmes. One could argue that the raison d'être for the programme was its methodology, especially because one of the main goals of these genomics innovation programmes is to facilitate the development and enhancement of new techniques and technologies. As a result of this, the use of this particular methodology can be considered a prerequisite and thus a rather stable factor in the construction of both experiments, as well as for instance the layout of the laboratories and their connections. To adopt a genomics methodology, means to focus on effects on a molecular level. If one desires to research food-health interactions on a molecular level, that is, to express oneself in terms of for instance RNA (the micro-arrays) or proteins (gel electrophoresis), measuring equipment, experimental design, the data and knowledge produced and the explanations given will restrict themselves to the molecular level. Genomic methodologies are considered to be powerful tools in molecular research. If effects of diets on health are sought after through the use of these techniques, as the Gut Health programme proposes to do, these health effects will be noticed solely on a molecular level.

While a doable configuration of the modular programme was being worked out, the notion of health residing within the umbrella problem continuously remained 'an issue' in the discussions in the programme. The rhetoric of externalising responsibility for defining health to the NuGO consortium did not succeed in externalising health from Gut Health practice.

The time and effort needed to get the experiments to work was more than just a 'technological setback'. It was a process that enabled the Gut Health programme to shape itself, as well as its experimental strategy to fit the task at hand. Perhaps even more so, it enabled the partners in the programme to mould that task into a task that was doable. In other words, both the programme itself, including most of its elements, tools or materials, as well as the job to be done and the goals to be reached were made to fit one another. Getting the experiments to work did, however, divert attention from the issue that was identified earlier on, namely that 'one cannot research health, for health is everything ${ }^{\text {'78 }}$. Given 
the restrictions genomic methodologies impose upon the scope of measurement, the notion of 'health is everything' cannot be considered in alignment with the configuration and content of the Gut Health or NuGO programmes:

One can measure [health] just as bad with nutrigenomic technologies or transcriptomics or whatever omics, as one previously could with any other method. Interview Scientist N002, 20051211.

Alongside the scientists, industry representatives also identify the incompatibility of the notion of 'health as everything' and the practical limitations of doing genomic science: 'Gut health is a nice word, but without a scientific content" ${ }^{\text {" }}$. Exactly that 'scientific content' is what the programme partners intend to provide, possibly stimulated by new EU regulations that are being developed, in which companies have to prove health claims connected to their products (Commission of the European Communities, 2003; Katan, 2004; European Parliament and Council, 2006a, b). To this end, they are restricted to the types of knowledge that can be produced through (nutri)genomic methodologies.

Industry representatives I001 and I003 argue for a health based upon 'molecular markers with a clinical relevance' ${ }^{80}$ and health effects that are based upon 'genes that are to be up or down regulated' ${ }^{81}$. Their proposition for health is exclusively molecular, suggesting that health in genomic practice is shifting away from a 'health is everything' and towards a 'health is molecules'. Scientist M002 explains how the great unknown that health still is, may grow within reach when made molecular:

What we study is the function of a gut cell. Actually hoping to learn a lot of fundamental processes by which nutrients [manage to] regulate genes in these gut cells. Perhaps [we do this because] we hope to conclude from it what a healthy situation is, based upon a profile of gene expression, as well as a [what a] not so healthy gut [is]. Interview Scientist M002, 20051018.

However, such a shift is restricted towards the sites that are part of nutrigenomic practice. Outside of laboratories, even to the scientists themselves, a different health ${ }^{82}$ remains to exist:

To me, health has not changed. The babies I am researching, there is nothing wrong with them. I am confident nothing is wrong with their poo and their proteins. [...] I think that regular health, the way they look, the way they feel is far more important than some protein is. Observation Scientist W006, 20040607. 
In order to introduce health into genomic practice, it had been redefined towards the molecular. Despite this redefinition, the relationship between health and nutrition remained close. The Gut Health programme had selected three compounds to act as exemplars for nutrition based upon the existing expertise of the partners. Amino acids, fatty acids and gut bacteria are not nutrition, but nutrients - building blocks of nutrition. They are molecules and above all homogeneous as contrasted to the heterogeneous mixture that is a pizza, an apple or even a cup of tea and especially any life-long diet. Furthermore, as a result of the modular setup, connections between the different nutrients were loosened. Whereas they usually coexist in a single diet, they are not present in the same experiments, not even in the same laboratories: a second step away from a mixture and towards a single molecule. Alongside health, nutrition has shifted towards a molecular state, being able to influence health via interaction on a cellular level:

To a cell, a molecule is a certain signal $[\ldots]$ it can measure them. $[\ldots]$ A cell, and that is a recent thing ... food does something to cells. Lots of processes depend upon entering metabolites. It can adapt to that skillfully. That is ... sort of a revolution in nutrition research, us knowing that food is not just ballast or energy. No, they are in fact very powerful signals. Interview Scientist W001 20050214.

Nutrition was actively reduced to the molecular level, focusing on the molecules in foodstuffs and restricting the effects to the molecular level. Furthermore, it was given the ability to signal, influence, and to tell the cell what it needs to know: a molecular herald of its own coming:

Today I will take you to a microscopically small world full of signals, sensors and signatures concerning food and human health. [...] Nutrients as molecules that carry certain information with them and are of great importance to the accurate regulation of the metabolism [...].

Nutrients are molecules that contain certain information and cells are able to recognise this information and subsequently react adequately through [...] adjusting their metabolism (Müller, 2002).

From a nutrigenomics perspective, nutrients are dietary signals that are detected by the cellular sensor systems that influence gene and protein expression and, subsequently, metabolite production. So, patterns of gene expression, protein expression and metabolite production in response to particular nutrients or nutritional regimes can be viewed as 'dietary signatures' (Müller and Kersten, 2003).

In nutrigenomics health and food have been linked via the genomics technology and through its restrictions, exerting a pressure to shift towards 
the molecular on both of them. Following Galilei's adagium 'Measure what is measureable and make measureable what is not so', both health and nutrition have been rearticulated into interlinked quantitative entities and have become part of nutrigenomic practice through the ability of genomic technologies to quantify molecules on a large scale.

The quest for doability has detached certain ties and forged new ones; it has made some problems more doable and other less so. In the labs of NuGO and Gut Health, a lot of work has been invested in making health and nutrition into molecularised entities in order for them to be aligned with the materialities as they exist in both programmes and the field of nutrigenomics in general. In chapter 6, we will see whether the molecularisation in the lab implies a broader, social process of molecularisation as is argued by those who critique such trends under the heading of biopolitics. 


\title{
CHAPTER FOUR
}

\section{WALKING THE LINE BETWEEN LAB AND COMPUTATION IN NUTRITION SCIENCE ${ }^{83}$}

\author{
We are not students of some subject matter, but students \\ of problems. And problems may cut right across the \\ borders of any subject matter or discipline. \\ Karl Popper (1963, p. 88) \\ 'Welcome to the world of point-and-click biology'. \\ Former motto of INCYTE Pharmaceutical Company
}

I

nterdisciplinarity is one of the buzz-words that has been around for nearly sixty years (Riegler, 2005) and it continues to be as popular as before. However, it is argued that what actually is popular is promoting interdisciplinarity in its many forms, whereas practising interdisciplinarity is notably less popular and much harder (Weingart, 2000; Gannon, 2005). The debate on interdisciplinarity is conducted in many vocabularies, of which the notion of social world, as it was used both in chapter 3, is but one. Namely, social worlds have been conceptualised as 'activities carried out in common with respect to a particular subject or area of concern [...]. Thus the traditional disciplines and sub-disciplines may be considered worlds or sub-worlds' (Gerson, 1983). When adopting such a conceptualisation, disciplines such as biology and computational sciences are two distinct social worlds. To Clarke, social worlds are 'groups with shared commitments to certain activities, sharing resources of many kinds to achieve their goals' (1991). When adopting the conceptualisation Clarke puts forward, 
biology and computational sciences would form a single social world. The main issue at stake is one of cooperation. If social worlds in some way correspond to disciplines, as Gerson argues, their cooperation would indeed correspond to interdisciplinarity. However, such cooperation is not a given, nor, presumably, easy, since disciplines themselves, as well as the cooperation between disciplines, are not uncontested.

This chapter addresses issues regarding disciplinarity in nutrigenomic research practice. It does not wish to answer 'once and for all' whether genomics consists of one or multiple social worlds, but instead analyses how it is possible that nutrigenomic professionals are capable of cooperating despite obvious (and often, large) differences. Insights in interdisciplinary cooperation can help to understand what type of knowledge nutrigenomic practice produces and how this affects notions of health, nutrition and the individual. Along the way, we will be able to reflect upon the organisation of nutrigenomic practice, in terms of cooperation or collision.

\subsection{DISCIPLINES AND INTERDISCIPLINARITY}

Disciplines are fascinating entities. They are very old and were used as early as in the Middle Age universities, as structures to categorise knowledge and teaching (Aram, 2004). They are the result of specialisation in scientific practices, with respect to the scientific questions pursued and the hypotheses addressed, they are 'the eyes through which modern society sees [...] the world' (Weingart and Stehr, 2000, p. xi). It is important to realise that disciplines must be understood, not solely in terms of 'thought' or a fragmentation or specialisation of scientific problems. No, disciplines are as material as they are cognitive. Machineries, technologies, protocols and institutions as well as buildings are included in (and excluded) from disciplines and disciplinary cultures alongside ways of reasoning (e.g. Schoenberger, 2001). There is, however, a price to be paid for specialisation, or fragmentation into specific parts namely that 'the parts can no longer be put together easily' (Karlqvist, 1999). It is argued that as science moves closer to applications, whether material of political, problems arise that cannot be confined to 'narrow' disciplines, or, as Thompson Klein phrases it: 'researchers tend to work on problems, not in disciplines' (Thompson Klein, 2000, p. 13). Consequently, interdisciplinarity' is highly sought after, yet 'the step from an appealing idea to an operational method is large indeed' (Karlqvist, 1999). Hansson (1999) concurs: 'interdisciplinarity, no matter how desirable, is very hard to achieve'.

Nutrigenomic research practice, as all genomic research practices, takes pride in its multi- or interdisciplinary approach. Still, upon entering nutrigenomic 
research practice, it may appear somewhat homogeneous. Laboratories look alike, offices look alike and people often speak alike. Nonetheless, even a short immersion in contemporary genomic practice reveals remarkable differences. For example, take a look at figure 4.1. It shows a number of places where Gut Health scientists work. The two laboratories look alike, as do the two desktops, even though nothing appears to be exactly the same. Materials differ and setups differ. Considering that all four pictures correspond to work places in the same programme, the differences between the desk tops and the lab benches are most striking, they represent two types of work sites. To distinguish between these two work sites, I will call them - following actor classifications - 'wet', referring to the laboratory work bench or laboratory work, and 'dry', referring to desktop or in silico work. The classifications 'wet' and 'dry' are used to refer both to the places where tasks are carried out (the 'wet lab'), as well as to the tasks themselves ('wet work'). Nutrigenomic practice, as a process of knowledge production, relies on both these types of work and on both these sites of work, to address a problem that is confined to neither of them, the umbrella problem of gut health and function.

Despite this interdependence in nutrigenomics, 'wet' and 'dry' practices do not always mix very well. This can sometimes be considered rather literally. When I attended my first Gut Health programme meeting, in a meeting room separated by a central corridor, 'dry' and 'wet' scientists did not sit together, separated by this corridor. Furthermore, in the interviews I conducted, a 'we' versus 'them' was actively constructed and maintained by both groups. Members of both NuGO and Gut Health acknowledged the existence of multiple disciplinary boundaries within both the 'wet' and the 'dry' sections of the programmes, but assigned a special status to this particular division

For this reason, this chapter will focus upon this particular boundary, nonetheless acknowledging the existence of many more. It analyses whether and how cooperation has been achieved in nutrigenomic research practice, considering the differences between 'wet' and 'dry' research.

\subsection{FROM PARADIGMS TO STYLES OF SCIENCE}

How should the differences between 'wet' and 'dry' be conceptualised? The fragmentation of science is not new to us. Kuhn (1970 [1962]) has coined the notion of paradigm, as a framework of thought and reasoning. It is modelled upon an exemplar, for instance, an experiment, which helps a scientific community define which problems they address and what counts as scientific in terms of problems and method. Practitioners, according to Kuhn, do not always recognise these paradigms, and are often unable to 'think outside of the box'. Scientists 

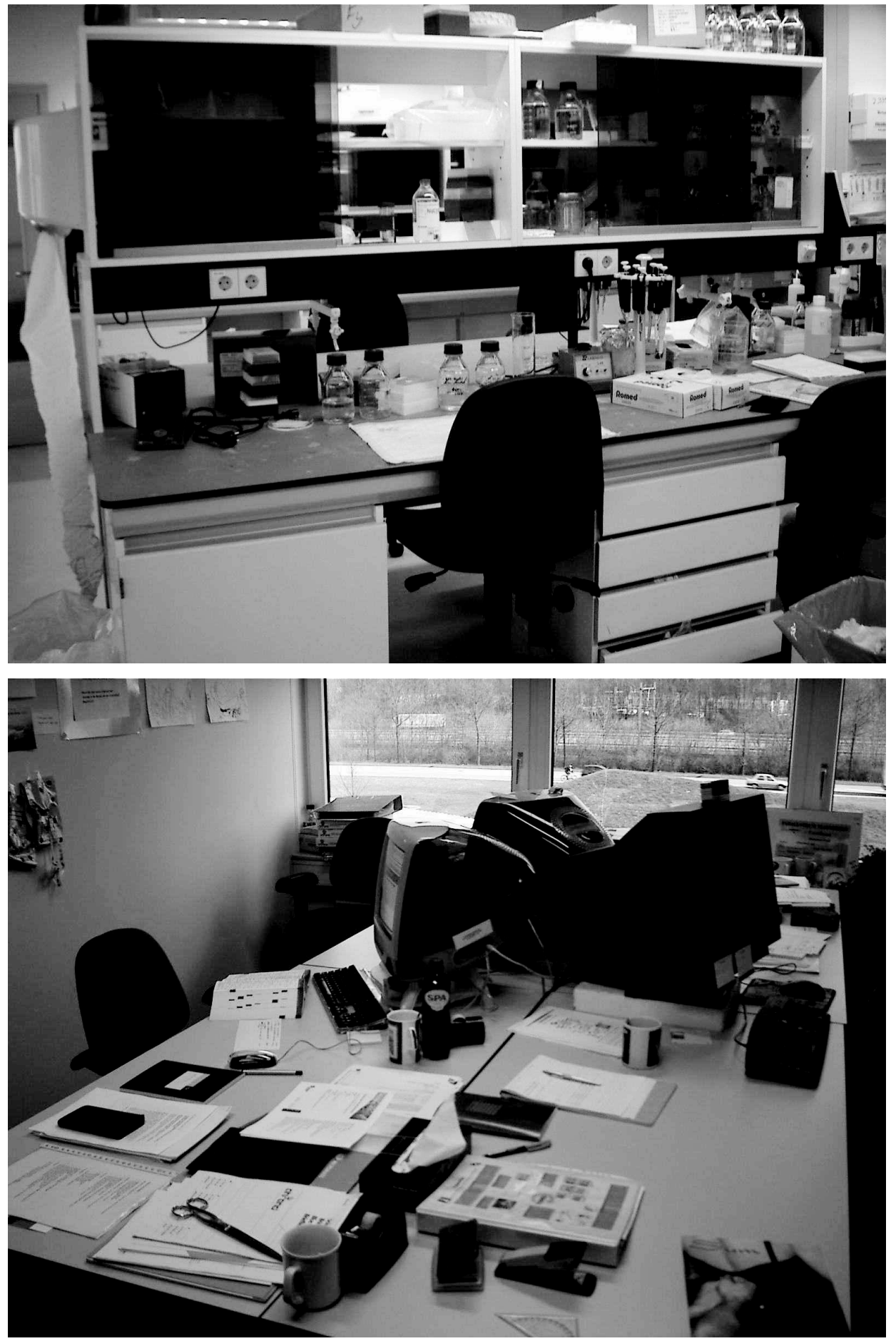

Figure 4.1. Work places of Gut Health scientists. The bottom two pictures are 

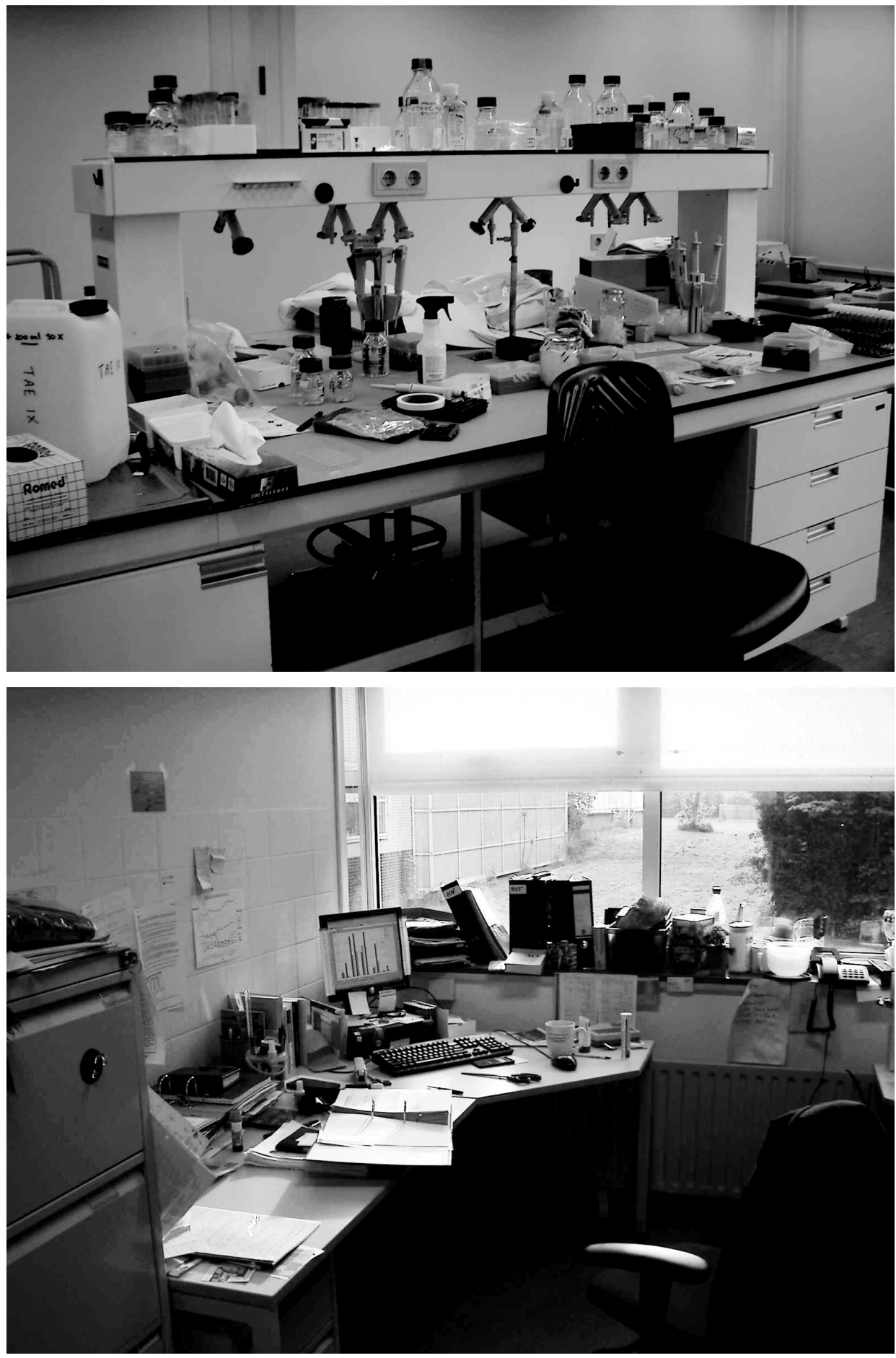

laboratory workbenches, whereas the top two are desktop work sites ${ }^{84}$. 
operating under a different paradigm perceive the world differently, resulting in a situation which he calls incommensurability. This means that scientists inside different paradigms use different languages to refer to 'the same' entities, but also that, experienced from inside different paradigms, the entities actually are different.

The work of Kuhn has been greatly inspired ${ }^{85}$ by that of Ludwig Fleck (Kuhn, 1970 [1962]; Schnelle, 1981). Fleck (1980 [1935]) introduced the notion of thought collectives (Denkkollektive) to describe organised fragmentations of scientific practice, which carry knowledge that supersede the abilities the individual (Harbers, 1986, p. 74). Perspectives of those, who are a member of one or more of such collectives, resemble one another: thought styles (Denkstile). Combined, they constitute the knowledge production process. Inside such collectives, traffic of thought (Denkverkehr) acts to stabilise the thought style of a collective, for instance through sharing an extensive terminology. Fleck argues that such thought styles are collective phenomena, the products of socialisation into (relatively) closed communities (or collectives) and as a result of this. Thought styles are invisible to their members. Furthermore, because of their ubiquity in scientific collectives, they become part of everything that such a collective generates: artefacts, knowledge, concepts and facts. Fleck argued that change can happen when traffic of thought exists between collectives, invoking change inside both collectives. In Kuhn's work, paradigms also are not stable, although transitions and change occur in more spectacular ways, in the shape of scientific revolutions.

Fleck argues that the genesis of a thought style gradually enforces a social and cognitive way of doing and way of seeing. Observations and practices are gradually stylised into a thought style and a thought collective is formed out of the connections between scientists and the relative size and stability of the community. However, such styles and collectives are not homogeneous and consist of a core (or esoteric circle) and a periphery (or exoteric circles). In such a periphery, further away from the core, penetration of a thought style is less ubiquitous. Furthermore, individuals can be or become part of multiple peripheries and one or no core at all. Cores and peripheries depend upon one another as the former is mainly rooted in expert knowledge and knowledge production, whereas the latter depends more on layman knowledge and (uncritical) application of that knowledge, again, in a continuum (see Harbers, 1986, p. 72-77).

Despite the conceptual richness of Flecks work, it under represents the materialities that accompany research practices. In both Fleck and Kuhn's work, they are not absent, as they are incorporated in the experimental setups that accompany an exemplary experiment or become part of the identity of a collective. However, more recently more attention has been devoted to the material 
aspects of science. This is the case in Hacking's concept of styles of reasoning. Hacking based his concept of styles of reasoning on the historical analysis of Crombie, who coined 'styles of scientific thinking' (1994c; 1994b; 1994a). He renamed them since "thinking is too much in the head for [his] liking. Reasoning is done in public as well as in private: by thinking, yes, but also by talking and arguing and showing' (Hacking, 1992c, p.3). Hacking stresses that styles distinguish themselves from one another by different objects, evidences, new candidates for truth (and falsehood), laws, modalities and possibilities (Hacking, 2002). This list can be a simple aid to those seeking to distinguish between two or more styles in a research practice. Even more explicitly emphasising activity and materiality, Fujimura and Chou coin styles of scientific practice, whilst referring to Hacking: 'Styles of practice are historically located and collectively produced work processes, methods and rules for constructing data and theories and verifying theories' (Fujimura and Chou, 1994). This is nonetheless a mere matter of emphasis, especially since Hacking lists new (tangible) objects amongst the products of a scientific style, hence incorporating the material alongside the cognitive and the normative, clearly stating that 'it includes a lot of doing' (Hacking, 1992b, p. 138).

The 'wet' versus 'dry' dichotomy can be perceived as a boundary distinguishing two styles of scientific reasoning (Hacking, 1992c) or styles of scientific practice (Fujimura and Chou, 1994). Hacking has analysed and described a number of these styles of which two are of interest to this chapter. These are the laboratory style or reasoning (Hacking, 1992a), which correspond by and large to 'wet' research practices, and the statistical style of reasoning (Hacking, 1992b) ) $^{86}$ corresponding, in this case, to 'dry' research practice.

Styles and disciplines share some characteristics, but they are not the same. Where disciplines are mainly object-centred, styles have, alongside elements of this division of science, also elements of a method-centred division. For instance, a 'wet' style encompasses a lot of elements from disciplines such as biochemistry, molecular genetics, microbiology, cell biology. Nonetheless, these disciplines also encompass modelling efforts, which would, in a style-based division of scientific practice, belong to a 'dry' style of science. Thus, disciplinary boundaries, as well as style boundaries result in a division of scientific practice, but these divisions do not completely overlap. While this distinction is relevant, I will use the notion of 'interdisciplinarity' to prevent an overly complex vocabulary. This conceptualisation respects the complexity of interdisciplinary cooperation while simultaneously accounting for, and thus allowing, the description to be centred upon a specific boundary.

Central to each style of reasoning are its 'truth sentences'. A style of reasoning generates new sentences and new types of sentences that refer to 
aspects of the world, cognitive, normative or material, that had not been noticed or did not exist before. Such sentences would not make any sense at all, outside of 'their own' style of reasoning, since they draw upon a particular conceptualisation of the issues involved (Hacking, 1992c; Radder, 1997; Radick, 2000; Hacking, 2002). As a result, a 'wet' truth, a 'wet' significance or even a 'wet' relevance need not correspond to its 'dry' counterpart and nor do the routes of getting to them. Nutrigenomic practice is divided exactly by these differences, namely in silico tools versus laboratory equipment, statistical versus physiological relevance and significance or envisioning a biomarker as cholesterol-measurements or as dimensional reductions of over 800 gene expressions. Such differences, which become larger, as a boundary becomes wider (i.e. the epistemological proximity diminishes), make it harder to talk to one another and even harder to understand one another. Different and possibly conflicting truth sentences further complicate fruitful cooperation.

A research practice may consist of elements derived from multiple (in this case, two) styles of research (Radick, 2000). Although the style boundary may be a hurdle to this cooperation, it does not exclude $i^{87}$, which can account for the observation that cooperation in nutrigenomics does indeed exist. Still, from an analytical point of view, the introduction of a division into styles accounts for a number of particularities that can be observed in cooperative efforts in nutrigenomic practice. This does, however, leave the matter of how cooperation, across this intricate epistemological geography, sliced in two by the aforementioned style boundary, can be and has been achieved. When disciplines or styles are understood in the terms presented by Hacking, Fleck or Kuhn, cooperation between them becomes highly problematic. For despite their flexibility, they include and exclude certain lines of thought as well as certain materialities. How then, does nutrigenomic research practice deal with the inclusion of both 'wet' and 'dry' styles?

\subsection{BITTERSWEET COOPERATION BETWEEN 'WET' AND 'DRY'}

The computer, cybernetics and the information discourse have been demonstrated to have fathered current terminology, understanding and contemplation about genetics (Kay, 1999; Fox Keller, 2000; Kay, 2000; Fujimura, 2005; García-Sancho, 2006, 2007). Unsurprisingly, contemporary genetic and genomic practices show a mixture of computational and laboratory work. As a result of such 'shared' 
roots in information discourse, one might expect bioinformatics and biology, or 'dry' and 'wet' nutrigenomics to result in a nice fit, two supplementary practices, cooperating in the production of knowledge.

Nutrigenomic practice, however, presents a different view. Cooperation exists, yes, even on a very large scale. However, the nice fit appears to be a forced fit, reached under conditions of high-pressured necessity and interdependence. To provide but a few examples, the vastness of the datasets generated by nutrigenomics is so great that manual analysis is no longer an option to the transcriptomicist; the micro-array experiments yield tens of thousands of data point per experiments, and a micro-array never comes alone. Secondly, for the proteomicist, the computer is needed to compare gels and identify protein spots on that gel (Sivakumar, 2002). If she identifies spots that are different in the two (sets of) gels, she needs to perform a mass spectrometry analysis on the protein, to identify it. This process produces a mass spectrometry spectrum that makes no sense whatsoever to the human eye. An online database is then needed to identify the protein. The bioinformatician may be an expert in handling and managing large amounts of data, but she is unable to generate it. Contemporary high-throughput biology is lost without computational aid, unable to 'get the most out of it', without the help of bioinformatics. Therefore, many scientists stress the need for teamwork:

Measuring stuff, that we can do. The transcriptome for instance, one can hire services for that and then one gets data. But if you want to get a lot out of that data, then it is important to cooperate with different experts [...], bioinformatics [...]. Yes, I think so, one produces such a gigantic amount of data, that it would even be irresponsible to solely look at it oneself and only pick out the things that fit and throw away the rest, or let it disappear in a drawer. No, genomics is teamwork: teamwork in an interdisciplinary team. Interview Scientist W001, 20050214.

However, actually performing teamwork turns out to be a lot more difficult than propagating teamwork. Scientist W008 recalls her first experience with bioinformatics, when she sent out her first bits of data for analysis. She is struck by the way bioinformaticians view her data:

Initially, in the very beginning - when we were still working with Agilent, I got some data back from [lab H]. They struck out all high gene expressions, because they did not fit in a linear gradient for the dye. To us, those are the most important ones and they just strike them out. Not that they ask us, or even tell us. I just got the data back and then I saw it. I thought 'hey, how is that possible?'. I checked it, and then I asked them. Then they told me what was going on. When I saw that, and when I heard [the explanation] I 
thought I was going to quit. I was that angry. I simply just do not understand it [...]. I know quite a bit about statistics. I want to understand and I tried, but it simply doesn't work. Observation Scientist W008, 20040416.

It must be noted, however, that scientist W008 identifies this same particular moment as the all-time low, as far as cooperation between her and the bio-informaticians in the Gut Health programme is concerned. As a result, the only way is up. However, besides criteria for importance in terms of gene expression, cooperation is further hindered by physical location and difficulties in communication:

It is a bit troublesome that [the bioinformatician] isn't here, but we phone a lot. [If] I have new data, I call her and I send them to her and then we can look through them together. Via email, or I go [to lab G]. If she has time, it works all right. Interview Scientist W008, 20050531.

Please write this down. I really find it hard to talk to [bioinformatician W003]. Partly, that is because of the language, of course ${ }^{88}$, but they ${ }^{89}$ say things very differently sometimes. That makes it very hard to talk to one another, and it takes a lot of time. Observation Scientist W008, 20040407.

Communication is identified as one of the main problems. Although in a jesting tone, industry representative I005 makes a similar point, when he rhetorically asks: 'You ask a bioinformatician for clarity?'90, a question that is answered by laughter. Both W008 and I005 identify problems with respect to communication. In an interview with biostatistician X002, this issue pops up as well. He argues that biologists and bioinformaticians 'have something else in mind' when discussing an issue, such as 'biological variability' 91 . However, difficulties in communication are but one hurdle. A further discrepancy between 'wet' and 'dry' research practices can be observed, namely that 'wet' findings and interpretations need not correspond to their 'dry' counterparts. For instance, bioinformatician M004 discusses two methods for clustering genes and argues that:

Non-supervised clustering [provides us] with mathematically correct clusters, that contain biological nonsense. Supervised clustering is done on paper by biologists. It is biologically correct, but mathematical nonsense. Observation Scientist M004, 20041116.

Clustering is a method that groups certain genes based upon certain parameters. Whether those parameters are based upon mathematics or physiology, scientist M004 argues, matters a great deal. Scientist M002 agrees wholeheartedly: 'No, statistically relevant does not need to correspond to biologically relevant at all!'92 
Thus, with respect to communication, location as well as criteria for relevance and significance - and through them, ultimately: truth - differences add up into a major epistemological and practical boundary between 'wet' and 'dry' styles of scientific reasoning.

Following this description of the 'style boundary' and its role in nutrigenomic practice, it is even more remarkable that cooperation actually does occur. At the chaperone committee meeting of November 12, 2003, scientist Z003 presented preliminary data to his colleagues and the committee members. To the data he presents, he adds the qualification: 'These data have not yet been checked by bioinformaticians and thus are but indications, speculations, ${ }^{93}$. Thus, data collected by 'wet' scientists apparently need to pass through the hands of 'dry' scientists before acquiring the status of biological information. 'Wet' and 'dry' practices rely upon one another not solely because of the size of the datasets, but also 'to extract the biology from the data'.

This process of understanding nutrigenomic experiments requires both styles. Scientist W002, for instance, argues that 'one measures signals, and subsequently says "this is the biological consequence". That is what bioinformatics shows us ${ }^{\prime 94}$. Or, as scientist M002 phrases it: 'I always say [to understand things], for that we have bioinformatics, to make heads or tails out of this [...]. We really do not understand how things work ${ }^{95}$. Scientist M001 and bioinformatician M004 agree. They see an ever-growing role for bioinformatics in nutrigenomics:

[O]ne ends up with a blob of data with which one cannot do a lot, with which one cannot do anything at all, it is just one huge grey blob. Look at it as tens of thousands of pages of grey mass. [Bioinformaticians] produce five or ten pages of colours from that for us. Only bioinformaticians can do that. Interview Scientist W001, 20050316.

Actually, what omics researchers presently do, is doing micro arrays, to view large amounts of genes expressed at the RNA level. What happens afterwards is that they do not know what [the results mean]. The task for bioinformatics is to put forward this understanding. Interview Scientist M004, 20051025.

This way, an enormous responsibility is put on the shoulders of the bioinformaticians and simultaneously great trust is placed in them. Scientist M001 continues: 'However, I cannot check whether they extracted the wrong colours' ${ }^{96}$. However, the trust 'wet' scientists place in 'dry' nutrigenomics is by no means completely voluntary: 
It absolutely is a matter of trust, for I do not think that non-informaticians or non-bioinformaticians - to put it bluntly - know jack shit about it, how all those analyses and how those statistical tools are performed and used. Interview Scientist W001, 20050316.

Furthermore, some of the scientists do not simply trust their 'dry' colleagues, and check on their work. Their trust had to be earned:

If one looks at what happens in terms of bioinformatics, what [Scientist M005] does, that is done properly. I've sat with her once and they really are experts in that area. We trust them. Interview Scientist M007, 20050621.

A mutual interdependence pushes 'dry' and 'wet' scientific practice in nutrigenomics towards one another. Yet, the existence of significant epistemological and practical differences between these two practices makes cooperation in practice very difficult. Scientists cooperate on a large scale, but not always by choice. Furthermore, as this cooperation has been built mainly on necessity, for profound expertise in the 'alien domain' is rare. Over time, after it had been earned, a certain degree of trust might arise alongside necessity. Nonetheless, mutual dependency is not necessarily a recipe for successful cooperation. If necessity does not suffice in overcoming the boundary between 'wet' and 'dry', the cooperation that does take place (often quite successfully) needs to be explained otherwise.

\subsection{THE POWER OF MAPS ${ }^{97}$}

Conceptualising, reinforcing as well as overcoming boundaries in practices and in between practices and disciplines or social worlds, has been discussed in STS literature intensively. Well known examples include the notions of boundary work (Gieryn, 1999), boundary objects (Star and Griesemer, 1989; Fujimura, 1992), standardised packages (Fujimura, 1987, 1992, 1996), trading zones (Galison, 1999), or combinations of them ${ }^{98}$, as well as their institutionalisations (see e.g. Guston, 2001). The boundaries discussed in this literature encompass disciplinary boundaries inside science, as well as boundaries between science and policy, for instance. Here, the boundary between 'wet' and 'dry' is at stake.

This boundary exists on multiple levels, a number of which has been shown in the previous section. However, alongside epistemological differences, there are institutional and material differences as well, that need to be overcome. Institutional, since bio-informatics and bio-statistics groups are placed in their own departmental structures, separated from the laboratory sciences, and material, 
since the tools and materials used within both styles of reasoning differ greatly from one another. Overcoming the boundary between 'wet' and 'dry' involves all of these.

In nutrigenomic practice, one object, or perhaps better defined as a loose set of objects, exhibits potential with respect to overcoming this boundary. It actively brings together 'wet' and 'dry' scientists. This is the gene pathway $m a p^{99}$, an example of which is shown in figure 4.2. It is a set of boxes and arrows in which the boxes represent genes and the arrows represent their interaction. Connected to the image shown, lies a database with gene expression values which can be 'mapped' upon the image. The gene expressions subsequently appear in the image as colours of the boxes, as well as values, shown next to the boxes. It enabled understanding data and exchanging this understanding. Scientist A002 explains what the gene pathway map can do:

[I]t is much easier to look at things that resemble things that look like textbook-somethings, things one is used to. So it is indeed easier to talk about a pathway when it is drawn, even if it is just a little list of genes positioned into space, then to compare gene lists. It is also useful for just exchanging conclusions, for exchanging information. I guess that, for instance [W008] and I will meet in three weeks or so, to compare our [results]. Interview Scientist A002, 20051122.

To 'wet' scientist A002, these images resemble drawings from biology textbooks and have the ability to contain results and even conclusions. However, to 'dry' scientist E001 a pathway map is but a picture, not necessarily a vehicle for understanding, and thus the images represent something else:

A [pathway map] shows reactions in a cell. But you do not know what actually happens. If one adds [gene] expression data, one can see that something happens within certain biological processes. However, you do not understand what the image is or means. It does not give direct biological information. That is what we want, to provide biological understanding [...]. Glucose is turned into ethanol, but if glucose becomes scarce, the ethanol is turned into gluco-6-phosphate again. That is the biological interpretation that is given afterwards. But if I look at the image I do not understand it [...]. You can only interpret this if you are knowledgeable. Interview Scientist E001, 20050308.

E001 argues that these pathway maps can hold data, but they most certainly do not simply or automatically generate understanding with respect to biological processes. To 'dry' scientists, such a pathway image is merely an image, incapable of holding or containing knowledge: 'There is no logic in GenMAPP. If an expert 


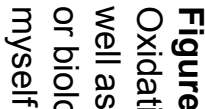

등. 들 흑

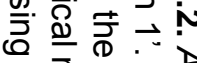

고은 근

$3 \stackrel{\mathbb{Q}}{\mathrm{Q}} \overline{\mathrm{O}} \mathrm{O}$

D․ के $\times$

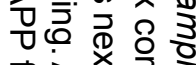

$\Rightarrow \stackrel{\longrightarrow}{\Rightarrow}$

(1)

은 은 윽

응 응 응

¿ क

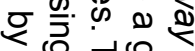

ผ

बำ

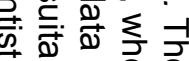

乙응ㅇㅇ

응랄을 일 $\infty \stackrel{0}{\varrho}$

걱으요

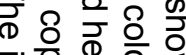

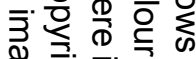

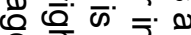

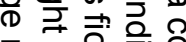

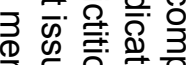

言. 这 $\frac{\vec{D}}{\mathbb{D}}$

क \宁

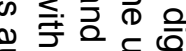

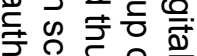

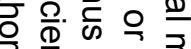

손 응 응

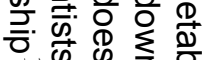

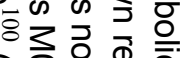

入ิ으ㅇㅠㅛ

(1) 요응

음 윽 要

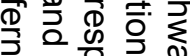

(1)

응을 흥

-

승 으웡 을 긱

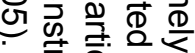

产

응

这密害

守希市

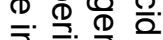

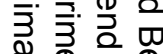

迥

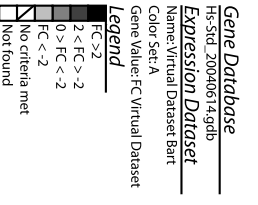

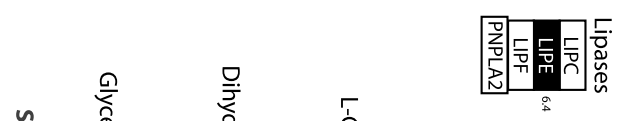
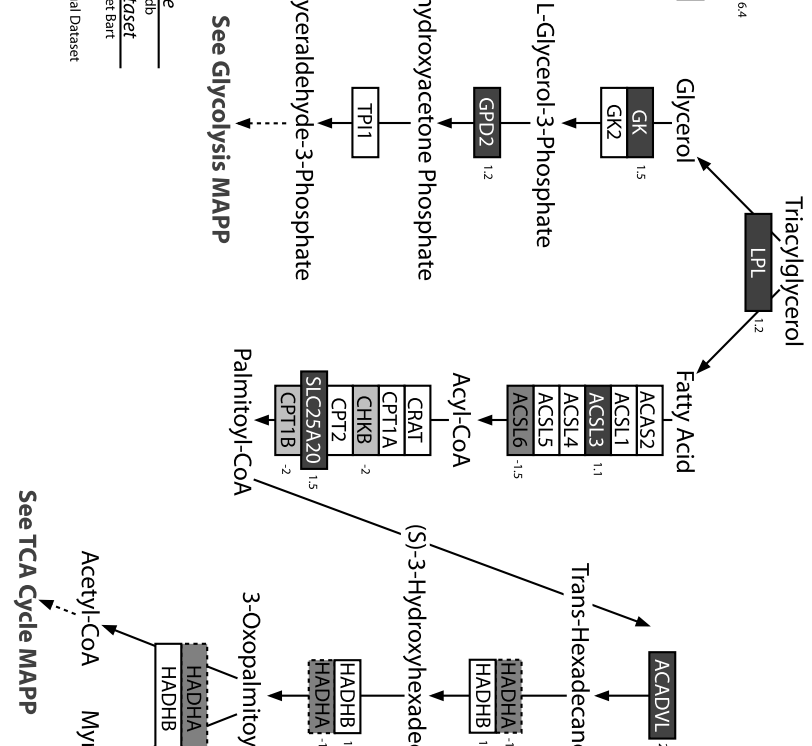

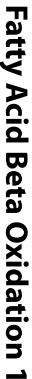
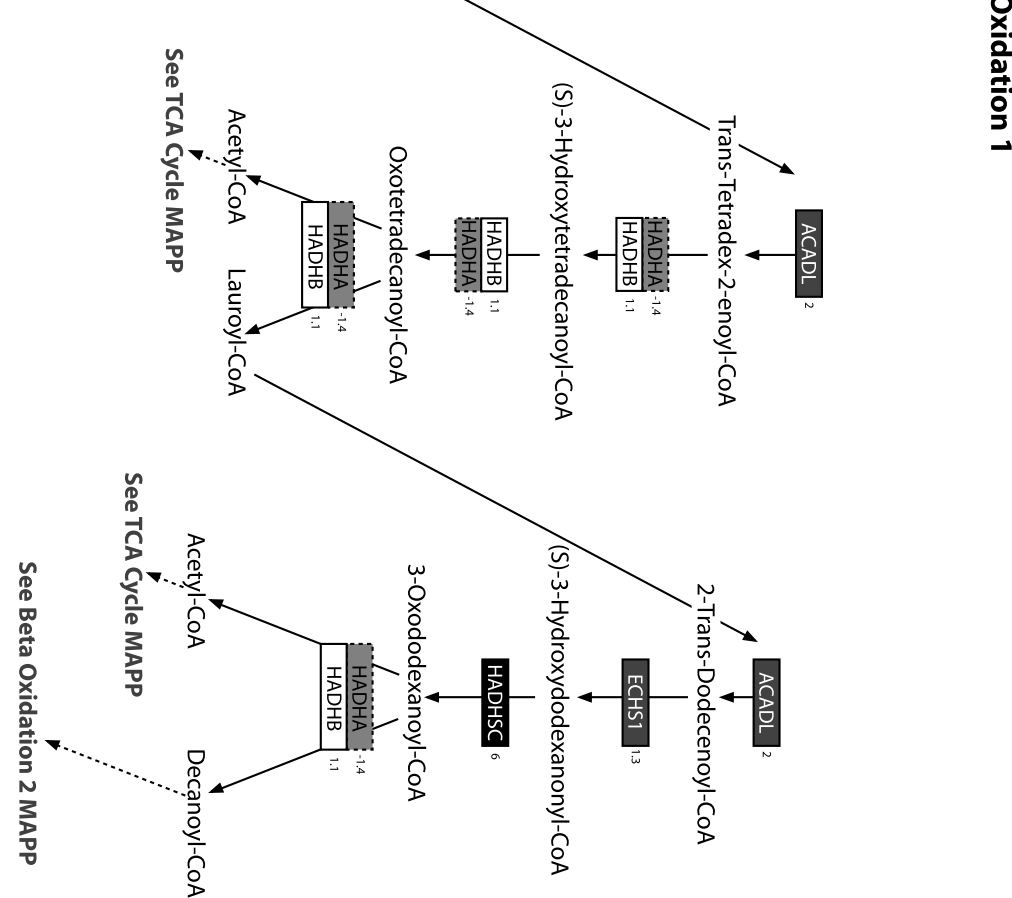
tells us what an arrow means. We have no way to store it ${ }^{\prime 101}$. Despite these weak points, scientist E001 is very much in favour of using these maps to facilitate cooperation:

I am convinced that [a 'wet' scientist] views the image [of the pathway map] very differently. He tries to understand the biology. I think about that too, but [I think] about what is missing as well. On which chromosome do the genes lie - actually [these genes] have to be enzymes, not gene names as well as which isoforms are involved - that sort of thing. I cannot convince them. Biologists are sceptical towards this, they are not used to looking at things this way. Close cooperation is the only way to advance here. Interview Scientist E001, 20050308.

The way in which cooperation around the gene pathway maps is shaped is by dividing tasks and responsibilities. Both the biology and the mathematics, upon which all such maps are based, need to be 'gotten right'. The 'dry' scientists are in the business of constructing such maps, but they lack the expertise that would enable them to pass judgement upon their content. Where 'wet' needs to request assistance in data analysis from 'dry', 'dry' in turn needs to invite biological and physiological expertise from 'wet' to construct robust gene maps: 'We can build a gut health pathway, but you have to give us the genes' ${ }^{102}$.

When both groups get together to build maps, small and big problems arise because of different criteria used to define an improvement, or a 'good' pathway map. Scientist M004 explains that

If a gene is in a pathway twice, you will see it in [the computer program] twice. For physiological relevance, that is a good thing, for statistics that's terrible. The maps are based on physiological relevance, which is nice for a biologist but a disaster for a bioinformatician. Observation Scientist M004, 20040511 .

The process of mapping is 'to choose among competing interests; that is, to embody those interests in the map' (Wood, 1992, p. 57). Such differences can be reasons for discussing the trustworthiness and value for interpretation accredited to the pathway maps. Nevertheless, these maps continue to serve as key objects in the cooperation between 'wet' and 'dry'. As a result, gene pathway maps serve as a site for input of existing biological knowledge and experimental data, as well as a site for performing statistics, starting points for the development of new bioinformatical tools and very importantly, information exchange between biologists and bioinformaticians. 
We arrive with chips ${ }^{103}$ and ask GenMAPP pictures [...]. The added value is that before, one has a large grey page without a beginning and an end and because of the selection they [the bioinformaticians] can make, based upon statistical grounds, one actually starts to see a beginning and an end. Interview Scientist M001, 20050214.

The gene pathway map is the site where biology is 'extracted' from the data, where understanding is constructed, since it is there that existing knowledge and new data can be put together, while at the same time statistical considerations can be taken into account. It is an object that incorporates elements from both a statistical style of reasoning, as well as a laboratory style of reasoning, even though it is conceptualised significantly differently by 'dry' and 'wet' nutrigenomic scientists. The gene map is not passive and stable, no, it works ${ }^{104}$. It can work because it acts as a boundary object, facilitating both information exchange and cooperation across this style boundary, acting as a bridge across an epistemological divide. Boundary objects are a tool to get the job done (Holmes, 1992). In this case, the job is twofold, first facilitating the transition from data to knowledge and second, facilitating cooperation between 'dry' and 'wet' scientists. Furthermore, the pathway maps are not only seen as a tool in constructing biological understanding from data. Creating new pathway maps and improving the existing pathway maps is clearly identified as one of the goals of Gut Health, as well as NuGO. After all, 'What great king, what emperor, what great republic has failed to signal its coming of age by the mapping of its domains?' (Wood, 1992). Mapping is a practice of boundary work (Gieryn, 1999), a way for nutrigenomic practice to claim part of the surface of the Boehringer map (Roche Applied Science, 1992) and as a result, it is never complete.

Nonetheless, performing a micro-array experiment and analysing a microarray experiment remain two very distinct things. Even though they may be united into a single pathway analysis, performing the experiment is 'wet' work, performing the analysis is considered 'dry' work. The Gut Health programme proposal is quite clear about who should perform which tasks. For instance, bioinformatician M005 explains: 'Strictly speaking, [Scientist W008] is not allowed to analyse her own data. That is the way the programme was written' ${ }^{\prime 05}$. However, in practice, such rules do not apply that strictly, and laboratory scientists do analyse their own data. Scientist M005 expresses sympathy for this 'digression': 'If it were my data, I would do so as well' ${ }^{\prime}$. In fact, even though the previous sections of this chapter spoke of 'wet' and 'dry' scientists, this does not mean that 'wet' scientists cannot perform 'dry' work ${ }^{107}$. For instance, referring to picture 4.1, the right two photographs correspond to two working sites occupied by a single scientist, as do the two left photographs. Both scientists have both work sites readily available to perform both types of tasks. 
Because the maps are digital, it is easy to distribute them. The boundary crossing ability of the gene pathway map is not the result of some metaphysical trait, but of the concrete possibility to distribute and share them. One of the major computer programmes used to manage and create the maps, is freely downloadable from the internet. So are the data files that comprise the image of the map ${ }^{108}$. This way, the pathway map as a tool is freely available to all. Furthermore, even though 'wet' scientists do not consider themselves experts, user-friendly analysis programs enable them to do some of the analyses themselves. The map itself, although a digital entity, starts to materially exist on both sides of the boundary, as more and more 'wet' scientists install the program on their computer and freely exchange maps by email. The boundary between 'wet' and 'dry' has not only been crossed with the help of pathway maps, it has become more permeable as objects, ideas, information and people move easily between 'wet' and 'dry' practices, resulting in what we may call a 'moist' zone (Penders et al., 2007b).

This process of actively crossing the boundary between 'wet' and 'dry' is, however, not always to everybody's liking. Scientist M004 states that 'GenMAPP is easy to use and that is nice, but it is a disadvantage as well, because everybody is doing it themselves and they are not doing it right ${ }^{109}$. However, since the pathway map is conceptualised differently by 'dry' and 'wet' scientists, one has to consider that 'rightness' is constructed along with the tools, goals and especially the users themselves (Clarke and Fujimura, 1992). Thus, we can expect each set of sites of nutrigenomic practice, which exist within a style of scientific research, to exhibit their own standards for 'right use' or 'rightness' of these tools. This, however, demonstrates that despite the crossing and deconstruction of the boundary between 'wet' and 'dry', differences between these two styles continue to exist.

\subsection{BRIDGING AND REDRAWING THE BOUNDARY}

The story could have ended here, with the identification of a boundary object and the description of how it makes cooperation doable. However, there is more going on which is of interest, besides style-boundary crossing. Alongside the cooperation between 'wet' and 'dry', both styles of reasoning continue to exist themselves as well. Next to a trend towards cooperation, a trend exists to 'get it done' within a single style of reasoning. Instead of just handing over databases to 'dry' scientists, 'wet' scientists start new experiments to validate this data within their style of reasoning. The journals in which they want to publish the results, exist inside a single style of reasoning. They - and this will not surprise you - demand a logic, a reasoning confined to their style: 
If one wants to publish properly, one has to confirm micro-array data via the use of RT-PCR. One has to confirm it, or at least a big part of it, otherwise the better journals will not accept it. Observation Scientist W008, 20050415 .

A similar scenario can be found in the 'dry' style of reasoning, where two tasks are prominent. On the one hand, 'dry' scientists act as consultants in data analysis. On the other hand, they develop new algorithms and bioinformatical tools for data analysis. However, there is little credit to be gained from merely assisting 'wet' scientists, as scientist M004 explains: 'Our interest mainly lies in the development of new tools and approaches which we will need in the future, while simultaneously learning to improve operation of what is around. Nothing is routine at the moment' 110 .

Scientists want to be convinced that what they do, actually gets them to the truth. Not just to get it published, but to account for what they conclude. Scientist W008 for instance, argues that 'the answers do not lie in pathway analysis but in experimentation' ${ }^{111}$. However, actually validating all genes within their own style of reasoning is subject to practical, material limitations. Realtime PCR is, namely, a process that costs a lot of time and money, since it has to be performed one gene at a time, whereas a micro-array analysis can span the whole genome in a single measurement. Despite this, 'wet' and 'dry' practices continue to work on their own, trying to, at least partially, overcome problems inside their style of reasoning as well. This, in turn, results in more experiments being performed, more measurements recorded, more algorithms constructed, and more statistics applied. Phrased differently, 'wet' becomes wetter, while 'dry' becomes dryer. Ultimately - to make it doable - interdisciplinary nutrigenomic research practice has resulted into two coexisting extremes: both cooperation and further specialisation.

The question of independence brings forward a question of power-balance. Fox Keller (2005) argues that in the collaborative effort between 'dry' (in her words: computational) and 'wet' (biological) professionals, 'for now, at least in most places, the biologists seem to be in the driver's seat' (Fox Keller, 2005, p. $6)^{112}$. However, my analysis has so far shown that no specific style, discipline, sub-discipline or social group is in the driver's seat - if there is such a thing as a driver's seat in science. No, what is true and not true, what can and will be done and what the meaning of existing data and performed experiments is, is something that is the result of a negotiation process. In the negotiations that constitute such multi-site multi-disciplinary practices, that grant 'biological 
meaning' to experimental outcomes and analyses, some groups may have the upper hand at some sites of nutrigenomic practice - but in the practice considered as a whole this cannot be said to be so:

This is one of my worries [...]. A typical problem for a bioinformatics group is the threat statistics groups have always had. If one does it right, one ends up with two publications, a biological one, and one on the [bioinformatical] approach taken. Both will have a high impact. If one continues cooperation the same way, this will lead to a new publication in biology, but no new one about the [bioinformatics] approach. It still is new, so one ends up in the author list somewhere. The next time it's the acknowledgements. But it still is the same amount of work. This will not work. Interview Scientist M004, 20051015.

As scientist M004 argues above, the symmetrical relationship, which can be observed with respect to cooperation and knowledge production processes in research practice, can not be recognised in for example publication politics. They produce fewer papers in lower impact journals and are often restricted to $x^{\text {th }}$ authorship positions. It seems that 'dry' research practices do not have the tools, or the network, to generate a science-political product that does justice to their role in scientific practice. The 'dry' science political network does not seem to span into the editorial boards of journals, or to the policy level, distributing funds for research. Given the youthful character of the field, this situation may very well improve in the future.

To understand how cooperation and specialisation have come to coexist, it is fruitful to briefly revisit both Fleck and Hacking. The boundary drawn between 'wet' and 'dry' has become more permeable. This boundary is not a boundary that directly borders on the epistemic cores (or esoteric circles) of what constitute 'dry' and 'wet' styles of science. As the boundary between 'wet' and 'dry' evaporates, scientists are taken up in the periphery (or exoteric circles) of the other style of reasoning. As interdisciplinary cooperation advances, peripheries of 'wet' and 'dry' are starting to overlap, but the cores that constitute 'dryness' and 'wetness' remain (relatively) unaffected. As more and more 'wet' scientists are socialised into 'dry' methodologies and vice versa, connections between them multiply. Furthermore, large numbers of scientists are actively involved in performing genomics and nutrigenomics. These are both elements that constitute a knowledge production process, according to Fleck, and they are both beginning to emerge in nutrigenomic practice. A possible consequence is the 'birth' of a new core from the overlapping peripheries: a 'moist' knowledge production practice, 
accompanied by its very own thought style, or style of reasoning, thought collective and stabilising thought traffic. This is a process that requires time, but above all else, a lot of work.

Hacking has presented a shortlist of characters that define styles of science. These included objects, tools, and new candidates for truth (and falsehood) and the truth sentences. Looking into what has been coined 'moist', we can recognise specific biomarkers, which are exclusively 'moist', databases and pathway analysis maps as new, specifically 'moist' tools and many a sentence and claim that is confined to 'moist' research practices. The 'moist' knowledge production practice can indeed be identified as a style of science. What has yet to be decided upon, is whether it will stabilise and be taken up successfully. Furthermore, since styles have the ability to coexist temporally and geographically (Radick, 2000), the coexistence of both cooperation and specialisation is not the paradox it may appear to be. From an epistemological point of view, the 'birth' of a 'moist' style and collective, need not exclude the continuation and proliferation of 'wet' and 'dry' styles.

The debate on the desirability and the possibility of interdisciplinarity is still as active as it was many decades ago. Positions reach from one extreme, which argues in favour of a scientific enterprise that transcends all disciplines, both epistemologically and institutionally to the other extreme which argues that interdisciplinarity does not exist except, perhaps, as an opportunistic rhetoric 'to get to the money' and the resulting organisational shifts ${ }^{113}$. Given the coexistence of interdisciplinary cooperation, or inter-style cooperation, with continuing specialisation within styles, there is no need to seek a position in between these extremes, nor is it fruitful to maintain such a polarisation. In between these extremes an endless number of intermediary positions exist. One particular position is of relevance to the argument presented here. In line with my argument, Peter Weingart, also diagnoses the non-existence of the paradox between cooperation and specialisation: 'interdisciplinarity and specialisation are parallel' (Weingart, 2000, p. 40) ${ }^{114}$. He argues that knowledge production within such interdisciplinary structures, 'always refers back to the existing modes of knowledge production and its criteria of validation' (p. 39, my emphasis). Indeed, where 'wet' and 'dry' practices are established ways of doing science, a 'moist' style of reasoning is a 'young' style. Whether stabilisation will occur cannot be predicted, despite the presence of all the ingredients. This difference does show itself in the institutional affiliations that come with these styles. Whereas 'dry' and 'wet' practices are firmly embedded in research infrastructures, 'moist' practices exist in virtual consortia or temporary cooperations such as the NuGO consortium and the Gut Health research programme. Nonetheless, to deny the epistemological base of interdisciplinarity, to argue that 'moist' inevitably always 
refers back to 'wet' and 'dry' styles of knowledge production, grants too little credit to the work scientists have invested in nutrigenomic practice and the forms of cooperation that accompany it.

Nonetheless, the creation of a 'moist' style of science out of 'wet' and 'dry' styles has created new boundaries in genomic research practices (Weingart, 1997b). These new boundaries, however, span significantly smaller epistemological differences - for now.

\subsection{MULTIPLE HEALTHS FROM MULTIPLE STYLES}

Interdisciplinarity and the coexistence of 'dry', 'wet' and 'moist' research practices and sites carry relevance not only for the shape or socio-material organisation of nutrigenomic practice, but also for its content. The styles that are part of a scientific practice are also part of the knowledge that results from this practice. Notions of health and nutrition, as key notions within nutrigenomics, co-evolve with this research practice. These coexisting trends of cooperation and further specialisation can be recognised in, and continue to affect, the ways in which health and nutrition are conceptualised. Alongside broad definitions of health, narrow ones are created - whether digital, statistical or molecular. The same goes for nutrition, which is narrowly conceptualised in terms of molecules or signals.

Throughout this chapter, both 'wet' healths and 'dry' healths, or criteria that are part of them, have been displayed. For instance, 'wet' scientists referring to biomarkers of health may include blood pressure, weight, speed and characteristics of metabolism and the gene expressions of a number of physiologically relevant genes. To 'dry' scientists, a dimensional reduction of thousands of expression profiles, may result in the 3D modelling of a healthy zone, which can be 'statistically occupied'.

'Moist' research practices are the sites where such negotiations can be found and observed. Such sites are meetings, conferences and workshops where researchers from all disciplines gather, for instance, the NuGO workshop 'Defining markers of health', which took place on May 25 and 26 of 2005 in Krakow, Poland ${ }^{115}$. How do scientists negotiate health across the boundaries between styles of scientific reasoning? Discussions on the healthy phenotype tempt scientists into philosophical arguments from time to time ${ }^{116}$, but overall arguments remain practical. Health refers to the 'normal state' of the body, whereas a 'diseased state' is considered abnormal. One of the speakers presented a statistical analysis, a method called 'principal component analysis' or PCA (Ringnér, 2008), through the use of which a normal metabolic profile of control rat urine was mapped into 
three-dimensional space, into a 'cloud' (Ebbels et al., 2003) that occupies both 'normal space' and 'the space of normality'. Every rat urine sample that does not occupy this space is therefore not normal, deviant from the healthy state.

This particular style for constructing normality can be considered 'dry'. The measurements themselves are conducted in a laboratory, but the act of deciding what is, and what is not normal is a mathematical endeavour (of a huge complexity). Non-mathematicians have a hard time determining the value of such approaches, and often disagree with biostatisticians or bioinformaticians on what PCA can or cannot do (as well as within the group of 'dry' nutrigenomicists), especially because all the thousands of variables that are put into the algorithm all correspond to a biological entity, whereas the three variables that are produced by the algorithm are mathematical constructs, not relating to any specific measurement: 'PCAs are great, but they do not correspond to any biological criteria or function. It is very hard to relate them to health" ${ }^{117}$.

To 'wet' scientists, health means something completely different. In the context of nutrigenomic research, they speak of genes, gene expressions, proteins and chemicals and their interaction. They speak of the physiology and function of all these parts, that is proper function. If everything works the way it should, you're healthy, which means that health is the absence of any problems, that normality equals the absence of disease. Every element in it has a biological meaning:

It depends upon concentrations of antioxidants, oxidants, their interaction, their localisation. It depends on molecules, systems, pathways, reponses [...]. We are looking for a golden standard, the philosopher's stone. I hope we get lucky, but remember that it was never found. Observation Regina Brigelius-Frohé, 20050523.

The list of things to consider is so long, that the normal, the healthy, is impossible to encompass in a positive definition. The absence of disease, a negative formulation, suits best. However, a biological interpretation of health is not exclusively a matter of negative definitions. According to the experts gathered in Krakow, a healthy status is a status in which the body is able to actively maintain the balance that is health, i.e. maintain homeostasis. Nutrition can actively modify the health status, make it worse, make it better and even make it better through making it worse ${ }^{118}$, as well as strengthening the balance, i.e. create a buffer ${ }^{119}$. In the end, over the course of two days, the experts gathered in Krakow came up with an informal definition of health ${ }^{120}$. Health, they argued, was (1) the absence of disease, (2) the absence of increased risk and (3) the ability to respond to health threats. When reviewing this three-legged definition from the perspective of nutrigenomic practice as a scientific practice built out of two styles 
of scientific research, the first part (besides having a large common-sense part), as well as the third part of the definition relate to the biology, the physiology, of health. In contrast, the second part uses the vocabulary of risk, which is intricately bound to statistical practices (Hacking, 1990).

It is evident, that at such a 'moist' site, in the process of defining a 'moist' health, the negotiations between 'dry' and 'wet' nutrigenomics have resulted in both of them being able to contribute to the construction of health in nutrigenomic practice. Such contributions are conceptual, methodological as well as material. Nutrigenomic research practice defines health in its own mirror image: 'wet' and 'dry' elements in an intricate yet incomplete entanglement. Health, as it exists in complete nutrigenomic practice, equally is such a mixture. Depending on whether a site of nutrigenomic practice is closely linked to the core of either 'dry' or 'wet' practices, or part of the 'moist style in the making' certain elements contained in that style, alongside their ways of doing and seeing will be dominant at certain sites.

The coexistence of multiple healths and nutritions in nutrigenomic research practice is the result of a practice of co-evolution between nutrigenomic research practice and the notions of health and nutrition. Multiple healths and nutritions, in turn, also both facilitate as well as simultaneously constrain scientific advancement in nutrigenomic research practice. Again and again, health and nutrition have to be renegotiated, prior to starting a new series of experiments, new research programmes and the rights or wrong of, say, health claims. As a result, at specific sites of nutrigenomic practice a 'specific health' is favoured over others alongside its 'nutrition' counterpart. If we, for instance, revisit the last section of the previous chapter, we observe that a molecularised health, a notion of health which has been actively rearticulated into a notion which is built out of (as of yet still unknown) quantitative molecular values, we are able to identify a 'wet' conceptualisation of health. The 'dry' counterparts, visible in this chapter, are not so much 'molecularised', as they are statistics- or informationbased, and encompass notions such as risks. Both the molecule- and risk-based conceptualisations of health will be revisited in chapter 6 , discussing the political effects of such re-articulations.

Interdisciplinary practice has resulted in a complex epistemological topography of 'wetness', 'dryness' and 'moistness' accompanied by the concepts, objects and methods that constitute each three. To briefly revisit the first few sentences of this chapter, which refer back to the notion of social worlds, as used in the previous chapter: it is not a matter of choice between one or two social worlds, but both. We can conclude that nutrigenomics is a complex (of) social 
world(s), in which a number of social, cultural, epistemological and material elements, intertwine into a complex topography. Ultimately, cooperation and specialisation fruitfully coexist in contemporary nutrigenomic practice. 


\section{CHAPTER FIVE}

\section{PERSONALISED NUTRITION: IS IT DOABLE? ${ }^{121}$}

Fat runs in the family, but so do frying pans

Steve Jones (2006).

$\mathrm{I}$

$\mathrm{n}$ their wide-spread social analysis of (economic) science, Levitt and Dubner write that ' $[\mathrm{t}]$ he gulf between the information we publicly proclaim and the information we know to be true, is often vast' $(2005$, p. 77$)$. What people say and what they do need not correspond fully. It may occur when only partial information is available, resulting in partial comprehension of the situation at hand or when practical or material requirements fail to be met and does not have be a deliberate attempt, or an unknowing attempt to manipulate the relation between the two. Promises and expectations, however, do have consequences for practice. This chapter looks into a particular challenge in nutrigenomics practice, namely the notion of personalised nutrition, for it appears that promises and expectations on the one hand, and scientific practice on the other, do not neatly fit. If this is so, why is it so? And if not, what is happening that may make it appear to be so?

In this chapter, both expectations and promises that accompany the notion of personalized nutrition will be reviewed, as well the literature on ethical, legal and social issues (ELSI) related to personalisation. The issues surrounding personalised nutrition, as discussed here, act as an exemplar for the relation between expectations and practices, and I intend to argue that the differences matter and that there is no intentional deception at play. In this chapter, I will not review whether these claims are justified, since no independent view from 
which this can be achieved is available, but instead I will review how promises, expectations and practices interact. Both expectations and laboratory practice are important to creating doable research problems, but in different ways. Understanding these differences will hopefully aid us in dealing with apparently conflicting notions in scientific practice.

After having demonstrated how scientific practices deal with complexities in terms of size, diversity and modularity in chapter 3 and in terms of disciplinary boundaries and styles in chapter 4 , this chapter will focus on dealing with complexity in terms of incoherent and seemingly even incommensurable voices in nutrigenomic practices. This chapter will first address the promises and expectations on personalised nutrition, followed by the (laboratory) practice directed at the construction of a doable version of the problem, and the ethical, legal and social issues. In this chapter, the theoretical framework of doable research problems, as explained and modified in chapter 3 , will be expanded upon. I will add to it, by introducing a 'move towards a position that sees expectations rooted in particular times and places' (Brown, 2003b, p. 18) and show how promises and expectations act in the processes surrounding doable problem construction.

\subsection{THE PROMISES OF PERSONALISED NUTRITION}

In 1937, Mary Schwartz Rose wrote that 'all men [of] all races of men have the same nutrition needs' (1937, p. 259). In contemporary nutrition science, this position is being contested. One of the most clear and presumably more radical expectations is voiced by German and Watzke stating that 'it is not a question as to whether personalised foods will become a part of the food marketplace, but simply when they will become the rule rather than the exception' (German and Watzke, 2004). Alongside German and Watzke, many nutrigenomic professionals are quite confident, that personalised nutrition, personalised diets or personalised foods will become reality. Opinions differ on whether this will be in the very nearby future, or whether it will take decades. Both Watzke and German are employed by Nestlé Switzerland ${ }^{122}$ and have displayed in their work that they do not only include scientific arguments, but also arguments relevant to the commercial realm in which food industry operates. Terms, such as 'added value' are thus of dual meaning, including both health value, as well as financial value. The main argument of their paper is directed at discriminating between individuals and under headings such as 'basis of differences among individuals that relate diet and health' and 'distinguishing individual differences', they carefully construct personalisation in terms of individuals. 
Research directed at understanding individuality is not new (Williams, 1956; Young and Scrimshaw, 1979), but has recently been discussed more prominently (e.g. Kaput et al., 1994; Perusse and Bouchard, 2000; Talmud and Waterworth, 2000; Watkins et al., 2001; German et al., 2003a, b; Kaput, 2004; Klaus and Keijer, 2004; Kornman et al., 2004; Arai, 2005). The same idea of nutrition specific to individual needs is not only named 'personalised' or 'individualised' but also 'tailored', which are used simultaneously by Hoolihan (2003), and by Hoolihan and Harlander (2004):

This growing body of nutrition science research, combined with the rapidly accelerating genomics movement has shown undeniably that everyone is a unique individual with specific needs. We have thus entered the stage of individualised, or tailored, nutrition [...]. We are developing the capacity to make dietary recommendations aimed at optimising health and reducing risks of the diseases to which one is genetically predisposed, based upon knowledge of one's nutritional status, lifestyle, disease risk and genetic make-up. [...] We are at a point in the history of nutritional sciences where we have expanded our knowledge of nutrition and are ready to utilise what we know for the better health and well-being of not just the population as a whole but every single individual (my emphasis), (Hoolihan and Harlander, 2004).

However, such expectations do not exclusively exist in written form, they are expressed in interviews and at conferences as well. In an interview, the Gut Health programme leader assured me that:

I still am convinced that we will, in the end reach a personalised dietary advice, based upon nutrigenomics. Because I remain to be convinced that the effects of nutrition are immensely different between people and that can only be, based upon differences in genes and constitutions [...]. It might be very complicated, but in the end one must be able to find the right combinations that can predict why one's cholesterol rises and the other's doesn't. And [...] with the calculation power and the immense acceleration at which several things are being analysed $[\ldots]$ that sort of information becomes available faster [...]. I think that nutrigenomics will, and this obviously is oversimplified, that in your food disc [...] radials ${ }^{123}$ will shift a bit like this and mine will shift a bit like that [arm gestures]. So certain compartments will grow bigger and other smaller, depending on what nutrigenomics will tell you. Interview Scientist M001, 20050316.

In their expectations, these scientists are presenting a certain picture of what 'personalised nutrition' is going to be like. They express the conviction that 'personalised nutrition' will indeed become reality This future nutrition is going 
to be tailored to the unique needs of every individual ${ }^{124}$, based upon 'difference in genes and constitutions' as scientist M001 stated above, or based upon 'nutritional status, lifestyle, disease-risk and genetic-makeup', according to Hoolihan and Harlander. At the centre of these claims lies the shift from a 'one size fits all' approach towards a focus on individual (genetic) differences:

Theprevious 'one-size-fits-all' approach to diet and dietary recommendations of the distant past is limiting and may even be erroneous [...]. This new paradigm and way of viewing foods and their components will ultimately shift broad population-based nutrient recommendations to ones more tailored to the individual. (Hoolihan, 2003).

The popular and popular-scientific press have not ignored such promises and expectations. They have used catchy phrases such as 'Eat right for your genotype' or 'the DNA diet' (or the Dutch 'elke eter de juiste hap' ${ }^{125}$ ) to explain the tailoring of nutrition to individual needs (van Ommen, 2001; Grierson, $2003 a)^{126}$. In such magazine and newspaper articles, regularly mini scenarios are used to illustrate and to monitor this trend away from 'one size fits all' ${ }^{127}$. In these mini scenarios we read about someone pricking their finger, sending the blood to a lab and receiving an email indicating the recommended diet for the next month, which 'doesn't look too bad: lots of salmon, spinach, selenium supplements and bread with olive oil' (Grierson, 2003b).

Expectations are - by their very nature - about the future and have the luxury of being able to abstract from certain practical requirements that actually doing the experiments in a laboratory may introduce. Many of these practical conditions can be reasoned away by assuming technological advancements, like scientist M001 does when he refers to the 'immense acceleration at which several things are being analysed', or are simply ignored. When it comes to studying techno-scientific practices like nutrigenomics, we should look further than programmatic visions and expectations. Douglas (2005) argues that "a fruitful line of inquiry should be centred on the relationship between the rhetoric contained within various expectations and the concrete physical processes that provide an emerging techno-science a path through labs [...]" (Douglas, 2005). So, we should take a look at nutrigenomics as a laboratory practice and as an economic enterprise as well. Programmatic expectations have conceptualised personalisation as being about single individuals, but what does personalisation mean from the perspective of laboratory practice or from the perspective of an industrial or commercial practice?

Let us turn to the laboratories where nutrigenomics is performed, the conferences where nutrigenomics is discussed and the journals where findings are reported: let us turn to the sites where nutrigenomic science is performed 
and personalised nutrition is (becoming) a practice, both academically and commercially. Here, scientists and nutrigenomic professionals cannot avoid practical problems by assuming that they will be solved. They have to solve them themselves.

\subsection{THE DOABILITY OF PERSONALISED NUTRITION}

The practice of nutrigenomics is an interdisciplinary one and the personalised diet is merely one of its goals - the core being investigating nutrient-gene interactions (see e.g. Gillies, 2003; Müller and Kersten, 2003; Labadarios and Meguid, 2004; Kaput et al., 2005b). At one of the conferences I visited, one of the speakers said to the audience: 'Look to your left and to your right. Chances are high that your neighbour is from an entirely different discipline than you are ${ }^{128}$. Even though colleagues tend to sit together - her overall message was true. Yet, out of all of these disciplines, one in particular is very much involved in diet-genotype interaction, the base of personalised nutrition: epidemiology.

Epidemiologists are in the business of correlating a variety of parameters - such as genotypic variation and dietary intake - measured in large cohorts of patients or volunteers. Even though historically a very fruitful line of investigation, there are upper limits to the number of variables that can be handled in practice, as Ben van Ommen argues:

The current way people work, from epidemiology, the manner at which cohorts are screened do not allow us to reveal complicated relations for more than a few genes at a time, or for more than a few genetic differences at a time. Interview Ben van Ommen, 20060125.

In order to ever reach the unique diet for every individual, it is imperative to incorporate gigantic numbers of variables. At a previous occasion Van Ommen gave a quantitative example, illustrating where he thinks practical limits will be encountered:

Imagine a cohort of 10,000 people. If polymorphism $A$ exists in $2 \%$ of all people, and $\mathrm{B}$ in $20 \%$ and $\mathrm{C}$ in $3 \%$ of all people, you will end up with 1 person in your population who has all three. That is not enough. Even if you screen the whole world you will not find enough people and you will not find out, and that with only a few genes. Observation Ben van Ommen, 20050330 . 
The task of 'doing the math' with respect to these correlations, that comes with these large studies, rests upon the shoulders of bioinformaticians. In their work, they too cannot abstract from the practicalities that come which their type of work. Larry Parnell, one of the genomics computational experts, tells us that 'the number of combinations and permutations of genes and environmental factors is so huge that one will never be able to evaluate all such interactions ${ }^{129}$.

Where Van Ommen restricts his thought-experiment to gene-gene interactions and identifies that set of variables to be too large, Parnell includes environmental factors - amongst them, diet - increasing the number of possible combinations even more. Both Van Ommen and Parnell identify obstacles on the path towards unique nutrition for individual genotypes: practical obstacles such as the huge numbers of volunteers needed and the huge number of variables to be considered. They do not contest the notion that all people are different, but what they are telling us is that they think finding out how all of that is relevant in terms of nutritional requirements, is subject to practical limitations.

Van Ommen takes up this point to show that this way of approaching the diet-genotype interaction is not only impractical, but also that there is no reason for unique diets tailored to single genotypes:

If you reason the other way around, there are a number of pathological deviations known from differences in genotype. There are lethal mutations and there are a number of mutations that make people truly obese, pathologically obese. But there are only six of them. If you go to the more subtle deviations .... at a certain moment the relevance of the difference between the trees in the forest disappears. The art is not to wander to deep into the forest but still notice the use of your work. [...] It matters that one is capable of separating sense from nonsense and useful from the useless and find out for which nutritional parameter it is useful to keep looking for differences. Interview Ben van Ommen, 20060115.

Van Ommen argues, that with health in mind as the sole driver for the tailoring of nutrition to individuals, there is no reason to regard everyone individually as unique because the majority of differences on a genotypic level are irrelevant.

Van Ommen identifies both practical and theoretical reasons for personalised nutrition not being directed at the individual, but at groups. The personalised diet is not about tailoring to the individual:

We do not tailor every article of clothing to the individual, we live comfortably with the fact that clothing sizes exist. This is the way in which I see genotyping. In the end we will be able to match a clothing size 42 
to a genotype size 42 . That means that we do not have to go down to the individual level, but we can also stay on the level of clothing size cohorts. Interview Scientist N002, 20051211.

To scientist N002, the personalised diet thus is about groups, about assigning certain diets to certain groups or subpopulations. As Jim Kaput, one of the leading US nutrigenomicists, stated at the "From Nutrigenomics to Personalised Nutrition" conference in 2005: "the better word for personalised nutrition would be group nutrition. Lets be practical about that. [That is] the way to better health ${ }^{130}$. His position both as a senior scientist and the Chief Scientific Officer of the biotech firm Nutraceuticals urges him to consider both scientific and commercial limitations to individualisation ${ }^{131}$.

Scientist N002 compares these groups to clothing size cohorts and because the word 'tailoring' is prominent in the nutrigenomic vocabulary, the clothing metaphor is used regularly. Scientist I007 takes it up as well. He is an R\&D scientist working at a large dairy company in the Netherlands. To him these groups have to be large:

What we actually do with products, is that we make confection products, like in the clothing industry. One has no tailors anymore, just plain confection clothing. That means one uses several sizes, for its own size, a group has to be big enough. We are talking about larger groups here, to which [...] one can sell a large quantity of products. Interview I007, 20051221.

He uses an economic argument to restrict the personalised diet to groups, even large groups. Where scientist N002 explicitly mentions the genotype as the entity to tailor to, I007 tailors to the individual, not exclusively mentioning the genotype. As I mentioned in previous chapters, there is more to nutrigenomics than genes and genotypes. A large part of nutrigenomics is neither about genes nor about gene expression at all:

The fields of clinical chemistry and clinical biochemistry are very well developed. They can tell you precisely what optimal cholesterol values are, without measuring the expression of 300 genes involved in cholesterol expression. So I think one has to be pragmatic here too and that is why I'd like to loose the term genomics, as being linked strictly to genes or gene expressions, let alone the difference in genes. Interview Ben van Ommen, 20050125 .

That is why scientists like Ben van Ommen and Michael Müller, presumably the two main Dutch nutrigenomic 'champions' increasingly refer to their field 
as 'molecular nutrition studies' (Afman and Müller, 2006), 'nutritional systems biology' (van Ommen and Stierum, 2002; van Ommen, 2004) or 'biomics in nutrition research' (Corthésy-Theulaz et al., 2005).

The genotype does not 1 on 1 reflect the phenotype. Earlier, Parnell included environmental factors as relevant modifiers and Bruce German has summarised the relationship of genotype and environment in what he calls 'the equation of life' (German and Watzke, 2004):

$$
\text { Phenotype }=\text { Genotype }+ \text { Environment }+\int_{\text {now }}^{\text {birth }} \text { Genotype } x \text { Environment }
$$

Summarised, it states that genotype is relevant, but at every moment in life the environment one has been exposed to up to that moment is equally important. In this formula, environmental exposure is a direct result of lifestyle.

What does all of this show us? Nutrigenomics in practice is increasingly less and less about genes and more and more about other molecules, and so is personalised nutrition. These other molecules are measured in high-throughput systems and they provide nutrigenomicists with lots of information about both genotype and environment, but in an integrated way. In their quest for the healthy phenotype, understanding the relationship between nutrition and the genotype enables intervention. However, the human genotype is not a site for intervention. At the centre of nutrigenomic enquiries lies thus not the eaters' genome, but the foodstuff. With the human genotype only subject to limited relevant variation, as Van Ommen told us earlier, reaching the healthy phenotype is mainly about environmental exposure and thus all about lifestyle.

A 2005 review paper, co-authored by 88 nutrigenomic professionals ${ }^{132}$, lists several examples of non-nutrient environmental factors or lifestyle related factors that might be of importance: sleep time, altitude, non-prescription drugs, water intake related to other beverages, physical activity, stress, allergens and pollutants, circadian rhythms and seasons changes and energy balance (Kaput et al., 2005a). Furthermore, scientist W001 expresses himself quite clearly when saying that he is convinced 'that when one eats varied and with moderation and exercises a bit, that - with the exception of a few unfortunate people - one does not need any nutrigenomics to stay healthy ${ }^{\prime 33}$.

I suggest rephrasing 'Genes load the gun, environment pulls the trigger' - a statement accredited to many people in genomics - into 'Genes load the gun, but lifestyle pulls the trigger'. What we can learn from watching Crime Scene Investigation is that (nutrigenomic) research may look for the bullets mobilising every piece of technology in their labs, but only to find the triggerman. That may 
very well be the reason why Michael Müller, in his contribution to the NuGO weblog, rephrased the acronym NuGO to mean: Never use Genomics Only (Müller, 2005).

\subsection{INDIVIDUAL AND GROUP NUTRITION: AN INCONSISTENCY?}

In expectations voiced by nutrigenomic professionals, the personalised diet is being conceptualised in terms of genetic individuality. At other sites and from other perspectives people have argued that personalisation is about genetic categories. Does this mean that the expectations with respect to the personalised diet are untrue, just clever deceptions to make the field more attractive to sponsors and lay people? ${ }^{134}$ Or is there a lack of foresight or faith amongst the 'bench workers' with respect to the goal of nutrigenomics? Such moralistic interpretations, that blame either the programmatic leaders or the practical scientists in the field, are not fruitful to understand the dynamics of expectations and practices in modern research.

Rephrased in the vocabulary of doability, which I have introduced an expanded upon in chapter 3 , the relationship between expectations and promises on the one hand and laboratory and commercial practices on the other hand will become clearer.

Complex scientific practices consist of several different sites, where different actors perform different kinds of work, different kinds of relations are developed with the social world and different kinds of constraints are met. Programmatic statements articulating the expectations of a new scientific field for instance, serve a purpose, namely the gathering of social and financial support for developing the field ${ }^{135}$. Hence, conceptualising the notion of personalisation in terms of genetic individuality serves the purpose of relating nutrigenomics to the outside world. By doing so, people abstract from the practical requirements of doing laboratory work.

The concept of doable problems requires the alignment of all elements from social words, laboratories and experiment. The question forced upon us, when observing actors abstracting from laboratory and/or experimental practice, is how it is possible to dismiss complete alignment. In other words, how can nutrigenomic practice continue without 'proper' alignment? In order to answer this question, it is important to consider where these expectations are formulated. Here, 'where' does not refer to a geographic locations, but to a site of nutrigenomics practice.

Scientific workers at the laboratory bench do not utter these expectations. In publications that report experimental finding, we also do not find any of these 
promises and expectations, nor do they pop up in laboratory meetings. When seeking the sources of promises and expectations, one has to travel to plenary lectures conferences and programmatic publications in high-impact journals. Furthermore, they can be found in popular press interviews and in the interviews conducted in the context of this research project.

The latter interviews serve a dual purpose, because I, as the interviewer can (partially) direct from which position the interviewee speaks. Questions can be specifically framed in the context of the laboratory, or seek out expectations. In a single interview, the interviewee can thus be led from sites of nutrigenomic expectations to sites of laboratory practice.

Let us take a scientific conference as an example. At this particular site, no experiments are being conducted. When a scientist reports findings from his experiments in either a poster or an oral presentation, he presents solutions to a problem that he (together with others) has constructed doable before visiting the conference. A programmatic lecture at such a conference very often refers to experiments done in the past, but it does not report them. The work performed by the speaker is not directed at managing experimental setups, but at managing the social setup of the scientific practice he addresses. One may call it rallying, fundraising or creating enthusiasm, or from a Latourian perspective, the gathering of new allies for one's network.

Fujimura has drawn heavily upon the work of Anselm Strauss, in the construction of the framework of doable problems. Strauss coined the notion of articulation work, which, as Fujimura argues, takes place between the three layers of organisation. I have shown the local character of doability in chapter 3, in which I have focused on the site of nutrigenomic practice. Previously, Strauss has discussed articulation work in medical practices in which he discerns three layers of articulation work. He focuses not upon the site of practice, but upon the actor (Strauss et al., 1985). Henceforth, in medical practice he discerns the 'big picture' belonging to the physician in layer one, the tasks of coordination and organising by the head nurse in layer two and the actual jobs, belonging to nurses and technicians in layer three ${ }^{136}$. Each of these actors has his or her own task set, to be performed at complementary sites of practice ${ }^{137}$. It is only together that they can 'manage and shape a trajectory' (Strauss et al., 1985).

By focusing on work exclusively, Strauss can legitimately focus on actors. I, however, do not restrict myself only to tasks and kinds of work, but also to the material and social elements existing in nutrigenomic practice. These are not only actor-dependent but also site-dependent, resulting in site-specific alternative assemblies of social and material entities in nutrigenomics and consequently in alternative conditions for achieving doable problems. Therefore I here choose to centre my argument on sites of nutrigenomic practice instead of actors in 
nutrigenomic practice. Whisked all together, all types of work and all elements can create (local) doability as described in chapter $3^{138}$. However, they are not homogeneously spread around the sites of nutrigenomic practice. When certain tasks or elements are absent or underrepresented from a site of practice, they are also absent or underrepresented in the local alignment pertaining to that site. For instance, 'abstracting from practical requirement of the laboratory', an act not seldom noticed in expectations uttered in, for instance, conference lectures, the laboratory and experiment levels are underrepresented. In figure 5.1 I have depicted a visual representation of what 'abstracting from practical requirement of the laboratory' would look like when conceptualised in terms of alignment.

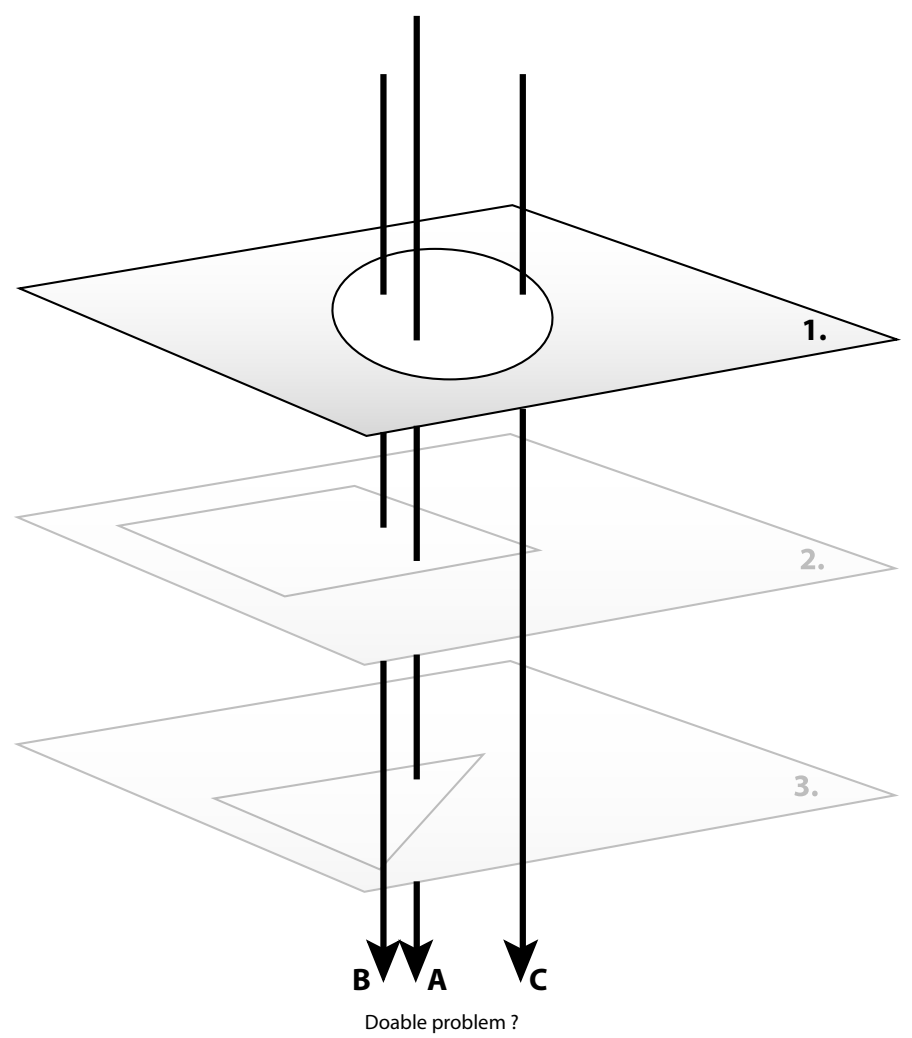

Figure 5.1. Incomplete alignment. When elements or tasks from the laboratory or the experimental world are absent or underrepresented at a site of nutrigenomic practice, they are also absent or underrepresented in the alignment. The possible restrictions or limitations they pose can be ignored and a larger subset of problems can be considered doable (as is represented by arrows $B$ and $C$ ignoring one or two absent tasks or elements, respectively). (1) Social world; (2) Laboratory level \& (3) Experiment level. 
As a vertical mirror image, so to speak, the nutrigenomicist at the laboratory bench may be able to abstract from the requirements the social world poses upon the experiment she is conducting. I must add that these two situations of partial alignment do not exist independent of each other. In a complex scientific practice, as I have demonstrated nutrigenomic science to be, multiple sites of practice together are needed and are mobilised to create a doable set of problems. In such a network of sites, each graced with its own local doability, sites such as depicted in figure 5.1 coexist with sites in which other elements in the practice are only present to a lesser extent. It is only as a whole, that all elements in the practice can be conceptualised in terms of alignment.

When referring to scientific practices not only in terms of local doabilities, but especially in terms of complementary local doabilities, it becomes clear that promises, expectations and laboratory practices complement one another, and continuously interact with each other. Expectations for instance help in structuring the research agenda, by positioning specific topics on that agenda and by enabling the prioritisation of specific research questions (see e.g. van Lente, 1993). In fact, the expectations with respect to the personalised diet have been very important for stimulating research into genotypic differences. However, the very same expectations have also mobilised resistance to this research. This bidirectional process is currently referred to as the 'dynamics of expectations' (Brown, 2003b). Although different meanings of the personalised diet - as an individual diet or group diet - might co-exist at different sites of nutrigenomics for quite some time now, the opportunities and constraints that come to the fore in every day laboratory practice in turn might redefine expectations (van Lente, 2000). So, the genotype-nutrient interaction is subject to expectation-practice interaction as science proceeds.

The two meanings of 'personalisation' - genetic individuality and genetic categorisation - will most likely both continue to exist, as long as there are reasons for them to co-exist. Individualisation as a result of partial alignment, may still serve its rallying purpose, while at the same time scientists in the lab determine which factors are relevant in distinguishing between categories and which are not. The shift of scientific expectations from individualisation towards categorisation should become visible when the need of the rhetorical strategy of individuality starts to decline and the integration of alignment advances. This analysis of 'personalisation' suggests that in time, as a result of this integration, the limitations posed by laboratory, experiment, and commerce will result in personalised nutrition leading away from individuality and towards membership of a genetic category of an undetermined minimum size. 


\subsection{WHY DOABILITY MATTERS TO ELSI}

A relatively new tradition in science policy states that large-scale technological research programmes should be accompanied by studies of the social, political and legal issues which surround the theme of such programmes. It all started out when James Watson announced that the Human Genome Project would devote a significant amount of its funding to so-called ethical, leal and social issues (ELSI) that surround the Human Genome ${ }^{139}$. Following the example of the Human Genome Project, and further strengthened by a desire to prevent any further GM-scares, most of the international large-scale research initiatives have set up ELSI projects to broadly study societal implication of new technologies. The European Framework Programmes and the Netherlands Genomics Initiative have done so as well.

As far as nutrigenomics goes, social scientists, ethicists, philosophers and lawyers have been interested almost from the very beginning. Nutrition science is an interesting subject, where description and prescription lie very close to one another. Furthermore, genomics technologies introduce their own set of interesting problems and issues. In her report on the subject, the Utrecht Ethics Institute explains why it is relevant for ELSI researchers, to look into nutrigenomics in an early phase:

It is not too early to review and discuss the ethical consequences of the development towards tailor-made diets, even though currently no such diets are available. Ethical questions are not questions that are only related to the application of certain knowledge or technology but are often already implicitly present in the research stage [...]. Even though we are not yet confronted with tailor-made dietary advice offered in the medical sphere, it is possible to imagine topics that are likely to become morally relevant when food is tailored to an individual person's genetic makeup (Ethics Institute, 2005).

Many ethical, legal and social issues have been identified related to nutrigenomics. To name but a few: the shift from curing to preventing to enhancement (Korthals, 2002b, p. 195-196), the creation of new risks and uncertainties, issues surrounding the screening and sampling of every individual (Korthals, 2002b, p. 198), the loss of the meal as a moment for sharing and gathering (Korthals, 2002a, p. 317; Swiersta et al., 2002), the relation of identity to nutrition (Meijboom et al., 2003), the abundance and availability of genetic information (Korthals, 2002b, p. 199; Chadwick, 2004; Ahlgren et al., 2005) and 
the conflict between whether it is legitimate to consider health as the main, or even sole, value relevant to food choice (Lemke, 2002; Chadwick, 2004; Görman, 2006, 2007).

Certainly not all, but many of these issues are related to the presumed individualising effects of genomics (Korthals, 2002b, p. 196; Swiersta et al., 2002; Chadwick, 2004). Michiel Korthals notes in his book: 'Individualising effects of genomics are being identified by nutrition scientists and nutrition journalists $[\ldots]$ ' (Korthals, 2002b, p. 196). He continues by telling us that:

This individualised approach means that individuals are to be screened and sampled, that their information needs to be stored and that individualised prescriptions need to be given. Of course this can mean an enhanced control; furthermore it burdens the individual with new responsibilities with respect to their kin, their partners and networks (Korthals, 2002b, p. 198).

In his work, he draws from the expectations expressed by scientists and popular scientific press and he uses similar mini-scenario's to the one I have listed earlier in this chapter (Korthals, 2002b, p197-198; Korthals, 2002a, p. 317) ${ }^{140}$.

I have chosen the example of personalised nutrition exactly because many of the ELSI aspects are connected to a fear, or a worry, that nutrigenomics will somehow hyper-individualise society, or at least adds some scientific momentum to the ongoing trend when '[c] ommon meals threaten to disappear, simply because my DNA profile prescribes a different menu from yours' (Swiersta et al., 2002).

This fear of the individualising effect of genomics and nutrigenomics has an empirical foundation. The material used by the ELSI researchers to draft their first normative agendas with respect to personalised nutrition, is derived from the context of expectations and promise ${ }^{141}$. The first reason for this is because in the beginning the personalised diet existed only in those terms. A second reason is that the laboratory and the experiment are on the one side highly technical, requiring at least a basic interactional expertise ${ }^{142}$ in nutrigenomics, and on the other side, a lot of the experiments are hidden away on academic campuses and in 'dark corners' of the laboratory. Thus, the initial normative ELSI agenda is empirically rooted in sites of nutrigenomic practice, which have a significant under representation of actual laboratory and experimental work and restraints. It is here, that ethnography shows its added value in unlocking sites of nutrigenomic practice that are necessary in completing the picture of nutrigenomic practice. Through ethnography, sites of nutrigenomic practice can be unlocked, in which laboratory and experimental work is present, thus providing a more representative account of nutrigenomic practice. After all, in the ELSI normative agenda, it is personalised nutrition not as a certainty, but as a doable problem which is to be addressed. 
This normative agenda, set up by the ELSI researchers, empirically rooted in the expectations uttered by nutrigenomic professionals, is in need of some revision. Besides uttering programmatic statements, rooting ELSI in (laboratory) nutrigenomic practice means making two significant shifts: firstly, shifting the focus from genes to almost all other molecular entities. These other molecules reflect both genetics and lifestyle, with the emphasis on the latter one. Secondly, there is a shift from individuals to groups. Many of the issues brought forth by ELSI researchers are very relevant still, whereas others might deserve some finetuning with respect to these shifts. What happens to our normative agenda when it is empirically rooted in a more complete geography of nutrigenomic practice, based upon a doable version of the personalised diet?

The loss of the meal as a moment for sharing is indeed under pressure from existing trends towards individualisation of lifestyle - but not as the result of a nutrigenomically prescribed individual diet, but as the result of differences in life and lifestyle which have been recognised for a long time:

If one would issue a [population-wide] advice with respect to healthy nutrition, only very few people would get uncomfortable from that. So, again, it is merely a fine-tuning for segments of the population. I do not think food industry wants to produce ten million different confections, but I do think it is good that everyone of those ten million people thinks - and has the means available to find out - what is healthy for him or her. For a professional athlete, something else is healthy then for a baby... that type of personalisation has existed for a long time. That it gets more firmly rooted in science, fine... that more target nutrition arises, that is merely logical. Interview Ben van Ommen, 20050125.

Genomic information might not always be relevant for healthy nutrition choice and despite talk about the one-thousand-dollar genome (Wolinsky, 2007), experts consider screening the whole population irrelevant:

I actually am convinced that it is not necessary to sequence each an everyone's genome to find out that this person has a nutritional problem. [...] Let's phrase it this way: nutrigenomics is not needed for such applicated questions; I am convinced about that. I have expressed that in Mallorca [Personalised Nutrition Conference, BP], when I said that the solutions to the large nutritional diseases, from adiposity, diabetes type II and cardiovascular disease, do not need nutrigenomics. They need political steering. Interview Scientist N002, 20051112. 
Furthermore, as Ben van Ommen explained earlier, looking into other molecules and variables may be much more enlightening. He used the well-known example of cholesterol, but others exist as well, varying from blood pressure to blood free fatty acid levels. Is all genetic information still the threat it was thought to be?

Nevertheless, the fact remains that issues of personal responsibility remain relevant. When lifestyle becomes the focus of nutrigenomic research, pressure towards healthy living may grow and the question whether health is the only value worth pursuing through food, remains unchanged. The Food Ethics Council conceptualises personalisation as a 'political project' in which both food industry and government are actively involved (Food Ethics Council, 2005, p.5-6). In the part of their report that addresses nutrigenomics, the quoted scientific and ELSI research is, however, also largely based upon expectations (p.24-30) and thus on a partial alignment of elements and tasks in nutrigenomics. This analysis shows that nutrigenomic ELSI research needs to shift its agenda away from the politics of personalisation and look into the politics of classification that the practice of personalised nutrition generates. New questions arise from such a politics with respect to nutrition and society. I will conclude this chapter by suggesting a few of these questions. Nutrigenomic practice is creating group related nutrition. Who is going to be in a group at all? No classification is perfect and every classification has some sort of 'left over' category. What advice do people in that group get? Which groups are getting their own advice and based upon which criteria? And do the categories created by science match the categories created by industry through the products and options it supplies? What if not?

Who will pay for issuing an advice when it is not individual? What are the consequences of being in a certain category? And how do you get into a different one? Is there a reason to try? Is there going to be pressure towards being in a certain category? By health insurance companies, by the government or from one's own drive towards health? Does every category get the same health insurance, or any insurance at all (Aarden, 2006; Horstman, 2008)? How are notions of solidarity shaped based upon health or nutrition categories (Van Hoyweghen and Penders, 2007)? Is there a top category? Who says so? Can it be full? What if I choose unhealthy living? Who gets to know that? Furthermore, in the light of increasing international alliances (Kaput et al., 2005a), will the classifications be global, national or local? What consequences does this have for worldwide public health?

The normative agenda initially drafted by ELSI research identified several relevant issues based upon expectations by nutrigenomics professionals. Many of them remain relevant when based upon practice; however, many also require a shift of focus, from genes to lifestyle and from individuals to groups. Helga Nowotny stated it very eloquently, when she reminded us that 'science is a moving target 
and those that study that target simply have to move along' (Nowotny, 2006) ${ }^{143}$. If, within a scientific practice, research problems and agenda's are rearticulated based upon a quest for doability, normative agenda's drafted by ELSI researchers can only be improved by paying close attention to doability by visiting relevant sites of scientific practice, both in order to better describe where science is moving and for us to be able to move along. 


\title{
CHAPTER SIX
}

\section{THE POLITICS OF LARGE-SCALE NUTRITION SCIENCE}

\begin{abstract}
Scientists need to know what lunch consists of, what defines a lunch [...]. Some of us are exploring the intricacies of lunch, reducing it to our intellectually preferred level of understanding. The physical biochemistry of toasting (why does the bread turn brown rather than some other colour, say aquamarine?); the physiology of water homeostasis in lettuce, and how to keep it from wilting; the molecular biology of casein digestion by bacteria (and what makes cheese taste so good); and innumerable studies on pastrami and its relatives. This is, in short, why science is so hard. We ask so many hard questions, at so many different levels. [Now] look how many people have contributed to our study of lunch, and none of them comes up on a PubMed search for 'lunch' (Mole, 2004).
\end{abstract}

Large-scale science has a halo of expectations, ranging wide and far. It was anticipated that more cooperation and more interdisciplinarity will get to more reliable and robust technologies, facts, insights, knowledge, and products. In nutrigenomics research goals hint at finding out what the best diet for all of us is, in order to make all of us healthy. Even more ambitious is the goal to feed the Third World. Although very often these ambitions are driven by the best of 
intentions and might be considered a bit naïve, the intrinsic normative character of such ambitions stresses the need for an explicit account of a politics of largescale nutrition science.

This final chapter will draw together the arguments presented in this book. In reading this book, the reader has been enabled to accompany me on my journey to learn how contemporary large-scale science in general and large-scale nutrigenomics in particular, works. Although inseparable in practice, analytically a separation has been made into two questions. The first has asked how problems are conceptualised, and solutions are constructed in large-scale science; the second has asked how norms are constructed alongside solving such problems. As a result of this analysis, conclusions will initially be formulated on two levels, referring to each of these research questions.

In the following sections I will first discuss the status of the arguments as they have been developed in this book, integrating the conclusions reached in chapters 3 through 5. I will discuss how these lessons should affect the way in which we perceive and understand the workings of large-scale science and how the insights provided here relate to the current approaches for conceptualising largescale science, as introduced in chapter 1. I will show how the modular structure and infrastructure as elaborated in nutrition science have shaped the doability of research problems directed at understanding (gut) health. Subsequently, I will address the new norms for the relationship between health and nutrition and the concept of individuality, as they have evolved alongside the advancing nutrigenomic research programme. The fundamental point I want to make is that while a quest for understanding health had been initiated, multiple healths have been crafted, as a result of the re-articulation of research problems in order to achieve doability. Combined, these conclusions add to our understanding of large-scale science in general and large-scale nutrition science in particular, with a focus on the co-evolution of knowledge and norms.

\subsection{LEARNING FROM LARGE-SCALE NUTRIGENOMIC RESEARCH}

\subsubsection{A network of doabilities}

In discussing large-scale scientific practices, the approaches named the 'New Production of Knowledge', the 'Triple Helix' and 'Big Science' share a single position as far as cooperation is concerned. Cooperation is necessary, it is possible and it should be promoted. This assumption suggests that cooperation in general, and interdisciplinary cooperation in particular, should lead to increased 
knowledge production, or at least an increase in innovation or patents. In the previous chapters, the ways in which scientists and laboratories cooperate, in order to collectively solve a research problem, have been studied. To understand how such cooperation works, and especially why it is difficult to achieve, as well as why it requires a lot of work, it is necessary to recognise the large amount of boundaries that traverse a large-scale research practice such as nutrigenomics. Problems are often complex, as is demonstrated by Mole's somewhat humoristic example of 'lunch' above. In the previous chapters, certain types of boundaries have been identified and discussed along three 'dimensions of complexity' of large-scale nutrition science. First, as discussed in chapter 3, the boundaries between research sites, whether geographical or not; second, as discussed in chapter 4 , the boundaries between epistemologies employed in nutrigenomic research and third, as discussed in chapter 5 , the boundaries between laboratory practices and expectations. These three dimensions have to be linked in order to analyse large-scale nutrition science as a 'network of doabilities' ${ }^{144}$.

The quest for doable problems has acted as a powerful motivator for the decisions which have shifted the configuration of the Gut Health programme. Similarly, doability has acted as a motivator in the manipulation and re-articulation of health and food, as has been shown in chapter 3. The manipulation of health, nutrition and individuality is not restricted to the experimental situation or to the material world and can include every element that is part of the network managed by the scientists attempting to achieve doability. Gut Health resulted from a merger in which the elements of the different programmes had to be rearticulated several times, until the eventual modular design, shown in figure 3.1, was comprised. The re-articulation and manipulation work has been done since modular problem construction is considered to be more doable. While scientists were addressing the sub-problems they were faced with, in their own module of the programme, this modular configuration changed: the connections between the modules changed and the relation between the modules and the umbrella problem of the Gut Health programme. For instance, well-described tasks for specific laboratories changed when deciding to use a different micro-array platform, and the food industries actively took part in the process of construction the proper problems at the laboratories. Phrased differently, in contemporary scientific practice, none of the landmarks are fixed.

Managing a network of doabilities is not as straightforward as the alignment of tasks on three levels of work organisation, which Fujimura constructed for single-site doability (1987). It encompasses managing a modular configuration of various local doabilities that together comprise a doability network belonging to a large-scale scientific enterprise. The visual representation of doability as alignment, as proposed by Fujimura and as shown in figure 3.2 is thus a display 
of a local problem doability, of which every module has a number to work with. Actions undertaken and decisions made to improve upon local alignment, to achieve or re-achieve the doability of a local sub-problem have unforeseen effects throughout the network. None of the elements necessary to construct and reconstruct problems in the Gut Health programme are spread evenly through it. No single research material, type of tissue sample or technology, nor expertise, third party interest or financial or clinical payoff can be found at all the sites of the programme or in all the modules in the programme in equal or even comparable quantities. This uneven distribution results in a heterogeneous set of sub-problems and local doabilities, actively and continuously constructed and reconstructed under the single banner of gut function (and health).

With scientific work being local and situated, or phrased differently, understood in terms of 'local doabilities', a lot of effort needs to be put into keeping a research programme together, to reach a certain level of agreement (or alignment) across various situations and through time. Fujimura suggests that standardisation reduces the articulation work needed to craft these ties (Fujimura, 1987). Genomic practice, however, although rooted in molecular biology, very much depends on high-tech and experimental technologies: for instance, two micro-array technologies exist alongside one another; three if one includes the home-made array constructed by lab B. As a result, a larger network including tools that are not (yet) standardised, will require more effort to keep together as well as be subject to a lot of internal manipulations because of the processes of problem construction that influence one another.

Three elements in the research situation are mainly responsible for 'keeping things together', as discussed in chapter 3. These three elements share a common feature, namely that they are not restricted to single sites, but exist in the programme as a whole. These three elements are the genomic technology, the chaperone committee and the food industry. The actors in large-scale research take up different roles, and the three elements here have also brought about their effect in different ways. The genomic technology was able to 'keep things together' because it provided a shared problem-and-solution structure and a shared vocabulary. Most importantly, however, micro-arrays and 2D gels were physically present at many sites. The actual glass and plastic parts of a gel casting system, or a micro-array were shared by the programme members, acting as 'organisational glue'. Even though it was not fully standardised, the technology still acted as a tie between the modules. Second and third, the chaperone committee and most notably food industry, were relatively independent of single modules and could thus act on the overarching umbrella problem level. In case of the chaperone committee, one could consider it their task, to 'keep things together'. However, setting up a committee does not $d o$ anything. The committee members, 
the committee itself has to perform a lot of work, keeping things together. They continuously monitor contingencies as they occur, and cope with minor and major setbacks, re-articulate the problem over and over again. Finally, one can argue that it was food industry that kept the programme on track by putting health back on the research agenda multiple times, also re-articulating the problem of 'gut health and function'. Furthermore, in most cases, the industrial research partners kept at equal distance to most of the research sites, not restricting them to local doability construction.

Is it surprising that exactly these three elements are the ones keeping Gut Health in one piece? As far as food industry goes, the idea that it is an important element in getting Gut Health to work, provides a positive counterbalance to views that industry involvement acts as a distraction, or even worse, a bias to scientific practice ${ }^{145}$. Furthermore, the role of the chaperone committee as ad hoc decision maker, as a kind of 'meta-doability-manager', shows that an organisational structure can provide the tools for cooperation. However, it is not the organisational structure itself that does so, but the enormous amount of work the members of the committee have performed. Large-scale research programmes do not run themselves. In Science and Technology Studies, sharing specific technologies or concepts, is a well-documented way of achieving cooperation across many types of boundaries ${ }^{146}$. Therefore, some of this does not come as a surprise. In this respect, the abilities of non-human actors never cease to amaze.

The second dimension of complexity in contemporary scientific practice is of an epistemological kind: different styles of 'doing science' may be present. Ties between sites of scientific practice may be difficult to maintain because of the way various scientists understand the world: their origin with respect to a style of scientific reasoning or scientific practice. Although no hand-to-hand combat has been observed in this research, this does not mean that no fights or struggles exist. Such epistemological struggles are important to recognise, for in the act of managing a network of local doabilities, they result in major variability, especially on the level of the social world. The main epistemological struggle in large scale nutrigenomics, but also in the life sciences in general, is the one happening between 'wet' and 'dry' styles of science. 'Wet' scientists are the bench workers, conducting experiments in the laboratory, whereas 'dry' scientists are the mathematicians, the bioinformaticians or biostatisticians, working behind a computer to analyse numerical data. Despite struggles across epistemological boundaries, ties can nonetheless be formed.

Ties across boundaries can be established via the identification and mobilisation of boundary objects. In chapter 4 , the gene pathway map was presented as such a boundary object, having the ability to cross the boundary between 'wet' and 'dry' styles of practice. Surrounding the gene pathway map, 
a 'moist' style of scientific practice is being forged in contemporary genomic research practice, bridging the gap between 'wet' and 'dry'. It has to be noted, however, that this third moist style of scientific practice does not necessarily need to act as a bridge between the two others. If it continues to stabilise, it will result in its own repertoire of, amongst many other things, materialities, norms, objects and truth sentences. This would facilitate cooperation for genomic or nutrigenomic practices, since they would not have to act inside different styles of practice, needing to constantly traverse across boundaries. These practices would then be located in a single style of reasoning. However, it would further complicate cooperation at different intersections of styles of scientific practice, since this new style of practice will most certainly border upon many others. Again, facilitating cooperation, making interdisciplinarity epistemologically doable at one set of sites, makes it harder (or less doable) at another: redrawing boundaries cannot halt exclusion, it can only alter it.

The third dimension concerns the relation between practice and promise, which has been discussed at length in the literature on the sociology of scientific expectations (see e.g. van Lente, 1993, 2000; Brown, 2003b). Promises and imaginaries are part of research practice, but they exist primarily at specific sites. At such sites, for instance opening lectures of conferences, programmatic publications or project proposals, the division of elements in a research setting across the three levels of doabilty is uneven. The promise of individualised nutrition, for instance, lives on, but solely outside of the lab. Uneven distributions result in the relative under representation of specific levels as compared to others. Subsequently, the importance of some of the levels of scientific organisation in the construction of alignment is under represented as well. An 'incomplete' alignment may result in doable local problems, yes, but they misrepresent the doability of the overall problem. Those who act upon such incomplete representations are often addressing problems that do not exist in that particular shape or constellation. Alongside styles of scientific practice, doabilities of local problems, promises and expectations are situated as well. Expectations act on scientific practice and on the research agenda, both of the scientists themselves and those studying these scientists. Promises and expectations enable and simultaneously restrain. They enable agenda-setting and the construction of research programmes and questions, whether cognitive, normative, or material. Simultaneously, they exclude certain questions and prioritise some technologies and problems over others.

An integration of the three dimensions discussed above, results in a complex network of large-scale scientific practice in the shape of a de-flattened network $^{147}$ in which sites, styles and incomplete alignments exist next to one another. Together they comprise the whole of a complex scientific practice. Some scientists are not so sure whether they are able to manoeuvre through 
this network of intricate complexities of innumerable entangled large and small research problems, epistemologies and expectations. Scientist M002 has spent quite some thought on the complexities of the problems he is faced with in his daily work. He is worried that these complexities will grow too large for science to handle and he even doubts whether in the nearby future any sensible thing, such as promoting or even defining health through the use of genomic technology will ever be possible:

I have this thought from time to time, and colleagues tell me so as well, even though perhaps not as explicitly as I do, that we have been at this for many a year. We have managed to surface the globin gene in science and we have been going at it for 50 years and still do not completely know how it works and what it does. That is one single gene. Now, we have genomics, because we have said that many things, many diseases are so complex and so many genes are involved that to ever understand them we need to know everything about every gene. [We need to] both understand and be able to measure [all of them]. But [...] how will we ever understand all of this if of a single gene, after 50 years, we haven't been able to find out - even with

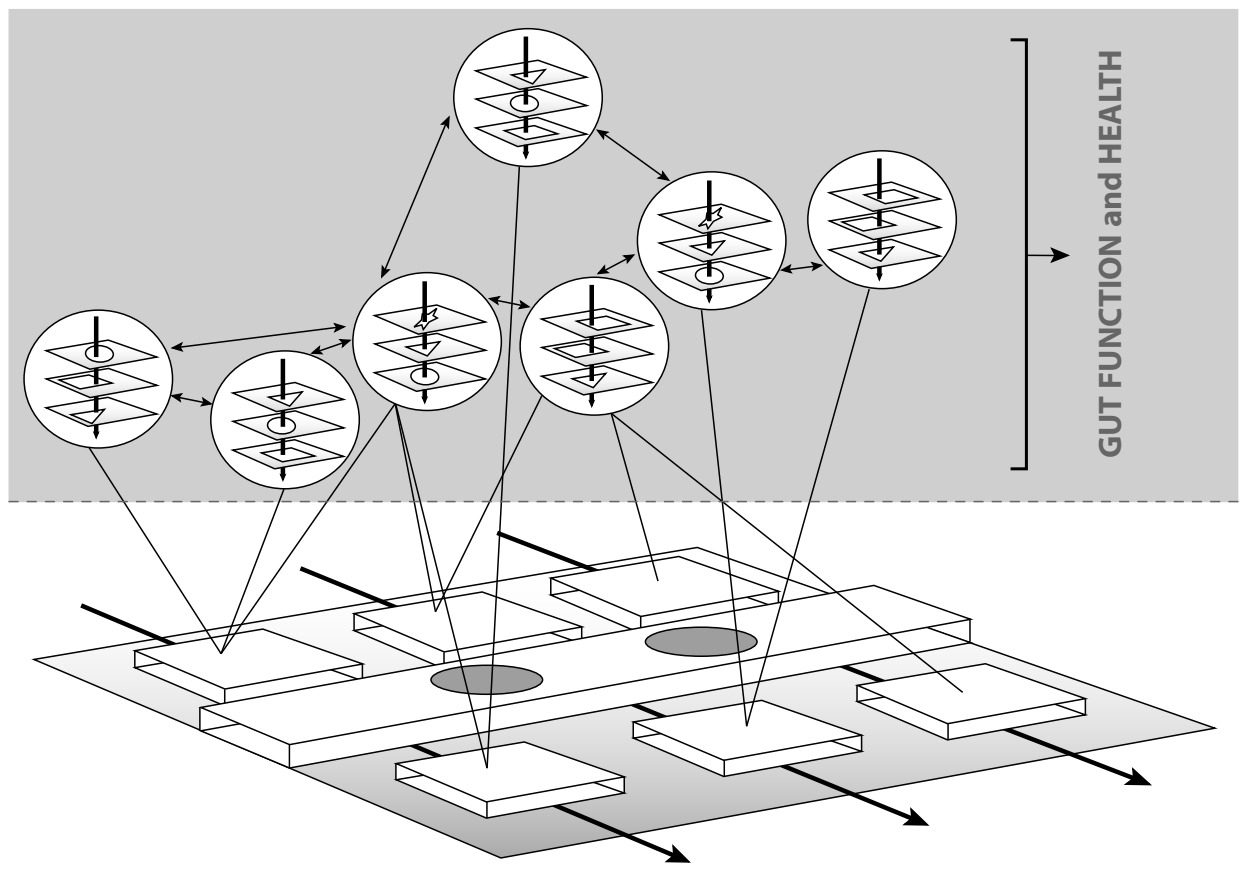

Figure 6.1. The doability network visualised. The lower image, drawn from picture 3.1 , is the representation of the Gut Health organisation. Every laboratory deals with a (smaller) subset of problems, which all have to be constructed doable. An abstract selection of such problems is shown in the grey box. All the sub problems interact, resulting in a complex mixture, determining the overall doability of the umbrella problem of 'gut function and health'. 
the current level of science - what it can and what it does. How can we, in the Lord's name [understand all of them]? We construct micro-arrays with all the genes on them, all twenty thousand of them, and then we receive all those data sets and we think: 'let's analyse this, now we will know how things are $[\ldots]$ '. We already know that it will not be enough, because RNA doesn't translate into protein one on one, so we proceed to measure all the proteins. That obviously isn't enough, we need all the metabolites as well; we need to do metabolomics as well. The pile of data grows into enormous proportions. If we cannot know what happens with one gene, how will we ever find out what is happening to all twenty thousand of them. Will this ever lead to anything sensible? [...] I wonder. Interview Scientist M002, 20051018.

Attempting to oversee the entire network of doabilities, as represented in figure 6.1, may result in the conclusion scientist M002 reaches: doubt whether it all can be done. A doability network belonging to a large-scale research programme is vast - too vast for a small number of scientist to oversee, or manage. Through the act of collectively managing small bits of it, a degree of doability can be, and has been reached on the 'umbrella' level. Scientist M002 cannot make it happen all alone. What such large-scale scientific practice requires is cooperation and collective action directed at creating doable problems. Achieving such cooperation and reaching a doable, solvable, problem form a perilous road, scattered with trouble: 3 dimensions of trouble, to be exact. Shared technologies, such as illustrated by the analysis of the shared gene pathway map above, have resulted in the involvement of external parties, such as food industry, and have facilitated the large amount of physical work, articulation work and manipulation work which has been performed by all programme members. As a result, nutrigenomic research practice has become a doable practice - even if the research problems require further articulation and manipulation.

\subsubsection{The size and entanglement of science}

In chapter 1, we have started our journey by reviewing the approaches for studying and understanding large-scale science. It will be helpful to the reader to list and discuss a number of interesting similarities as well as discrepancies between the conclusions reached above, and these existing approaches. From these approaches I will take a number of assumptions about science and scientific practice, which I will subsequently compare to the insights reached above. Firstly, all three take a position that perceives science and scientific research practice as a site at which cooperation is to be promoted, since cooperation is the key to innovation and new knowledge and wealth production. Cooperation is to be monitored, both quantitatively and qualitatively, as well as to be promoted, and even though there 
might be organisational, financial and institutional hurdles, it can, and should be done. Secondly, large-scale scientific practice is traversed and surrounded by numerous boundaries. The 'Triple Helix' approach leaves them intact, whereas the 'New production of Knowledge' approach does not pay a lot of attention to them, and even attempts to reduce them.

On our journey, we have learned that major epistemological hurdles exist on the path towards interdisciplinarity and that 'supersizing a problem' does not need to improve its solvability. Furthermore, although multi-sited research programmes, research consortia and cooperative networks of laboratories do indeed add to the knowledge production process, the act of doing research is anchored at single sites, anchored in one or very few disciplines and subject to local contingencies. Making it work is difficult enough, even without the additional complexities that come with European collaborations and the like. For example, one of the non-European experts has a difficult time understanding how it is possible at all, for an interdisciplinary, multi-sited, multi-national and above all, enormously large consortium such as NuGO to be managed properly and to come up with some relevant answers:

I think New Zealand is one of the few countries in which you can get people to work together in the way that we have succeeded in doing here. I compare it with $\mathrm{NuGO}$ in which you have some fabulous expertise and skills combined and a number of interactions going but you are not pooling your expertise. And I think it is because different countries have different research priorities, different research groups think differently. Within New Zealand we have a very strong sense of science and a sense of health and also, the people working together are a group of people who probably interacted very peripherally in the past, but who respect one another as scientists, who like one another as people and who feel they can trust one another significantly in a way to move forward. I think it is difficult to do that across countries, where you have a slightly different way of looking at things, thinking about things, and quite often a different language [...]. The way we run things, is that the management group meets once a month. So, there are six of us that make key decisions and we also set up subject meetings whenever they are necessary. That is at least twice a year, but when something is not quite working right, we will set up a videoconference or in some way respond to the fact that science isn't progressing the way it needs to. A small country, in a small geographic area, we have got the ability to work across it, interactively much easier then it would occur across Europe or even across America [...]. When we started we agreed that we needed to have a single focus [...]. We sort of picked an area in which none of us had particular expertise, or special interest and pooled our expertise to centre on one particular programme and one particular project. Interview Scientist X003, 20060505 (my emphases). 
If a research network is very heterogeneous, increasing its size and encouraging people to cooperate, will not necessarily increase its potential with respect to knowledge production, or, say, commercialisation. On the contrary, networks can be too large and too complex. Problems can be too diverse and too scattered, expertises may be 'unmixable' and cognitive, geographical, epistemological, cultural and other distances can be too large ${ }^{148}$. Indeed, science can be too big ${ }^{149}$. This immediately raises the question of when this is the case. When is science too big, or too complex? Obviously, there is not a clear cut line that can be drawn beforehand, since every type of research practice has its own dynamics. Furthermore, the success of the actors that tie a practice together (gene pathway maps, chaperone committees, food industry, micro-array technology, etc.) can be expected to vary across programmes and consortia. However, this does demonstrate that bigger does not always mean better. The best way to scholarly demonstrate the latter would be studying the enormous research efforts currently underway ${ }^{150}$. Such studies can result in increased processes of social learning at the boundary of laboratory and society (de Vries and Horstman, 2008).

More importantly, as shown in chapter 3, the organisational geography, coinciding with the geography of sub-problems, is shaped and reshaped over time. Rigid structures, whether named consortia, networks or differently, hinder such rearticulations, when necessary. For instance, scientist M001 thanked all the participants of the Gut Health programme at the last chaperone committee meeting. A representative from the funding agency was present and was included in the oral acknowledgements. Here, scientist M001 does not thank the funding agency for the funding per se, but for the way in which it has been lenient and flexible, while the Gut Health programme slowly reinvented itself:

I am involved and have been involved in a lot of different programmes which have been funded out of a lot of different money jars, and I have to say that working with Senter/IOP has been one of the most pleasant experiences. They are prepared to listen and prepared to be flexible in their deadlines, their bureaucracy, the decisions jointly taken and the rules that apply. That can be very different. Some funders cannot be negotiated with, especially when a programme is financed by Europe. Observation Scientist M001, 20061116.

Mirroring scientist M001's acknowledgments are complaints (regularly in print, in editorials and commentaries) about the organisation and funding of science in the US and elsewhere (see e.g. Nurse, 2006; Weinberg, 2006). By (partially) releasing the rigid programme structure, by accepting movement and change, reorganisation and re-acticulation of problems and structures, the funding agency earned the scientists' approval and even gratitude. Inside scientific practice, room 
for manoeuvring was allowed for, facilitating the alignment of the organization of research practice, with the content of research practice, an ongoing process - in fact a never-ending process.

With respect to large-scale research practices, existing theories on contemporary science differ greatly. As discussed in chapter 3, the 'New Production of Knowledge' holds an anti-differentationist position. It argues for cooperation, while (partially) denying boundaries of scientific practice as well as boundaries in scientific practice. The 'Triple Helix, however, holds a neodifferentationist position, accepting existing structures, leaving them intact and adding new types of interaction. When rethinking the issues addressed above in terms of structure, it is obvious that neither of these theories fit the practice described. Boundaries have not vanished between industry and science, nor between disciplines or styles within science. Neither have they remained static, unaltered by the dynamic practice of large-scale nutrition science. We have witnessed a continuous reconstruction of these boundaries, both in NuGO and in Gut Health and both their (overlapping) contexts. For instance, lines between biology and computation have been redrawn, ties between laboratories and problems have been altered and shifted and programmatic papers and lectures and laboratory practices continue to influence one another generating a shifting meaning of what personalisation is about. Nonetheless, lines (or boundaries), ties and influences they remain to be nonetheless.

In this book I have shown that boundaries work. They enable large-scale research by dividing the enormity of a practice into chunks of manageable size, in the case of lines drawn through science, e.g. disciplines and styles, and chunks of comparable institutionalisation and culture, in the case of lines drawn around science, e.g. demarcation and science-industry relations. Notwithstanding, flexibility is equally important, in order to provide the room for manoeuvring and cooperation, mentioned before.

The alternative ways of knowledge production, whether Mode 2, the Triple Helix, or others, rhetorically positioned as novel or revolutionary, have, from a scholarly perspective, the status of theories about the workings of science and scientific practice. Notions of cooperation, regulation, commercialization, increased social accountability or interdisciplinarity have already been inserted into the vocabulary, as well as reports, texts and calls for proposals of European and national science policy makers, and subsequently into the proposals themselves. It should, however, not be ignored that their normative and organisational implications have been adopted by policy makers (especially with respect to 'Mode 2', the Triple Helix to a lesser extent). Scientific funding agencies, such 
as the Ministry of Economic Affairs, through the IOP, home to the Gut Health programme, and the EU framework programmes, home to NuGO, have, to a large extent, been modelled in their image.

We can only acknowledge that the elements which have been taken up from the 'New Production of Knowledge' and the 'Triple Helix', such as commercial involvement in scientific programmes and the promotion of interdisciplinarity, are indeed contributing to scientific practice. Indeed, it was a trend towards commercialisation which has interested food industry to become part of the chaperone committee to the Gut Health programme. Moreover, the IOP funding programme was mainly directed at stimulating Dutch industries. Furthermore, the explicit incorporation of health as a research goal is not solely a move towards socially accountable interventions, but towards commercial products as well, since health can be sold as 'healthy nutrition' or 'health foods' by food industry.

As far as understanding large-scale science is concerned, this book should be considered to be an addition to the existing approaches. Especially where the importance of the heterogeneous types of work is concerned and the flexible, yet important, role of boundaries as they traverse scientific practice is concerned, both the 'New Production of Knowledge', and the 'Triple Helix' may benefit from the analysis presented here.

\subsection{TOWARDS A MOLECULARISATION OF HEALTH?}

In chapter 1, I argued that in order to find out how large-scale science works, we need to address two main questions. The first question has been addressed above: how to make things work, how to find and understand problems and solutions. The second question, how norms are produced alongside the doable problems, is the subject of this section, focussing on nutrition and, primarily, on health.

Norms matter, for in the midst of all of this cooperation and problem solving, re-alignment and integration, the notion of health acts as a compass, providing direction to nearly all of such shifts. The existence of norms for what health or healthy is, subtly provides direction for an entire research practice. It results in a gentle normative 'pressure' that can be interpreted in terms of the rise of a new biopolitics with respect to health and food. The co-evolution of knowledge and norms results in shifts in our understanding of what is to be considered normal. Shifts in what is considered healthy, are not new. For instance, Steven Shapin shows how, already 500 years ago, an orientation towards health transformed into an orientation towards disease: 
[In the] first period (1470-1530), the doctors' presumption was that you were basically healthy, occasionally needing medical expertise to maintain you in that state of health, but by the second period (1530-70) the experts were trying to convince their readers that they were basically ill, requiring constant dietetic monitoring to prevent sickness from becoming disabling or even fatal (Shapin, 2002).

Such shifts are not the result of the doctors' humour, or even their cash purses. Around the 1530's, the concept of health changed in interaction with changes in the field of medicine and people's daily lives. Over time, categories such as health and disease or notions of normal and pathological, have not been stable. The 'normal' itself has been recognised to be subject to continuous rearticulation, which has resulted in a new social and political target: healthy life. How health can be reached through nutrition, and whether, which and how individual characteristics may matter, has been an important topic over a very long period of time, and nutrigenomic research practice is part of this shift.

In recent writing on the subject of shifting conceptualisations of health and the political effects of these shifts, a number of shifts can be recognised. Politics, after all, is 'something that moves; [...] something that has a trajectory' (Latour, 2007, p. 814). First, there is the re-articulation of the normal in terms of the molecular, which has, according to Rose, resulted in a molecularisation of health. He argues that molecularisation has not been 'merely a matter of the framing of explanations at the molecular level. Nor [has it been] simply a matter of the use of artefacts fabricated at the molecular level'. He argues that the process of molecularisation is a 'reorganisation of the gaze of the life sciences, their institutions, procedures, instruments, spaces of operation and forms of capitalisation' (Rose, 2001; Shostak, 2005; Rose, 2007b). Since the life sciences have been reorganized to fit the molecular, so has biopolitics. Rose has even suggested the rephrasing of biopolitics into molecular politics (2001) or molecular biopolitics (e.g. 2007a). A second example is the work of Beck, who coined the notion of the risk society (Beck, 1992). Following his work, contemporary biopolitics have been reconceptualised as risk politics ${ }^{151}$ (Rose, 2001). Both conceptualisations, molecular biopolitics and risk politics, articulate the rise of a new discourse with respect to a singular health ${ }^{152}$.

In the preceding chapters, it has become clear that the research practice of large-scale nutrition science cannot easily be described by the use of large unidirectional trends. Problems are often situated, as are the concepts that belong to, or are employed by, such problems. As a result, in this book, health has been portrayed as a situated notion. Health, so I have demonstrated, is fragmented epistemologically as well as subject to the interactions between expectations or 
promises and research practices. Furthermore, health may very well be quite a different thing for different groups of people. Because of this, we end up with several co-existing healths, several coexisting 'normals'.

In chapter 3, the modular research practice resulted in a number of local doabilities, a patch work blanket in which health acquired molecular characteristics. These molecular characteristics are not uniform, meaning that they are articulated differently, at different sites, but they do suggest a shift towards the molecular. In chapter 4, 'wet', 'dry' and 'moist' conceptualisations of normal, of health were shown to have co-evolved alongside interdisciplinary large-scale research processes. The 'dry' conceptualisations of normality border closely on the vocabulary of risk. Thus, out of this vast array of potential normals, existing next to one another, some can indeed be conceptualised in terms of molecularisation, as Rose describes, whereas others can be described in terms of risk. Where one health was sought, many were found.

The mobilisation of such conceptualisations can be described in terms of molecular politics or risk politics. However, neither molecular politics, nor risk politics spans the entire practice of nutrition science, not to mention biomedicine at large. As a result of these multiple healths, molecularisation and risk orientation, exhibit a normalising pressure in several directions, towards several healths, simultaneously. Thus, this book deals with nutrigenomics, to a large extent, as the fine tuning ${ }^{153}$ of disciplining effects to a normal which exist at a particular time and at a particular place, or pertains to a particular group of people. Questions about classification with respect to lifestyle, genome and diet subsequently become questions about which 'normal' is at the centre of the discourse at this particular moment, and which normal, which health ${ }^{154}$, one has a duty - as Foucault puts it - to strive after.

Political consequences of a shift from health to healths exist at those sites as well, in laboratories and institutes, but also in larger social aggregates and even society as a whole ${ }^{155}$. Therefore, in discussions on the normative effects of science, it is very important that all the sites of scientific practice are considered. Interpreting such effects in terms of biopolitics, implies focussing on longterm uniform social trends and shifts, for instance with respect to health. This book, however, shows that smaller, situated happenings, such as experiments, management of single programmes and the construction of a network of situated doabilities, are perfectly capable of influencing 'contemporary norms of selfhood' (Novas and Rose, 2000; Rose, 2007b) bottom-up. Taking a biopolitical approach in my analysis has been helpful in understanding the dynamics surrounding the notion of health. However, one may wonder how pluriform notions of health and normality can be mobilised to the benefit of biopolitical inquiry. Current 
biopolitical analyses are not paying enough respect to the pluriformity and diversity of (medical) research practices ${ }^{156}$. This book shows that investing in biopolitics in practice may alleviate this blind spot.

\subsection{DOABILITY TO NUTRIGENOMICISTS AND ELSI RESEARCHERS}

This book sets out to describe an alternative understanding of contemporary large-scale nutrition science. It has shown how parts of a research practice interact amongst one another, as well as with the whole of a practice - on an organisational and an epistemological level, as well as with respect to problems and expectations. Simultaneously, as such an understanding cannot be separated from knowledge production with respect to health, it has continued the 'cartography' of contemporary biopolitics' (Rose, 2007b, p. 5), of the co-production of scientific practices and norms for health, appropriate diets and dietary individuality. The thesis has been a conceptual and ethnographic journey of the normative and political character of life sciences, nutrition science and health, and shows that scientific 'form' and 'content' exist in intimate and perpetual embrace. Although they have been discussed separately on many a page of this book, this ought not to be ignored or forgotten.

Large-scale science is one of the actions contemporary science undertakes which is most efficient at changing our world. Here, changing the world is meant in most of the meanings of the word. From the tangible and visible results of large-scale engineering to the conceptual understanding of what it is to be healthy or to eat healthily? It is because of this, the importance of large-scale science in our world and for our world, that it needs to be studied thoroughly and continuously ${ }^{157}$. The better we learn to understand it, the better we learn to understand what it does to us. For instance, does super sizing science help (Vermeulen, 2008)? It most certainly does not make the practice of performing science easier, that much has been demonstrated above. Nonetheless, if it works by enabling to unlock additional research problems, it may be worth the hassle. However, given the situated nature of scientific practice, the local character of doable problems, it may very well be the case that, sometimes (or often), scaling down science may be a more prudent strategy.

Nutrition scientists do not have to be concerned by the analysis above. It demonstrates a vast complexity for their field, yes, but it also shows that they are able to deal with this complexity and manage to craft doable problems out of it. Normative effects of the process of creating doable problems are the creation of several healths, where only one was sought. The outcome of large-scale nutrition 
research may be very surprising; because of the dynamics of doability being pursued at many sites simultaneously, each re-articulating multiple elements in the research situation. In this case, it is a surprise with far reaching political and practical effects. For the pursuit of doable problems cannot be separated from the active construction and reconstruction of norms, a process of co-evolution which nutrition science would be wise to continuously monitor.

Numerous large-scale research programmes are currently underway, many of which have been referred to in the text above, or in the notes to this book. They provide a plethora of case studies, a plurality of different strategies and different solutions to contingent problems. Simultaneously, they produce new norms through which we experience the world we live in. This new scientific and normative arena these initiatives have crafted for themselves remains to be a happy hunting ground for those wishing to understand the inner working of largescale science, from a practical, a cognitive or a normative perspective. These researchers, studying the ethical, legal, social, political and economical effects of large-scale science lest not forget that doability matters to them, as much as it matters to the nutrigenomicists. 


\section{NOTES}

\section{NOTES TO THE PREFACE}

${ }^{1}$ Personal log, laboratory observation period.

2 If you would ever want to look them up: (Voncken et al., 2002; Boxma et al., 2005).

3 'No man is an island, entire of itself; every man is a piece of the continent, a part of the main'. From: Meditation XVII (1623) by John Donne (1572-1631).

\section{NOTES TO CHAPTER 1}

${ }^{4}$ Part of this chapter has been presented at the Theory Workshop 'Organisation of Science' at Melle, Germany (2007).

${ }^{5}$ He lectures: 'The first phase, which lasted 2,000 years, beginning with Hippocratic notions, and lasting really until the middle of the 18th century, made one simple presupposition about the whole phenomenology of nutrition: that foods contained one item, called nutriment. And if there were any distinctions to be made between foods, it was that they had more or less nutriment. As so often happens, the ghost of that simple idea that was current for so many years, is still in our mind. [...]. Now [...] we came into the second phase of a science of nutrition, a chemicoanalytical period, epitomized by the beheading eventually of the genius, Lavoiser, who founded the science of chemistry. Before we had a chemistry, we could not begin an analysis of foodstuffs, eventually developed by the genius of Liebig. By the middle of the 19th century there was, we realized, more than one thing called 
nutriment. There were four things: minerals, fats, proteins and carbohydrates. For a while we were satisfied with that [...]. It was only the genius of McCollum that begun the biological era around the turn of this present century. We turned away from chemical analysis and asked the question biologically. This is the biological era in nutrient history. We used laboratory animals that guided us into a whole new world of micronutrients: vitamins and trace minerals. The nutrient entries increased to 50' (Schneider, 1977). This historical simplification can be critiqued; I will nonetheless briefly stick with it.

${ }^{6}$ As Hannelore Daniel, a renowned expert in molecular nutrition, puts it: 'For the first time now, nutrition science is being taken seriously', Observation 20051104.

${ }^{7}$ For an overview of pre- and post-war science dynamics, see e.g. Bernal (1971 [1965]) and Rip (1978).

${ }^{8}$ See e.g. the editorials and several sections of Nature, Science, Cell and/or EMBO Reports.

${ }^{9}$ Quoted in Kennedy (2005).

${ }^{10}$ He writes that ' $[\mathrm{U}] \operatorname{sing}$ any reasonable definition of a scientist, we can say that 80 to 90 percent of all the scientists that have ever lived are alive now. Alternatively, any young scientist starting now and looking back at the end of his career [...] will find that 80 to 90 percent of all scientific work will have taken place before his very eyes and that only 10 to 20 percent will antedate his experience' (De Solla Price, 1986, p. 1).

${ }^{11}$ After coining 'Big Science', every discipline has been credited with bigness, resulting in 'Big Physics', 'Big Biology', etc. (Vermeulen and Penders, 2007).

${ }^{12}$ See also Furner (2003a; 2003b).

${ }^{13}$ This way, it can be argued that 'big' does indeed partially equal 'new'. However, I propose that it is not the size of science that matters here, but the restraint scientific practices exert upon social organisation.

${ }^{14}$ See e.g. Weingart (1997a), Jacob (2001), Harbers (2002), Tuunainen (2002), Jansen (2002), Shinn (1999; 2002), Edqvist (2003), Heilbron (2003), Pestre (2003) and Gulbransen and Langfeldt (2004). This list is potentially endless and continues to grow. 
${ }^{15}$ Nowotny, Gibbons and Scott identify, for example, the special issue of Minerva, directed at Mode 2 knowledge production, as an agora as well (Nowotny et al., 2003).

${ }^{16}$ The Triple Helix I in Amsterdam, The Netherlands (1996), Triple Helix II in New York, USA (1998), Triple Helix III in Rio de Janeiro, Brazil (2000), Triple Helix IV in Copenhagen, Denmark (2002), Triple Helix V in Turin, Italy (2005) and Triple Helix VI in Singapore (2007), resulting in many special issues in the fields of Science and Technology Studies and Science Policy (Minerva 1998, vol. 36; Science and Public Policy 1998, vol. 25; Journal of Technology Transfer 1999, vol. 24; Research Policy 2000, vol. 29, Science, Technology \& Human Values 2003, vol. 28; International Journal of Technology Management \& Sustainable Development 2003, vol. 2; Scientometrics 2003, vol. 58, Science \& Public Policy 2003, vol. 30).

${ }^{17}$ This is an argument that very much resembles a position originally taken by De Solla Price, who argues that 'the scientist now holds the purse-strings of the entire state' (1965, p.111).

${ }^{18}$ Including, but not restricted to, Etzowitz and Leydesdorff (1998a; 2001), Leydesdorff and Meyer (2003) and Woo Park et al. (2005).

${ }^{19}$ In the literature, several other issues can be found, centering on from the shapes, forms and status of the key publications, to the audiences of these publications, as well as from qualitative to quantitative identifiers to scientific and political impacts. The main point of critique, however, is whether the 'Triple Helix' and 'The New Production of Knowledge' actually represent something new (see e.g. Weingart, 1997a; Shinn, 1999; Rip, 2000; Martin, 2002; Shinn, 2002; Edqvist, 2003; Pestre, 2003), whether it only corresponds with 'new' fields of scientific inquiry (Gulbrandsen and Langfeldt, 2004) or whether, given its novelty, it has or has not yet had a large impact (Jansen, 2002), all summarised in the heading 'contested novelty'. With respect to novelty, 'Big Science', the 'New Production of Knowledge' and the 'Triple Helix' have a rhetorical strategy in common. They distinguish the little from the big, Mode 1 from Mode 2, linear innovation systems from spiral innovation systems or bilateral from trilateral network relationships. All of these distinguish the new from the old. Not only do they admit doing so quite literally from time to time, members from all three 'factions' use the vocabulary of 'their' conceptualisation quite deliberately. Bowker and Star (1999) have taught us that classifications and their rhetoric are not neutral, but produce new norms and politics. Why would someone want to be involved in 'little science', when there is 'big science' available? Adding subsequent numericals to the mode of science makes it rather 'obvious' that Mode 2 practices are more 'advanced' or 
'state-of-the-art' and the 'triple helix' is 'replacing' a linear model of innovation. Who would want to be accused of linear thinking in a world of complexities (Rip, 2000)? As a result, novelty is actively constructed.

${ }^{20}$ Other suggestions have been made to expand upon the 'Triple Helix'. A second alternative is the expansion of the 'tightly woven triple helix of science industry and the state $[\ldots]$ to a new quadruple helix with the military as a powerful actor' (Trischler, 2002). As a reply to the proposal of a number of 'Quadruple Helices' and even a 'Pentuple Helix', Leydesdorff and Etzkowitz explained that 'three helices are sufficiently complex to understand the social reproduction of the dynamics of innovation' (Leydesdorff and Etzkowitz, 2003).

${ }^{21}$ The main form of the 'Triple Felix' is a cartoon, which was included in Leydesdorff and Etzkowitz (2003) and can be found on its author's website (Simpson, 2006). Simpson adds: 'On the basis of no scholarship at all, and fuelled by an overwrought cynicism about the world, I proposed an alternative 'triple felix model'. This suggests that the interests of Academia, Government and Industry are fundamentally not aligned, and forcing a strong communication between the three will cause them to fight each other like the proverbial cats-ina-sack. Actually the whole idea was mainly an excuse to draw [the] cartoon, but there could be a grain of truth in the model nonetheless'.

${ }^{22}$ Shinn furthermore criticises the epistemological claims of the 'Mode 2 proponents' strive towards 'socially robust knowledge', as lacking empirical evidence and direction (Shinn, 2002).

${ }^{23}$ Here, biopolitics is referred to as the politics of life, bodies and health in the approximate definition Rose presents. However, other conceptualisations of biopolitics exist which argue that biopolitics does not mean politics of living bodies and their state of being, but the politics of (biomedical) scientific practices and scientific organisations (cf. van den Daele, 2005). Such conceptualisations of biopolitics should not be confused with others, which are notably different, such as biopolitics as a 'short-hand term used to describe the approach of those in [political science] who believe that biological concepts [...] and biological research techniques can help us study and understand political behaviour better' (Somit and Peterson, 1998, p. 599).

${ }^{24}$ See also Zwart (2007b), for a biopolitical disussion of contemporary dynamics around body sizes and obesity.

${ }^{25}$ Albeit that the Greek conceptualisation of 'dietetics', of which Foucault writes, is a larger body of activities and restrictions (regimen) which are applied to the 
body. Diet is but one of these activities. In this text, Foucault primarily focuses on sexual activity in relation to the other activities. See also Shapin (1998), who does focus on diet, nutrition and eating behaviour in relationship to embodied and disembodied modes of knowing.

${ }^{26}$ Greco argues that health policy 'promises normativity while it aims to deliver, and supposedly can only aim to deliver, normalisation: hence the gap between the terms of health and policy' (Greco, 2004, p. 6).

${ }^{27}$ It is important to realise that especially 'The new production of knowledge' has advanced from a theory about the production of knowledge and the organisation of scientific practices, towards a political reality in which scientific practices are actively persuaded to model themselves accordingly (Shinn, 2002; Heilbron, 2003). Analytically, the 'New Production of Knowledge' can be perceived as a highly normative theory about the workings of science. However, on national and supranational (e.g. the EU), Mode 2 has become a political reality. This is also the case in two large-scale research programmes that have been the core of my empirical studies throughout the last few years.

${ }^{28}$ The name Gut Health is an abbreviation of the official full programme name 'An integrated genomics approach towards gut health and nutrition' which is both used by the scientists involved, as well as the funding agency, simply because the complete name is too long. To ensure anonimisation, I will use codes for all programme member laboratories and individual names, as well as gene and protein names in case they haven't been extensively discussed in literature in comparable contexts.

${ }^{29}$ Most NuGO meetings and lectures are public, as are publications and project proposals. However, when meetings were not (entirely) public, names have been fully anonimised by coding.

${ }^{30}$ The term 'police officer' is an actor category - regularly used both in private conversations and public lectures. It refers to the European Union representative with the task of monitoring and reporting NuGO progress to the European Commission.

${ }^{31}$ This research is organised in units, called work packages. Originally named WP10 Communication and WP11 Nutrigenomics and Society, these two work packages have been merged into one during the course of the programme: the WP Communications. 


\section{NOTES TO CHAPTER 2}

${ }^{32}$ Previous versions of this chapter have been presented at the $9^{\text {th }}$ PFGS Colloquium in Cardiff, UK (2005), the International Workshop Interdisciplinary Research, Utrecht, the Netherlands (2006) and the NWO Conference, Ede, the Netherlands (2006). Also see Vrouwe (2007, p. 21-24, 59-62).

33 The number of references providing examples can be continued nearly indefinitely. Throughout this chapter, a limited number of examples will be named and referenced.

${ }^{34}$ In STS, others have conceptualised this particular research method as a travelling along with the object. This means that the researcher does not just look at his research objects' struggles from the outside, but travels along with it, trying to see what they see and experience what they experience (Van Hoyweghen, 2004b). This thesis has also been published as a book (Van Hoyweghen, 2007). However, the methodological issues, which are explicitly analysed in the thesis, have been skipped from the book. In itself, this may indicate a more widespread acceptance of ethnographic travels.

${ }^{35}$ In Martín Cortés de Albacar (1551), Breve Compendio de la Sphera y de la Arte de Navegar. Quoted in Lützhöft (2004, p. xvii).

${ }^{36}$ The metaphor of the sailing boat in scientific enterprise has also been used by Otto Neurath, who writes that 'We are like sailors who on the open sea must reconstruct their ship but are never able to start afresh from the bottom. Where a beam is taken away a new one must at once be put there, and for this the rest of the ship is used as support. In this way, by using the old beams and driftwood the ship can be shaped entirely anew, but only by gradual reconstruction' (Neurath, 1973). The metaphor was expanded from a single boat to a fleet of boats by Hilary Putnam, who writes that 'My image is not of a single boat but of a fleet of boats. The people in each boat are trying to reconstruct their own boat without modifying it so much at any one time that the boat sinks, as in the Neurath image. In addition, people are passing supplies and tools from one boat to another and shouting advice and encouragement (and discouragement) to each other. Finally, people sometimes decide they don't like the boat they are in and move to a different boat altogether. (And sometimes a boat sinks or is abandoned.) It's all a bit chaotic; but since it is a fleet, no one is ever totally out of signaling distance from all other boats. There is, in short, both collectivity and individual responsibility' (Putnam, 1981). 
${ }^{37}$ The choice for the laboratory as a prime site for observation was inspired by actor-descriptions of nutrigenomics. Such attempts have led to a melee of descriptions of the field. Nonetheless, nearly all agree on the fact that nutrigenomic practice is an experimental practice, a novel practice, an innovative practice and a practice that is in the process of shaping itself. Furthermore, superlatives, such as 'nutrigenomics: the rubicon of molecular nutrition', are used in scientific papers (Gillies, 2003). That does not help in defining nutrigenomics, but it does help identifying the sites at which to find, observe and follow nutrigenomics. Even though more recently, papers and reports have been published that deal with, or are directed at society or consumers (e.g. Food Ethics Council, 2005; Ronteltap and van Trijp, 2005; Wallace, 2006; Ronteltap et al., 2007a; Ronteltap et al., 2007b) and the possible effects and outcomes of nutrigenomics started to be object of philosophical and ethical deliberation (see e.g. Korthals, 2002b; Chadwick, 2004), nutrigenomic practice can mainly be found in laboratories and in research institutes, at conferences and meetings, as well as in scientific journals.

${ }^{38}$ This research project was funded as a part of a larger research programme and shared will all the other projects in that programme, a collective context from which its accountability was derived. This programme was called the 'Societal Component of Genomic Research'(MCG), funded by the Netherlands Organisation for Scientific Research (NWO). It was initiated alongside a second, larger Dutch research programme, the Netherlands Genomics Initiative (NGI), which is affiliated in a number of ways with the Gut Health project through its individual members. The 'Societal Component of Genomic Research' programme could in itself be considered part of the trend towards accountability of science - a readily identifiable site of institutionalised reflexivity with respect to genomic research. Here, research strategies and organisation can be said to have been modelled according to the existing perspectives with respect to contemporary science, as discussed in chapter 1 .

${ }^{39}$ For instance, to attend the NuGO annual meetings, NuGO membership had to be acquired. Acquiring membership was relatively easy since scientist M002 was able to grant both membership and facilitate attendance of such meetings.

${ }^{40}$ It should be noted that out of the 20 interviewed Gut Health scientists, the majority also is a member of NuGO. Interviews were digitally recorded and transcribed ad verbatim and coded along with the field notes.

${ }^{41}$ It is important to realise that this does not constitute a 'grounded-theory'approach, since it does not exclude any theoretical assumptions one may have before starting observations. 
${ }^{42}$ It is, however, important not take this too far. Latour reminds us, the social is not a material or an adjective, but a movement or a process which takes part in between the elements that make up a practice (Latour, 2005b).

${ }^{43}$ Latour, is very strict in this respect: ' $[\mathrm{N}] \mathrm{o}$ description, then no talk. Don't fill it in. It's like a map of a country in the $16^{\text {th }}$ century: no one went there, or no one came back, so for God's sake, leave it blank. Terra incognita' (Latour, 2005a, p. 150). There is no problem in not describing parts of a practice or an organisation, there is, however, in making up invisible entities to explain what wasn't observed. In order to look into the main question of this book, how large-scale nutrition science works, a restriction the sites mentioned here makes sense. With respect to issues of collaboration, collective problem construction as well as issues of (re)production of normative boundaries, observations in research settings were able to provide the empirical material needed for this analysis. Nonetheless, nutrigenomics exists elsewhere too. To name but a few additional sites, the marketing departments of food industry, nutrition communication groups, both as part of the government, affiliated with the government or affiliated with industry, advisory bureaus or consultancy bureaus and firms. The list potentially goes on and on. It may be interesting to look into these sites later on.

${ }^{44}$ See Labaree (2002) for a comprehensive listing of literature devoted to the 'insider-outsider'-debate.

${ }^{45} \mathrm{He}$ argues that 'I found my practical incompetence in the lab to be of dubious value for getting access to what members were doing' (Lynch, 1982, p. 529, note $35)$.

${ }^{46}$ The phrase 'the fine art of hanging around', or 'the fine art of hanging out' was coined by Gay Talese as the backbone of New Journalism, in order to, as he states 'move beyond the words and get into the actions of people' (Lewis, 2005). Knorr-Cetina contrasts this positive evaluation by conceptualising ethnography as 'being a pain in the neck' (Knorr-Cetina, 1981, p. 24). Both evaluations are equally applicable and often are so simultaneously.

${ }^{47}$ The argument presented there, later developed into what is now chapter 5 of this book, as well as having been published elsewhere (Penders, 2007a; Penders et al., 2007a).

${ }^{48}$ Observation Laurence Melton 20060501.

${ }^{49}$ The word 'sensitisation' is used in sociology, as well as in cognitive science and the various biologies. In sociology, a possible definition would be to 'increase or 
evoke critical reflection on an issue'. I draw from biology here, because that line of thought leads us into a system of actions and reactions (sensitisation, irritation, expulsion, etc.; I will get to them very soon) that is fruitful for this analysis.

${ }^{50}$ See also, e.g. Webster (2007, p. 465), who argues that even though STS may be in an interstitial position, the process of co-construction, here: co-traveling or sailing, is never an equal process. He argues so, based upon his experience as an STS analist in a plant science laboratory.

${ }^{51}$ I included contributory expertise here, because for some, given their background, contributory expertise can indeed be reached. Given my training as a biologist, I consider myself to have reached a moderate degree of contributory expertise.

${ }^{52}$ After one of my lectures on the subject, Michael Müller, one of the leading Dutch nutrigenomicists, made this point. In nutrigenomic research practice, sensitisation exists between biologists, nutritionists, chemists, bioinformaticians, etc. Observation Michael Müller 20061130. The notion of interdisciplinarity in nutrigenomic research practice is further addressed in chapter 4 .

53 The Netherlands Genomics Initiative has shown cognitive and normative recognition of this particular STS research project by devoting an article in their newsletter to it (van der Graaf, 2004).

${ }^{54}$ An 'acceptable level of expertise' is a pragmatic notion, open to much interpretation. By definition, expertise cannot be complete or ubiquitous, but expertise can reach a level of adequacy at which it enables the possessor to interact with practitioners as well as act in the practice of research.

55 This way, expertise overcomes Lynch's earlier complaint that 'I found my practical incompetence in the lab to be of dubious value for getting access to what members were doing' (Lynch, 1982, p. 529, note 35). Please note, however, that 'practical incompetence' can only be overcome by contributory expertise. 'Practical incompetence' cannot be overcome by interactional expertise, however, 'getting access to what members are doing' can.

\section{NOTES TO CHAPTER 3}

${ }^{56}$ Previous versions of this chapter have been presented at the $4 \mathrm{~S}$ conference in Vancouver, BC, Canada (2006) and the $2^{\text {nd }}$ Corsage Symposium in Wageningen, the Netherlands (2006). 
${ }^{57}$ The chaperone committee chair started out as an independent academic scientist. However, during the course of the Gut Health programme he switched careers and became CEO of an R\&D biotech company.

${ }^{58}$ Interview Scientist W001, 20050214.

${ }^{59}$ Every laboratory in the Gut Health programme works with tables comparable to the one below. Many are different in layout and setup, some even more detailed in the fragments of the sub-problem they show. However, all of them show a detailed scheme of task-division and classification.

${ }^{60}$ For an extensive review of the uprise of micro-array technologies and a brief overview of their history, see Lenoir and Gianelli (2006). In their paper (p. 18) they argue that through the micro-array innovation, researchers 'made genetics more relevant to their respective fields'. Furthermore, they argue (p. 21) that micro-arrays are not simple tools to be applied, but they require collaboration between laboratories and scientists, as well as with industry.

${ }^{61}$ All the modules using micro-array technology to measure gene expression do so in (human) gut cells. However, only laboratory $\mathrm{C}$ has to account for two active genomes in the experimental setup, namely the genome of the (human) gut and of the bacterium.

${ }^{62}$ Table 3.1 as it is displayed in this chapter was drawn from a mid-term report and was not part of the programme proposal.

${ }^{63}$ Opinions about the service the service provider provided were negative: "[The service provider] is clearly non-cooperative" and it was decided to end the contract, Scientist M001, observation 20031012.

${ }^{64}$ The Gut Health programme proposal identified the scientist responsible for the programme in laboratory $\mathrm{H}$ to be a post-doctoral fellow. However, in the early 2000s bioinformatics was a discipline in which there was a lot of demand and very little supply with respect to manpower.

${ }^{65}$ In the end, scientist A003 chose to abandon the programme, partly because of continuing struggles to forge such a new role, gravely interfering with his intentions to produce a $\mathrm{PhD}$ thesis.

${ }^{66}$ Observation Scientist M006, 20060830.

${ }^{67}$ Interestingly, also laboratory furniture comes in 'modular setups' now, in order to facilitate ease and functionality in the lab, 'well defined modules are 
important when building a laboratory'. If this is not the case, 'flows of materials and cooperation between employees will be subject to disturbance' (Hentzepeter, 2006).

${ }^{68}$ Interview Scientist W002, 20051108.

${ }^{69}$ One of such meetings was held March 1 1t, 2005 at one of Company Y's Dutch sites where food industry representatives explained what they expected and hoped would result from the Gut Health programme.

${ }^{70}$ As table 3.1 shows, these problems are mainly positioned as technological problems.

${ }^{71}$ This, one could argue, fragments the umbrella problem into smaller modules, reducing the complexity inside each of the modules. However, with more modules simultaneously working to reach their local doability, the task to integrate the modules of the problem grows harder.

72 Observation Scientist M001, 20050301.

${ }^{73}$ Interview Scientist W002, 20051108.

${ }^{74}$ Observation Scientist M001, 20050301.

${ }^{75}$ Observation Scientist E001, 20050301.

${ }^{76}$ I use incorporation here, in terms of an addition as an element in Gut Health's network, as an ally and not incorporation in terms of encapsulation.

${ }^{77}$ Observation Scientist M001, 20040524.

${ }^{78}$ Interview Scientist W001, 20050214.

${ }^{79}$ Observation I001, 20050301.

${ }^{80}$ Observation I003, 20040524.

${ }^{81}$ Observation I001, 20050301.

${ }^{82}$ Not only because of the alternative materialities in the laboratories of the Gut Health programme versus society at large, but also because of some active decision-making processes, that have led to an alternative health. 


\section{NOTES TO CHAPTER 4}

${ }^{83}$ Previous versions of this chapter have been presented at the CSG/Cesagen Conference in London, UK (2005), the $9^{\text {th }}$ PFGS Colloquium in Cardiff, UK (2005) and at the CSG/Cesagen Conference, also in London, UK (2007). A previous versions has also been published (Penders et al., 2008).

${ }^{84}$ For additional anonimisation purposes, the scientists who's workplaces are shown, do not appear in these pictures. Furthermore, the pictures are not coupled to specific scientist names or codes. Pictures were included after specific permission by desktop and bench 'owners'.

${ }^{85}$ Some argue that 'copied' would be a better word.

${ }^{86}$ See also Hacking (1990). An example of the social nature of mathematical proof can be read in MacKenzie (1993, p. 51-59).

${ }^{87}$ For example, in their evaluations, the chaperone committee repeatedly praised especially labs $\mathrm{G}$ and $\mathrm{H}$ for their cooperative endeavours: '[T] he two bioinformatics groups, they properly cooperate with the others' Observation chaperone committee chairman G001, 20040524.

${ }^{88}$ Although he has been studying and working in the Netherlands for several years now, scientist W003 was born and raised in Asia.

${ }^{89}$ Scientist W008 refers to the 'dry' scientists in the program as 'them'.

${ }^{90}$ Observation industry representative I005, 20050601. It is important to note, that industry representative I005 has a 'wet' background himself.

${ }^{91}$ Interview Scientist X002, 20051010.

${ }^{92}$ Interview Scientist M002, 20051018.

${ }^{93}$ Observation Scientist Z003, 20031112.

${ }^{94}$ Interview Scientist W002, 20051108.

${ }^{95}$ Interview Scientist M002, 20051018.

${ }^{96}$ Interview Scientist W001, 20050316

${ }^{97}$ It is not a coincidence that the title of this subsection reminds of the work of Denis Wood (1992). For an additional STS perspective on topography and cartography, see Monmonier (1991). 
${ }^{98}$ See e.g. Fujimura (1992) for a conceptualisation of standardised packages as sets of boundary objects constrained by standardised methodologies, or Gorman (2002) for boundary-object trading zones.

${ }^{99}$ In other practices involving both bioinformatics and biology, such role has been taken up by different notions, such as 'homology' (see e.g. Fujimura, 1999) or the database or bio-bank described by e.g. Hine (2006) and Brown (2003a).

${ }^{100}$ Wood states that '[e]very map has an author, a subject, a theme' (1992, p. 22). This author, however, is not an individual, but a collective, since both mapping and map-making are collective, social processes.

${ }^{101}$ Observation Scientist M005, 20041111.

${ }^{102}$ Observation Scientist M005, 20040226.

${ }^{103}$ DNA micro-arrays are sometimes also referred to as gene chips. This is because the Affymetrix micro-array system is called GeneChip@ .

104 Maps work: 'They work in at least two ways. In the first, they operate effectively. They work, that is ... they don't fail [...]. But of course to do this, maps must work in the other way as well, that is, toil, that is, labour. Maps sweat, they strain, they apply themselves. The ends achieved with so much effort? The ceaseless reproduction of the culture that brings them into being' (Wood, 1992, p. 1).

${ }^{105}$ Observation Scientist M005, 20041102.

${ }^{106}$ Observation Scientist M005, 20041102.

${ }^{107}$ There is no logical or theoretical reason which prohibits 'dry' scientists from performing 'wet' work. However, the materialities of the laboratories observed restricted the 'dry' scientists to dry work, simply because they had no access to a wet lab. A 'wet' scientist however may use a computer with the same specifications as a 'dry' scientist in his or her daily work. In fact, both scientists M004 and M005, employed in the Gut Health programme as bioinformaticians, have a PhD, which they earned doing what is considered 'wet' work.

${ }^{108}$ The computer program is called GenMAPP and the data files are called MAPP files. I have installed it on my computer as well, enabling me to gain a certain proficiency in using it (see figure 4.2).

${ }^{109}$ Observation Scientist M004, 20041116.

${ }^{110}$ Interview Scientist M004, 20051015. 
${ }^{111}$ Observation Scientist W008, 20041024.

112 Nuancing this position, Zwart argues that 'the use of high-throughput technologies is accompanied by in silico research gaining ground on in vivo research' (Zwart, 2005b).

${ }^{113}$ For an extensive overview of the debate, see (Thompson Klein, 1990, 1998; Weingart and Stehr, 2000).

${ }^{114}$ This issue has been publicly discussed before, see e.g. Weingart (1997b; 1997c) and the 26 critiques in the same issue, using the term 'Weingartian paradox'.

115 This particular meeting/workshop was referred to in chapter 3 as well.

${ }^{116}$ E.g. 'To define markers of health, one has to define the good life'. Observation Catherine Reynolds, 20050911.

${ }^{117}$ Observation Aldona Dembinska-Kiec, 20050523.

118 This is called hormesis, a situation in which a concentration of a certain chemical, which is considered to be harmful at certain doses, has beneficial effects at low (other) doses, or phrased differently: 'This means that a bit of stress is good for you'. Observation Ben van Ommen, 20050524. A second conceptualisation is that a specific concentration of a compound can increase function beyond what is considered normal. This has been observed for chemical, as well as radiation exposure (e.g. Calabrese and Baldwin, 1998).

119 The examples given at the Krakow workshop included resistance to infection, the ability to repair DNA and the ability to counteract toxicity. Observation, 20050523-24.

${ }^{120}$ Informal, since no written or formal statement resulted from this workshop.

\section{NOTES TO CHAPTER 5}

121 Previous versions of this chapter have been presented at the $\mathrm{NuGO}$ week in Lucca, Italy (2005), the NuGO 'Personalised nutrition conference' in Palma de Mallorca, Spain (2005) of which an expanded version of the abstract was published (Penders, 2007b), the First Corsage Symposium in Utrecht, the Netherlands (2005), the 'International Conference on Nutrigenomics and Gut Health: from science to a marketable food product', Auckland, New Zealand (2006), the CSG/Cesagen Annual Conference in Amsterdam, the Netherlands (2006) and at the CSG Nutrigenomics workshop in Utrecht, the Netherlands 
(2006). Also, a previous version, aimed at social scientists, has been published in the Graduate Journal of Social Science (Penders, 2007a) and a previous version aimed at nutrigenomicists and nutrition scientists, has been published in Trends in Food Science and Technology (Penders et al., 2007a).

122 J. Bruce German is not only employed by Nestlé Switzerland, but also by the University of California at Davis and is involved in the academic research initiative directed at nutrigenomics that is located at Davis.

${ }^{123}$ In the Netherlands, the nutritional education model is not a pyramid, but a compartmentalised disc (the schijf van vijf) indicating overall the same recommended daily intakes as other models such as the US MyPyramid. The 'schijf van vijf' (disc of five) was recently updated and reintroduced November 16, 2004. It was first designed in 1953 and in 1981 it was redesigned into the 'maaltijdschijf' (the 'dinner disc' or 'disc of four'), grouping meats and dairy into one compartment. In 1991 it was remodelled again, into the 'Voedingswijzer' (the food guide). In 2004 the 'drink' compartment was added to make it a 'disc of five' again. A disc-like model is also used in Germany (the Ernährungskreis), currently used in combination with a pyramid form (see e.g. Geerts, 2004; Hammink, 2005). For a review of the politics of constructing the food pyramid see Nestle (2002).

124 'Personalisation need not be limited to health; taste, for instance, has been identified as a further goal', Bruce German, quoted by van Roost (2005), see also Yeretzian et al. (2004).

${ }^{125}$ English translation: 'Every eater the right bite'.

${ }^{126}$ See also e.g. Grierson (2003b), King and Gora (2004), Gorman (2006), Brown (2007), Connor (2007) and Reistad-Long (2007). More critical popular articles have been published as well, more recently. See e.g. Burger (2006) and Biesel (2006).

${ }^{127}$ I intentionally say 'away from one size fits all' and not 'towards something', because these expectations do not make it sufficiently clear towards what this trend is leading us.

${ }^{128}$ Observation Sîan Astley, 20050913.

${ }^{129}$ Observation Larry Parnell, 20050910.

${ }^{130}$ Observation Jim Kaput, 20051103. He repeated this position on New Zealand television (TV One, TVNZ; Breakfast TV) 20060503. See also Hedgecoe who, in his analysis of personalised medicine, argues that 'If we consider the $[\ldots]$ concept of tailor-made medicine, then what is being proposed is more a case of buying a 
small, medium or large T-shirt from The Gap than being fitted for a Savile Row suit' (2004, p. 5) and by doing so also argues for a group-based consideration of the concept of 'personalisation'.

${ }^{131}$ However, when supplements (not diet) are concerned he supports individualised strategies. He added this note both to his lecture at the Personalised Nutrition Conference (2005), as well as on New Zealand TV.

${ }^{132}$ These 88 professionals are mostly academic scientists and R\&D scientists, but also ethicists and social scientists that address nutrigenomics in their research.

${ }^{133}$ Observation scientist W001, 20051005.

${ }^{134}$ As suggested in two reports, by Genewatch UK and the US Government Accountability Office (GAO, 2006; Wallace, 2006). See Finegold et al. (2005) for a contextualisation of such claims in the case study of Sciona, a pioneering company, selling nutrigenetic tests.

${ }^{135}$ Nutrigenomics has, in part, become 'a machine for inventing the future, because, paradoxically, [it] has already downloaded part of that future into [it]self, via promising' (Fortun, 2005, p. 165).

${ }^{136}$ Contrary to Fujimura, who argues that 'these levels of work organisation [...] are not stacked in any hierarchical order. I have no hierarchical intentions here. [...] The social-world level at the top and the experiment level at the bottom could just as well be turned upside down' (Fujimura, 1987, p. 287, note 8), Strauss et al. do have a hierarchical picture in mind, starting at the 'first, topmost level [of] articulation' pertaining to the physician (Strauss et al., 1985, p. 155-156). Similarly, Akera (2007) discerns 8 layers of social organisation (from the bottom up: actors, artifacts, knowledge/skills, organisations, occupations/disciplines, institutions, macro-institutions and historical events). He argues that 'the layers within the representation appear in a specific order and are not presented simply as a set of planes whose order can be transposed arbitrarily' (Akera, 2007, p. 427). However, later on he notes that 'I can also think of many instances where it will be necessary to introduce new layers, or to change the order of the layers as presented' (p. 435). In this book, I will not adopt a hierarchical view of work organisation.

${ }^{137}$ Strauss et al. argue that ' $[t]$ hese three levels of articulation are not so separate in all occupations as in hospital work'. However, they argue, even in hospital work, 'the three levels of articulation are, in fact, sometimes not so sharply distinct as 
delineated above, since under certain conditions the physicians will do second level work or head nurses will do third level work' (Strauss et al., 1985, p. 156157).

${ }^{138}$ As can be seen in figure 3.2.

139 At http://public.ornl.gov/hgmis/external/elsi_search_action.cfm (accessed December 3rd 2007), a list of over 6000 'early' (prior to 1995) ELSI publications are listed.

${ }^{140}$ In a later paper, Korthals explains that such scenario's (in the 2006 paper he includes the exact same scenario which is used in this chapter) has turned out to be an 'exaggerated utopia', especially when connected to issues such as the 'gene-passport' (Korthals, 2006).

${ }^{141}$ Ozdemir and Godard argue that because it is mainly based upon promises and expectations, 'the specific ELSIs associated with nutrigenomics have not been identified empirically' (Ozdemir and Godard, 2007, p. 1055).

${ }^{142}$ See chapter 2 of this book and Collins and Evans (2004; 2006).

${ }^{143}$ Also see Zwart (2007a).

\section{NOTES TO CHAPTER 6}

${ }^{144}$ In depth, 3D, or deflattened, if you will. See also figure 6.1.

${ }^{145}$ Lesser et al argue, for instance, that the funding source of research influences the research conclusions, favouring products of the funders. Katan argues that this can also be attributed to food industry's specific research agenda, only funding or supporting research expected to yield beneficial results (Katan, 2008, p. 18-19), however, an adjustment to a study design or a decision not to publish, may be the next steps (Katan, 2007). Nevertheless, to Lesser et al, this type of influence on research is 'producing selective bias that acts consistently in one direction over time' (Lesser et al., 2007). While these authors focus on the association of research outcomes and food industry involvement and research agenda and food industry involvement, this book has described the relationship between food industry and research practice and organisation. Therefore, while this book has demonstrated that food industry can hold a large-scale research project together, it does not provide insights about a research bias in general. I would like to quote Katan, who argues that 'We obviously need more studies of 
the relations between industry and nutrition research, and they may need to go beyond the data made public in scientific journals' (Katan, 2007). The request 'to go beyond published data' opens up a niche for further STS studies into publicprivate collaborations. Nevertheless, a distrust with respect to industry-academia collaborations is also contained in the triple felix critique by Simpson (2006), also see chapter 1 . In contrast, with respect to co-evolving knowledge and norm production in biomedicine, Lakoff has argued that genomics has been able to connect biopolitics and the market, 'directly linking illness populations to market segments, calibrating health need and consumer demand' (Lakoff, 2005, p. 171). The study of growing public-private collaborations in contemporary nutrition sciences is only just beginning.

${ }^{146}$ Chapter 4 provides a comprehensive list of relevant studies as references.

${ }^{147}$ A similar recognition and incorporation of hierarchy in a network through accepting differences between levels of analysis can be found in Akera's recent paper on the metonymic approach to knowledge (Akera, 2007). There, he revisits the 'ecology of knowledge', based upon Rosenberg's work, as a discussion on parthood and wholeness with respect to knowledge. He deflattens the notion of network resulting in an 'ecology' in which objects, actors or institutions are appointed a pre-designated position in the structural hierarchy, creating subnetworks on different levels, which are able to interact with one another.

${ }^{148}$ In innovation science, models exist to monitor proximities, a concept borrowed from geographical economics. Such proximities can be geographical, cultural, cognitive, etc. See Vandeberg et al. (2007) for an application of such a framework in nutrigenomic research practice. With respect to the relevance of cultural and geographical proximity in large-scale science, Reinhardt offers a perspective from the history of science (Reinhardt, 2006).

${ }^{149}$ Bram Brouwer, the director of the Dutch Ecogenomics Consortium, summarises this in the following words: 'A consortium is a challenge, a challenge which grows bigger when a consortium grows bigger and more diverse' (Observation 20071213).

${ }^{150}$ Examples would be the International HapMap Project (International HapMap Consortium, 2005), or the Personal Genome Project (Shendure et al., 2004; Church, 2005; Blow, 2007) in biology, NASA's Constellation Programme for getting 'back to the moon', in astronomy and physics as well as their counterparts in chemistry and engineering.

${ }^{151}$ Also: a ‘eugenics of risk' (Lemke, 2005, p. 102). 
${ }^{152}$ Rose balances lines of continuity with those of change (Herzig, 2007; Rose, 2007 b, p. 7), arguing not to 'overestimate the novelty of what is happening here' (2001, p. 22), while simultaneously arguing that, as a result of genomic science, 'today, we are $[\ldots]$ in a situation of major historical change whose directions are partially obscure and not yet solidified' (Rabinow and Rose, 2003, p. 34).

${ }^{153}$ Zwart argues that genomics is 'about the optimal fine tuning between genetic profile and lifestyle' (Zwart, 2005b), whereas Rose uses the term 'optimisation' (Rose, 2007b).

${ }^{154}$ Consider, for instance, the food pyramid. It is one of the best known public health nutrition initiatives. Over time, however, various alternative food pyramids have started to appear, which co-exist with one another. All of these alternative pyramids describe a different 'proper diet' for specific people (take for instance, the 'toddler food pyramid', the 'child food pyramid', the 'diabetic food pyramid', the 'food pyramid for older adults', the 'vegetarian food pyramid') or are results of differences between the national models. The latter differences cannot solely be contributed to food industry politics, despite Marion Nestlé's efforts to suggest so (Nestlé, 2002). All of these different proper diets can be operationalised differently, towards different 'healths'. These differences are based upon a large number of variables, including age, health status, but also ideas about what 'normal' meat or dairy consumption are. New norms, co-evolving with contemporary nutrition science, will generate additional alternatives.

${ }^{155}$ According to the 5 types of politics Latour (2007) distinguishes in his reply to De Vries' analysis of politics (2007) (type 1, new human-nonhuman associations; type 2 , the public and its problems; type 3, sovereignty; type 4, deliberate assemblies and type 5, governmentality), this book mobilises a number of types of politics simultaneously, most notably type 1 and type 5 , those which Latour describes as the one that are 'taken as totally 'apolitical' for everyone but historians of science, feminist scholars and various science students' (p. 818). This, however, is not a problem, since, according to Latour, 'each new issue deserves its own protocol' (p. 819) in traversing the various stages of politics, stages which may or may not all be visited and which may or may not be easily discernable.

${ }^{156}$ See also, for instance, Hedgecoe (2004).

${ }^{157}$ Take, for instance, the sequencing of individual genomes, which is just starting to take off by the release of the genomes of James Watson and the publication of that of J. Craig Venter (Check, 2007; Gross, 2007; Ledford, 2007; Levy et al., 2007; Marshall, 2007), or the relatively new field of epigenomics, researching how traits acquired during life are stored and passed on to the next generations 
(Davis and Milner, 2004; Gosden and Feinberg, 2007; Liu, 2007), or existing trends towards individualisation and a focus on risk. Contemporary nutrition science will have to come to terms with these and other movements or trends, and 'contemporary norms of selfhood' will co-evolve with the sciences and be incorporated into them. 


\section{REFERENCES}

Aarden, E. (2006). "Ethiek van verzekeringen en genetica." NVBe Nieuwsbrief (Newsletter of the Dutch Society of Bio-ethics) 6(2): 15-17.

Afman, L. and M. Müller (2006). „Nutrigenomics: from molecular nutrition to the prevention of disease." Journal of the American Dietetic Association 106: $569-576$.

Ahlgren, J., U. Görman and G. Önning (2005). "Ska genera styra vad vi äter." Miljöforskning 3: 16-17.

Akera, A. (2007). "Constructing a representation for an ecology of knowledge: methodological advances in the integration of knowledge and its various contexts." Social Studies of Science 37(3): 413-441.

Annas, G. J. and S. Elias (2004). "Politics, morals and embryos. Can bioethics in the United States rise above politics?" Nature 431: 19-20.

Arab, L. (2004). "Individualized nutritional recommendations: do we have the measurements needed to assess risk and make dietary recommendations?" Proceedings of the Nutrition Society 63(1): 167-172.

Arai, S. (2005). "Functional food science." Journal of the Science of Food and Agriculture 85: 1603-1605.

Aram, J. D. (2004). "Concepts of interdisciplinarity: configurations of knowledge and action." Human Relations 57(4): 379-412.

Augenbraun, E. (2005). "Weapons of mass attraction." Nature 433: 357-358.

Beck, U. (1992). Risk society: Towards a new modernity. London, Sage.

Beck, U. and E. Beck-Gernsheim (2002). Individualization: Institutionalized Individualism and its Social and Political Consequences. London, Sage.

Bernal, J. D. (1971 [1965]). De wetenschap als maatschappelijk proces, deel 3. Utrecht \& Antwerpen, Het Spectrum. 
Biesel, E. (2006). "Ernähren Sie Ihre Gene richtig! Nutrigenomik - der Traum vom maßgeschneiderten Speiseplan.“ Das Parlament 56(10): 10.

Blow, N. (2007). "Genomics: being well informed." Nature 449: 627.

Bonner, A. and G. Tolhurst (2002). "Insider-outsider perspectives of participant observation." Nurse Researcher 9(4): 7-19.

Bowker, G. C. and S. L. Star (1999). Sorting things out: Classification and its consequences. Cambridge, MT \& London, The MIT Press.

Boxma, B., R. M. de Graaf, G. W. M. van der Staay, T. A. van Alen, G. Ricard, et al. (2005). "An anaerobic mitochondrion that produces hydrogen." Nature 434: 74-79.

Brown, C. (2003a). "The Changing Face of Scientific Discourse: Analysis of Genomic and Proteomic Database Usage and Acceptance." Journal of the American Society for Information Science and Technology 54(10): 926938.

Brown, N. (2003b). "Hope against hype - Accountability in biopasts, presents and futures." Science Studies 16(2): 3-21.

Brown, S. (2007). The DNA diet. Sunday Times. London.

Burger, K. (2006). Diät nach Maß. ZeitWissen, http://www.zeit.de/zeitwissen/2006/02/Nutrigenomik. 02.

Calabrese, E. J. and L. A. Baldwin (1998). „Hormesis as a biological hypothesis.“ Environmental Health Perspectives 106(S1): 357-362.

Capshew, J. H. and K. A. Rader (1992). "Big science: Price to the present." Osiris, 2nd Series 7: 2-25.

Chadwick, R. (2004). "Nutrigenomics, individualism and public health." Proceedings of the Nutrition Society 63: 161-166.

Chalkley, L. (1945). "Science, Technology and Public Policy." Science 102(2647): 289-292.

Check, E. (2004). "David versus Goliath." Nature 432: 546-548.

Check, E. (2007). "Celebrity genomes alarm researchers." Nature 447: 358-359.

Church, G. (2005). "The personal genome project." Molecular Systems Biology 1: 0030 .

Clarke, A. E. (1991). Social worlds/arenas theory as organizational theory. Social organization and social process. Essays in honor of Anselm Strauss. D. R. Maines. New York, Aldine de Gruyter: 119-158.

Clarke, A. E. and J. H. Fujimura (1992). What tools? Which jobs? Why right? The right tools for the job. At work in twentieth-century life sciences. A. E. Clarke and J. H. Fujimura. Princeton, Princeton University Press: 3-46.

Collins, H. M. (1974). "The TEA Set: Tacit Knowledge and Scientific Networks." Science Studies 4: 165-186. 
Collins, H. M. (1999). The TEA set: tacit knowledge and scientific networks. The science studies reader. M. Biagioli. New York \& London, Routledge: 95-109.

Collins, H. M. and R. Evans (2003). "The third wave of science studies: studies of expertise and experience." Social Studies of Science 32(2): 235-296.

Collins, H. M. and R. Evans (2004). "Periodic table of expertises." www.cf.ac. $u k /$ socsi/expert.

Collins, H. M., R. Evans, R. Ribeiro and M. Hall (2006). "Experiments with interactional expertise." Studies in History and Philosophy of Science $\mathbf{3 7}$ A(4): 656-674.

Commission of the European Communities (2003). Proposal for a regulation of the European Parliament and of the Council on nutrition and health claims made on foods. Brussels. 2004.

Connor, S. (2007). Genes tell what's one the menu. The New Zealand Herald. Auckland.

Corthésy-Theulaz, I., J. T. den Dunnen, P. Ferré, J. M. W. Geurts, M. Müller, et al. (2005). „Nutrigenomics: The Impact of Biomics Technology on Nutrition Research." Annals of Nutritional and Metabolism 49: 355-365.

Crombie, A. (1994a). Styles of scientific thinking in the European tradition. The history of argument and explanation in the mathematical and biomedical sciences and arts, volume 1. London, Duckworth.

Crombie, A. (1994b). Styles of scientific thinking in the European tradition. The history of argument and explanation in the mathematical and biomedical sciences and arts, volume 2. London, Duckworth.

Crombie, A. (1994c). Styles of scientific thinking in the European tradition. The history of argument and explanation in the mathematical and biomedical sciences and arts, volume 3. London, Duckworth.

van den Daele, W. (2005). Soziologische Aufklärung zur Biopolitik. Biopolitik. Leviathan Sonderheft 23. W. van den Daele. Wiesbaden, VS Verlag für Sozialwissenschaften: 7-41.

Dalton, R. (2005). „Scientists unite in bid to drive policy.“ Nature 437: 600.

Davis, C. D. and J. Milner (2004). "Frontiers in nutrigenomics, proteomics, metabolomics and cancer prevention." Mutation Reseach 551(1): 51-64.

Dennis, M. A. (2006). Big Science; In: Encyclopaedia Britannica, Encyclopaedia Britannica Premium Service: http://www.britannica.com/eb/article9117806. 2006.

Douglas, C. M. W. (2005). "Managing HuGE expectations: rhetorical strategies in human genome epidemiology." Science Studies 18(2): 26-45. 
Ebbels, T., H. Keun, O. Beckonert, H. Antti, M. Bollard, et al. (2003). "Toxicity classification from metabonomic data using a density superposition approach: 'CLOUDS'." Analytica Chimica Acta 490(1-2): 109-122.

Edqvist, O. (2003). "Layered science and science policies." Minerva 41(3): 207221.

Ethics Institute (2005). Genetically tailor-made diets: future prospects and ethical challenges. Utrecht, Utrecht University.

Etzkowitz, H. and L. Leydesdorff (1995). "The triple helix - university-industrygovernment relations: a laboratory for knowledge based economic development." EASST Review 14(1): 14-19.

Etzkowitz, H. and L. Leydesdorff (1998a). "The endless transition: A "triple helix" of University-Industry-Government Relations." Minerva 36(3): 203-208.

Etzkowitz, H. and L. Leydesdorff (1998b). "Triple Helix of Innovation.” Science and Public Policy 25(6): 358-364.

Etzkowitz, H. and L. Leydesdorff (2001). "The dynamics of innovation: from national systems and "Mode 2" to a Triple Helix of University-IndustryGovernment relations." Research Policy 29(2): 109-123.

European Parliament and Council (2006a). Regulation (EC) No 1924/2006 of the European Parliament and of the Council of 20 December 2006 on nutrition and health claims made on foods. No 1924/2006: L 404/9-25.

European Parliament and Council (2006b). Regulation (EC) No 1924/2006 of the European Parliament and of the Council of 20 December 2006 on nutrition and health claims made on foods: Corrigendum. No 1924/2006: L12/318.

Finegold, D. L., C. M. Bensimon, A. S. Daar, M. L. Eaton, B. Godard, et al. (2005). Sciona Ltd. A pioneer in nutrigenomics: the path to consumer acceptance. BioIndustry Ethics, Elsevier: 201-218.

Fleck, L. (1980 [1935]). Entstehung und Entwicklung einer Wissenschaftlichen Tatsache. Einführung in die Lehre vom Denkstil und Denkkollektiv. Frankfurt am Main, Suhrkamp.

Food Ethics Council (2005). Getting personal: shifting responsibilities for dietary health. Brighton, Food Ethics Council.

Fortun, M. (2005). "For an ethics of promising, or: a few kind words about James Watson." New Genetics and Society 24(2): 157-173.

Foucault, M. (1986a). De geboorte van de kliniek. Een archeologie van de medische blik. Nijmegen, Socialistische Uitgeverij Nijmegen SUN.

Foucault, M. (1986b). Dietetics. The use of pleasure. The history of sexuality. Volume 2. M. Foucault. New York, Vintage, Random House: 95-140. 
Fox Keller, E. (2000). The Century of the Gene. Cambridge, MA, Harvard University Press.

Fox Keller, E. (2005). "The century beyond the gene." Journal of Biosciences 30(1): 3-10.

Fujimura, J. H. (1987). "Constructing 'do-able' problems in cancer research: articulating alignment." Social Studies of Science 17: 257-293.

Fujimura, J. H. (1992). Crafting science: standardized packages, boundary objects and translation. Science as Practice and Culture. A. Pickering. Chicago and London, University of Chicago Press.

Fujimura, J. H. (1996). Crafting science: a sociohistory of the quest for the genetics of cancer. Cambridge, MA, Harvard University Press.

Fujimura, J. H. (1999). The practice of producing meaning in bioinformatics. The practices of human genetics. M. Fortun and E. Mendelsohn. Great Britain, Kluwer Academic Publishers.

Fujimura, J. H. (2005). "Postgenomic futures: translations across the machinenature border in systems biology." New Genetics and Society 24(2): 195225.

Fujimura, J. H. and D. Y. Chou (1994). "Dissident in science: styles of scientific practice and controversy over the cause of aids." Social Science in Medicine 38(8): 1017-1036.

Furner, J. (2003a). "Little book, big book: before and after Little science, big science: a review article, Part I." Journal of Librarianship and Information Science 35(2): 115-125.

Furner, J. (2003b). "Little book, big book: before and after Little science, big science: a review article, Part II." Journal of Librarianship and Information Science 35(3): 189-201.

Galison, P. (1999). Trading zone: coordinating action and belief. The science studies reader. M. Biagioli. New York \& London, Routledge: 137-160.

Gannon, F. (2005). "Multidisciplinarity: by fiat or need?" EMBO Reports 6(12): 1105.

Gannon, F. (2006). "Science for society." EMBO Reports 7(6): 561.

Gans, H. J. (1999). "Participant observation in the era of "ethnography"." Journal of Contemporary Ethnography 28(5): 540-548.

$G A O$ (2006). Nutrigenetic testing: tests purchased from four web sites mislead consumers. Testimony before the Special Committee on Aging, U.S. Senate. Washington DC, United States Govenment Accountability Office.

García-Sancho, M. (2006). "The rise and fall of the idea of genetic information (1948-2006)." Genomics, Society and Policy 2(3): 16-36. 
García-Sancho, M. (2007). "Mapping and sequencing information: the social context for the genomics revolution." Endeavour 31(1): 18-23.

Geerts, A. (2004). "Voedingscentrum introduceert Schijf van Vijf: Een complexe boodschap." Voedingsmagazine $\mathbf{6}$.

Geertz, C. (1973). The Interpretation of Cultures: Selected Essays by Clifford Geertz. New York, Basic Books.

German, J. B., M.-A. Roberts and S. M. Watkins (2003a). "Genomics and Metabolomics as Markers for the Interaction of Diet and Health: Lessons from Lipids." Journal of Nutrition 133(6): 2078-2083.

German, J. B., M.-A. Roberts and S. M. Watkins (2003b). "Personal metabolomics as a next generation nutritional assesment." Journal of Nutrition 133(12): 4260-4266.

German, J. B. and H. Watzke (2004). "Personalizing foods for health and delight." Comprehensive Reviews in Food Science and Food Safety 3(4): 145-151.

Gerson, E. M. (1983). "Scientific work, social worlds." Knowledge: Creation, Diffusion, Utilization 4(3): 357-377.

Gibbons, M., C. Limoges, H. Nowotny, S. Schwartzman, P. Scott, et al. (1994). The new production of knowledge. The dynamics of science and research in contemporary societies. London, Sage.

Gieryn, T. F. (1999). Cultural boundaries of science. Credibility on the line. Chicago \& London, University of Chicago Press.

Giles, L. (1910). Sun Tzu on the art of war. The oldest military treatise in the world; http://www.chinapage.com/sunzi-e.html. 2005.

Gillies, P. J. (2003). "Nutrigenomics: The rubicon of molecular nutrition." Journal of the American Dietetic Association 103(12): S50-55.

Gorman, C. (2006). Does my diet fit my genes?, http://205.188.238.109/time/ magazine/article/0,9171,1200765-1,00.html. Time Magazine. 167.

Gorman, M. E. (2002). "Levels of expertise and trading zones: a framework for multidisciplinary collaboration." Social Studies of Science 32(5-6): 933938.

Görman, U. (2006). "Ethical issues raised by personalized nutrition based on genetic information." Genes and Nutrition 1(1): 13-22.

Görman, U. (2007). "Some ethical issues raised by personalised nutrition." Genes and Nutrition 2(1): 55-58.

Gosden, R. G. and A. P. Feinberg (2007). „Genetics and epigenetics - Nature‘s pen-and-pencil set.“ New England Journal of Medicine 356(7): 731.

van der Graaf, A. (2004). "Food gut research under observation. The social aspects of nutrigenomics.” news@genomics.nl 3(1): 5. 
van der Graaf, A. (2005). Research between laboratory and society. Bridging the gap between the developers and users of genomics knowledge. Den Haag, Netherlands Genomics Initiative.

Greco, M. (2004). "The Politics of Indeterminacy and the Right to Health." Theory, Culture \& Society 21(1): 1-22.

Grierson, B. (2003a). Eat right for your genotype. The Guardian.

Grierson, B. (2003b). What your genes want you to eat. The New York Times. New York.

Gross, L. (2007). "Anew human genome sequence paves the way for individualized genomics." PLoS Biology 5(10): e266.

Gulbrandsen, M. and L. Langfeldt (2004). "In search of 'mode 2': the nature of knowledge production in Norway." Minerva 42: 237-250.

Guston, D. H. (2001). "Boundary organizations in environmental policy and science: an introduction." Science, Technology and Human Values 26(4): 399-408.

Hacking, I. (1990). The Taming of Chance. Cambridge, Cambridge University Press.

Hacking, I. (1992a). The self-vindication of the laboratory sciences. Science as Practice and Culture. A. Pickering. Chicago, University of Chicago Press: 29-64.

Hacking, I. (1992b). Statistical language, statistical truth and statistical reason: the self-authentification of a style of scientific reasoning. The Social Dimensions of Science. E. McMullin. Notre Dame, Indiana, University of Notre Dame Press: 130-157.

Hacking, I. (1992c). "'Style' for historians and philosophers." Studies in History and Philosophy of Science 23(1): 1-20.

Hacking, I. (2002). "Style" for historians and philosophers. Historical ontology. Cambridge, MA, Harvard University Press: 178-199.

Hammersley, M. and P. Atkinson (1983). Ethnography: principles in practice. London and New York, Routledge.

Hammink, J. (2005). "Herziene modellen voor de voorlichting over gezonde voeding. Cirkel of pyramide, met of zonder bewegen." Voeding Nu 9: 2021.

Hansson, B. (1999). “Interdisciplinarity: for what purpose?" Policy Sciences 32: 339-343.

Haraway, D. J. (1991). Simians, cyborgs and women. The reinvention of nature. London, Free Association Books. 
Haraway, D. J. (1997). Modest_Witness@Second_Millenium.FemaleMan_ Meets_OncoMouse: Feminism and Technoscience. New York and London, Routledge.

Harbers, H. (1986). Sociale wetenschappen en hun speelruimte. Groningen, Wolters-Noordhoff.

Harbers, H. (2002). "Wetenschap en Samenleving. Naar een nieuw contract." Academische boekengids 33.

Hedgecoe, A. (2004). The politics of personalised medicine. Phamacogenetics in the clinic. Cambridge, Cambridge University Press.

Heilbron, J. (2003). "Veranderende kennisregimes en het onbehagen in de academie. Kanttekeningen bij de malaise in het Hoger Onderwijs." Amsterdams Sociologisch Tijdschrift 30(3): 315-329.

Hemlin, S. and S. B. Rasmussen (2006). "The shift in academic quality control." Science, Technology and Human Values 31(2): 173-198.

Hentzepeter, V. (2006). "Flexibele modulaire labopzet." Laboratorium 42(8): 1012.

Herzig, R. M. (2007). "Reflecting on the surfaces of life." Science 317(5837): 454-456.

Hess, D., J (2001). Ethnography and the development of science and technology studies. Sage Handbook of Ethnography. P. Atkinson, A. Coffey, S. Delamont, J. Lofland and L. Lofland. Thousand Oaks, SAGE Publications: 234-245.

Hine, C. (2006). "Databases as scientific instruments and their role in the ordering of scientific work." Social Studies of Science 36(2): 269-298.

Hinterberger, F. (2005). After the European constitution. Governance for sustainable development as a way out? 6th International Conference of the European Society for Ecological Economics. Lisbon. 14-17 Jun.

Holmes, F. J. (1992). Manometers, tissue slices and intermediary metabolism. The right tools for the job: at work in twentieth-century life sciences. A. E. Clarke and J. H. Fujimura. Princeton, Princeton University Press: 151171.

Hoolihan, L. (2003). "Individualization of nutrition recommendations and food choices - Diet and Behaviour." Nutrition Today 38(6): 225-231.

Hoolihan, L. and S. Harlander (2004). "Individualization of nutritional recommendations and food choices." Comprehensive Reviews in Food Science and Food Safety 3(4): 140-141.

Horstman, K. (2008). Lifestyle, genes and cholesterol: new struggles about responsibility and solidarity. Genetics from Laboratory to Society. Societal Learning as an Alternative to Regulation. G. de Vries and K. Horstman. Hampshire (UK) \& New York, Palgrave MacMillan: 64-89. 
Van Hoyweghen, I. (2004a). Genetica en verzekeringen. Het effect van wetgeving. Genetica van laboratorium naar samenleving. De ongekende praktijk van voorspellende genetische testen. G. Vries, de and K. Horstman. Amsterdam, Aksant: 118-139.

Van Hoyweghen, I. (2004b). Making Risks. Travels in Life Insurance and Genetics. Sociologie, Faculteit Sociale Wetenschappen. Leuven, België, Katholieke Universiteit Leuven: 23-54.

Van Hoyweghen, I. (2007). Risks in the Making. Travels in Life Insurance and Genetics. Amsterdam, Amsterdam University Press.

Van Hoyweghen, I. and B. Penders (2007). "Research in the Wild." Nature 450(7169): 478.

International HapMap Consortium (2005). "A haplotype map of the human genome." Nature 437: 1299-1320.

International Human Genome Sequencing Consortium (2001). "Initial sequencing and analysis of the human genome." Nature 409: 860-921.

Jacob, M. (2001). "Managing the institutionalisation of Mode 2 knowledge production." Science Studies 14(2): 83-100.

Jansen, J. D. (2002). "Mode 2 knowledge and institutional life: Taking Gibbons on a walk through a South African university." Higher Education 43: 507521.

Jones, S. (2006). "Prosperous people, penurious genes." Science 314(5807): 1879.

Jorgensen, D. L. (1989). Participant observation. London, Sage.

Kanuha, V. K. (2000). «»Being» native versus «Going native»: conducting social work research as an insider.» Social Work 5(1): 439-447.

Kaput, J. (2004). "Diet-disease gene interactions." Nutrition 20(1): 26-31.

Kaput, J., J. M. Ordovas, L. Ferguson, B. van Ommen, R. L. Rodriguez, et al. (2005a). "The case for strategic international alliances to harness nutritional genomics for public and personal health." British Journal of Nutrition 94: 623-632.

Kaput, J., J. M. Ordovas, L. Ferguson, B. Ommen, van, R. L. Rodriguez, et al. (2005b). "The case for strategic international alliances to harness nutritional genomics for public and personal health." British Journal of Nutrition 94: 623-632.

Kaput, J., D. Swartz, E. Paisley, H. Mangian, W. L. Daniel, et al. (1994). "Dietdisease interactions at the molecular level: An experimental paradigm." Journal of Nutrition 124(8): 1296S-1305S. 
Karlqvist, A. (1999). "Going beyond disciplines. The meanings of interdisciplinarity." Policy Sciences 32: 379-383.

Katan, M. B. (2004). "Health claims for functional foods." British Medical Journal 328: 180-181.

Katan, M. B. (2007). "Does Industry Sponsorship Undermine the Integrity of Nutrition Research?" PLoS Medicine 4(1): e6.

Katan, M. B. (2008). Wat is nu gezond? Fabels en feiten over voeding. Amsterdam, Bert Bakker.

Katz, S. and B. L. Marshall (2004). "Is the functional 'normal'? Aging, sexuality and the bio-marking of succesfull living." History of the Human Sciences 17(1): 53-75.

Kawulich, B. (2005). "Participant observation as a data collection method." Forum Qualitative Sozialforschung/Forum Qualitative Social Research 6(2): Article 43.

Kay, L. E. (1999). In the beginning was the word? The genetic code and the book of life. The science studies reader. M. Biagioli. New York \& London, Routledge: 224-233.

Kay, L. E. (2000). Who wrote the book of life? A history of the genetic code. Stanford, Stanford University Press.

Kennedy, D. (2005). "125." Science 309: 19.

King, E. and B. Gora (2004). The DNA diet. The Sunday Telegraph. Sydney.

Klaus, S. and J. Keijer (2004). "Gene expression profiling of adipose tissue: individual, depot-dependent, and sex-dependent variabilities." Nutrition 20(1): 115-120.

Knight, J. (2002). "Bridging the culture gap.” Nature 419: 244-246.

Knorr-Cetina, K. (1981). The Manufacture of Knowledge: An Essay on the Constructivist and Contextual Nature of Science. Oxford and New York, Pergamon.

Knorr-Cetina, K. (1995). Laboratory studies. The cultural approach to the study of science. Handbook of science and technology studies. S. Jasanoff, G. E. Markle, J. C. Petersen and T. Pinch. London, Sage: 140-166.

Kornman, K. S., P. M. Martha and G. W. Duff (2004). "Genetic variations and inflammation: A practical nutrigenomics opportunity." Nutrition 20(1): 4449.

Korthals, M. (2002a). "The struggle over functional foods: justice and the social meaning of functional foods." Journal of Agricultural and Environmental Ethics 15(3): 315-324.

Korthals, M. (2002b). Voor het eten; Filosofie en ethiek van voeding. Amsterdam, Boom. 
Korthals, M. (2006). "Opkomst en ondergang van de genen-of genomicsgezondheidskaart." NVBe Nieuwsbrief (Newsletter of the Dutch Society of Bio-ethics) 13(1): 13-14.

Kuhn, T. S. (1970 [1962]). The structure of scientific revolutions. Chicago, University of Chicago Press.

Kunneman,H.(2005). "Socialworkas laboratory fornormativeprofessionalisation." Social Work \& Society 3(2): 191-200.

Labadarios, D. and M. M. Meguid (2004). "Nutrigenomics: Unraveling man's constitution in relation to food." Nutrition 20(1): 2-3.

Labaree, R. V. (2002). "The risk of 'going observationalist': negotiating the hidden dilemmas of being an insider participant observer." Qualitative Research 2(1): 97-122.

Lakoff, A. (2005). Pharmaceutical Reason. Knowledge and Value in Global Psychiatry. Cambridge, Cambridge University Press.

Latour, B. (1987). Science in action: How to follow scientists and engineers through society? Cambridge, MA, Harvard University Press.

Latour, B. (2005a). On the difficulty of being an ANT. Reassembling the social. An introduction to actor-network-theory. B. Latour. Oxford, Oxford University Press: 141-156.

Latour, B. (2005b). Reassembling the social. An introduction to actor-networktheory. Oxford, Oxford University Press.

Latour, B. (2007). "Turning around politics. A note on Gerard de Vries' paper." Social Studies of Science 37(5): 811-820.

Latour, B. and S. Woolgar (1986 [1979]). Laboratory life: the construction of scientific facts. Princeton, Princeton University Press.

Lazzarato, M. (2002). "From biopower to biopolitics." Pli: The Warwick Journal of Philosophy 13(8): 1-6.

Ledford, H. (2007). "All about Craig: the first "full” genome sequence." Nature 449: 6-7.

Lemke, T. (2001). "The Birth of Bio-Politics' - Michel Foucault's Lecture at the Collège de France on Neo-Liberal Governmentality." Economy and Society 30(2): 190-207.

Lemke, T. (2002). „Der Mensch ist, was er ißt? Zur Nutrigenomik.“ Gen-Ethischer Informationsdienst 18(151): 24-26.

Lemke, T. (2005). From Eugenics to the government of genetic risks. Genetic Governance. Health, Risk and Ethics in the Biotech Era. R. Bunton and A. Petersen. London \& New York, Routledge: 95-105. 
Lenoir, T. and E. Gianella (2006). "The emergence and diffusion of DNAmicroarray technology." Journal of Biomedical Discovery and Collaboration 1(1): e11.

van Lente, H. (1993). Promising technology. The dynamics of expectations in technological developments. Delft, Eburon.

van Lente, H. (2000). Forceful futures: from promise to requirement. Contested futures. A sociology of prospective techno-science. N. Brown, B. Rappert and A. Webster. London, Ashgate: 43-64.

Leshner, A. I. (2005). "Where science meets society." Science 307: 815.

Lesser, L. I., C. B. Ebbeling, M. Goozner, D. Wypij and D. S. Ludwig (2007). "Relationship between Funding Source and Conclusion among NutritionRelated Scientific Articles." PLoS Medicine 4(1): e5.

Levitt, S. D. and S. J. Dubner (2005). Freakonomics: a rogue scientist explores the hidden side of everything. New York, William Morrow.

Levy, S., G. Sutton, P. C. Ng, L. Feuk, A. L. Halpern, et al. (2007). "The diploid genome sequence of an individual human." PLoS Biology 5(10): e254.

Lewis, I. R. (2005). An interview with Gay Talese. http://www.usc.edu/dept/LAS/ mpw/faculty/talese.php Accessed Jan 10, 2007.

Leydesdorff, L. and H. Etzkowitz (2001). A Triple Helix of University-IndustryGovernment Relations: Mode 2 and the Globalization of National Systems of Innovation. Science under Pressure. Aarhus, Denmark, The Danish Institute for Studies in Research and Research Policy: 7-33.

Leydesdorff, L. and H. Etzkowitz (2003). "Can "the public" be considered as a fourth helix in university-industry-government relations?" Science and Public Policy 31(1): 55-61.

Leydesdorff, L. and M. Meyer (2003). "The triple helix of industry-government relations." Scientometrics 58(2): 191-203.

Leydesdorff, L. and M. Meyer (2006). "Triple Helix indicators of knowledgebased innovation systems." Research Policy 35(10): 1441-1449.

Liu, Y. (2007). "Like father like son. A fresh review of the inheritance of acquired characteristics." EMBO Reports 8(9): 798-803.

Löwy, I. (1998). "Book review: Joan H Fujimura, Crafting science: a sociohistory of the quest for the genetics of cancer." Medical History 42(2): 252-253.

Lupton, D. (1995). The imperative of health. Public health and the regulated body. London, Sage.

Lützhöft, M. (2004). "The technology is great when it works". Maritime Technology and Human Integration on the Ship's Bridge. Division of Quality and Human-Systems Engineering. Department of Mechanical Engineering. Linköping, University of Linköping. 
Lynch, M. (1982). "Technical Work and Critical Inquiry: Investigations in a Scientific Laboratory." Social Studies of Science 12(4): 499-533.

Lynch, M. and S. Cole (2005). "Science and Technology Studies on Trial: Dilemmas of Expertise." Social Studies of Science 35(2): 269-311.

MacKenzie, D. (1993). "Negotiating arithmetic, constructing proof: the sociology of mathematics and information technology." Social Studies of Science 23(1): 37-65.

Marks, J. (2006). "Biopolitics.” Theory, Culture \& Society 23: 2-3.

Marshall, E. (2007). "Sequencers of a famous genome confront privacy issues." Science 315: 1780.

Martin, B. R. (2002). The evolution of the university - a new triple helix or return to an earlier social contract? 4th Triple Helix Conference. Copenhagen

M'Charek, A. (2005a). The human genome diversity project. An ethnography of scientific practice. Cambridge, Cambridge University Press.

M'Charek, A. (2005b). "The mitochondrial eve of modern genetics: of peoples and genomes, or the routinization of race." Science as Culture 14(2): 161183.

Mehta, M. D. (2002). Regulating biotechnology and nanotechnology in Canada: A post-normal science approach for inclusion of the fourth helix. International Workshop on Science, Technology and Society: Lessons and Challenges. Singapore. 19 Apr.

Meijboom, F. L., M. F. Verweij and F. W. Brom (2003). "You eat what you are: Moral dimensions of diets tailored to ones genes." Journal of Agricultural and Environmental Ethics 16(6): 557-568.

Merkel, A. (2006). “German Science Policy 2006.” Science 313: 147.

Merton, R. K. and E. Garfield (1986). Foreword. Little Science, Big Science... and beyond. D. J. De Solla Price. New York, Columbia University Press: vii-xiii.

Mesman, J. (2002). Ervaren pioniers. Omgaan met twijfel in de intensive care voorpasgeborenen. Amsterdam, Aksant.

Mole (2004). "No free lunches." Journal of Cell Science 117(5): 653-654.

Monmonier, M. (1991). How to lie with maps. Chicago and London, The University of Chicago Press.

Müller, M. (2002). Over genen en genieten. Signalen, sensoren en signaturen. Inaugural Lecture. Department of Molecular Nutrition. Wageningen

Müller, M. (2005). NuGO Weblog contribution, Monday August 15th, 2005; http://www.nugo.org/weblog. 2005.

Müller, M. and S. Kersten (2003). "Nutrigenomics: Goals and strategies." Nature Reviews Genetics 4(4): 315-322. 
Nature Editorial (2002). "Prize-winning multidisciplinarity." Nature 417: 471.

Nature Editorial (2003). "Who'd want to work in a team?" Nature 424(6944): 1.

Nature Opinion (2006). "Media studies for scientists." Nature 416(6880): 461.

Nestlé, M. (2002). Food politics : how the food industry influences nutrition and health. Berkeley, CA, University of California Press.

Neurath, O. (1973). Empiricism and Sociology. Dordrecht \& Boston, D. Reidel Publishing Company.

Novas, C. and N. Rose (2000). "Genetic risk and the birth of the somatic individual." Economy and Society 29(4): 485-513.

Nowotny, H. (2006). Lecture: Interdisciplinarity and ELSA research. CSG/ Cesagen 3rd International Conference: "Genomics \& Society: towards a socially robust science?" April 20th, 2006; Amsterdam. April 20th, 2006.

Nowotny, H., P. Scott and M. Gibbons (2001). Re-thinking science. Knowledge and the public in an age of uncertainty. Oxford, Blackwell.

Nowotny, H., P. Scott and M. Gibbons (2003). "'Mode 2' revisited: the new production of knowledge." Minerva 41(3): 179-194.

Nurse, P. (2006). “US Biomedical research under siege.” Cell 124(1): 9-12.

O'Malley, M. A., G. R. McOuat and W. F. Doolittle (2002). The triple helix account of scientific innovation. 4th Triple Helix Conference. Copenhagen. 6-9 Nov.

van Ommen, B. (2001). "Elke eter de juiste hap." Natuur en Techniek 10: 24-28.

van Ommen, B. (2004). "Nutrigenomics: Exploiting systems biology in the nutrition and health arena." Nutrition 20(1): 4-8.

van Ommen, B. (2005). (Lecture) Nutrigenomics: a new way of nutritional sciences. Moscow. March 14, 2005.

van Ommen, B. and R. Stierum (2002). "Nutrigenomics: exploiting systems biology in the nutrition and health arena." Current Opinion in Biotechnology 13: $517-521$.

Ozdemir, V. and B. Godard(2007). "Evidence-based management of nutrigenomics expectations and ELSIs." Pharmacogenomics 8(8): 1051-1062.

Palladino, P. (1998). "Book review: Joan H Fujimura, Crafting science: a sociohistory of the quest for the genetics of cancer." British Journal for the History of Science 31(110): 373-375.

Patrinos, A. and D. Drell (2002). "The times they are a-changin'." Nature 417: 589-590. 
Pearson, J. (2001). "'Going native in reverse": the insider as researcher in British wicca." Nova Religio 5(1): 52-63.

Penders, B. (2007a). "Aligning nutrigenomics and ELSA. Towards a politics of classification." Graduate Journal of Social Science 4(1): 34-49.

Penders, B. (2007b). "Personalised diet: is it doable? Individuality at different sites of nutrigenomic practice." Genes and Nutrition 2(1): 93-94.

Penders, B., K. Horstman, W. H. M. Saris and R. Vos (2007a). "From individuals to groups: a review of the meaning of 'personalized' in nutrigenomics." Trends in Food Science \& Technology 18(6): 333-338.

Penders, B., K. Horstman and R. Vos (2007b). "Proper science in moist biology." EMBO Reports 8(7): 613.

Penders, B., K. Horstman and R. Vos (2008). "Walking the line between biology and computation: the "moist' zone." BioScience: accepted.

Perusse, L. and C. Bouchard (2000). "Gene-diet interactions in obesity." American Journal of Clinical Nutrition 72(5): 1285S-1290S.

Pestre, D. (2003). "Regimes of knowledge production in society: Towards a more political and social reading." Minerva 41(3): 245-261.

Popper, K. R. (1963). Conjectures and Refutations. The growth of scientific knowledge. London, Routledge and Kegan Paul.

Putnam, H. (1981). Philosophers and Human Understanding. Scientific Explanation. A. F. Heath. Oxford, Clarendon Press: 118.

Rabinow, P. and N. Rose (2003). Thoughts on the concept of biopower today. Vital politics: health, medicine and bioeconomics into the twenty first century. London School of Economics, London, UK. September 5-7.

Radder, H. (1997). "Philosophy and history of science: beyond the Kuhnian paradigm." Studies in History and Philosophy of Science 28(4): 633-655.

Radick, G. (2000). "Two explanations of evolutionary progress." Biology and Philosophy 15(4): 475-491.

Radstake, M. (2007). Visions of Illness. An endography of real-time medical imaging. Delft, NL, Eburon.

Radstake, M. and B. Penders (2007). "Inside genomics: the interdisciplinary faces of ELSA." Graduate Journal of Social Science 4(1): 4-10.

Redfern, C., N. Salomonis and C. Evelo (2005). "GenMAPP (http://www. genmapp.org) pathway map for Fatty Acid Beta Oxidation 1. Maintained by C. Evelo for NuGO. Email: mapps[at]bigcat.unimaas.nl. Last modified: 11/22/05." Gladstone Institutes and BiGCaT Bioinformatics.

Reinhardt, C. (2006). „Wissenstransfer durch Zentrenbildung. Physikalische Methoden in der Chemie und den Biowissenschaften." Berichte zur Wissenschaftsgeschichte 29: 224-242. 
Reistad-Long, S. (2007). Eat your genes. Esquire. 147: 50.

Riegler, A. (2005). Inclusive world views: Interdisciplinary research from a radical constructivist perspective. Worldviews, science and us: Redemarcating knowledge and its social and ethical implications. D. Aerts, B. D'Hooghe and N. Note. Singapore, World Scientific: 20-37.

Ringnér, M. (2008). "What is principal component analysis?" Nature Biotechnology 26(3): 303-304.

Rip, A. (1978). Wetenschap als mensenwerk. Over de rol van de natuurwetenschap in de samenleving. Baarn, Ambo.

Rip, A. (2000). Fashions, lock-ins and the heterogeneity of knowledge production. The future of knowledge production in the academy. M. Jacob and T. Hellström. Buckingham, Open University Press: 28-39.

Roche Applied Science (1992). Biochemical Pathways Index. Penzberg, Roche Applied Science.

Ronteltap, A. H. and H. van Trijp (2005). Consumer acceptance of nutrigenomicbased food technology. Genomics 2030: Part of everyday life. M. Graef, de. The Hague, STT/Beweton: 88-96.

Ronteltap, A. H., H. van Trijp and R. J. Renes (2007a). "Expert views on critical success and failure factors for nutrigenomics." Trends in Food Science \& Technology 18(4): 189-200.

Ronteltap, A. H., H. van Trijp, R. J. Renes and L. J. Frewer (2007b). "Consumer acceptance of technology-based food innovations: Lessons for the future of nutrigenomics." Appetite 49: 1-17.

van Roost, M. (2005). "Nutrition meets genetics." Asia Food Journal 2005(5): June.

Rose, N. (2001). "The politics of life itself." Theory, Culture \& Society 18(6): $1-30$.

Rose, N. (2007a). "Molecular biopolitics, somatic ethics and the spirit of biocapital." Social Theory \& Health 5: 3-29.

Rose, N. (2007b). The politics of life itself. Biomedicine, power and subjectivity in the twenty-first century. Princeton, NJ \& Woodstock, UK, Princeton University Press.

Schneider, H. (1977). Nutrition Forum. Opening Remarks. Food and Nutrition in Health and Disease. N. H. Moss and J. Mayer. New York, New York Academy of Sciences. 300: 251-254.

Schnelle, T. (1981). "Book review: Ludwig Fleck: Genesis and development of a scientific fact." Theory and Society 10(5): 733-737.

Schoenberger, E. (2001). "Interdisciplinarity and social power." Progress in Human Geography 25(3): 365-382. 
SenterNovem (2006). Website Senter Novem (http://www.senternovem.nl/iop/). The Hague, Mininstry of Economic Affairs. 2006.

Shapin, S. (1998). The philosopher and the chicken. Science Incarnate. Historical embodiments of natural knowledge. C. Lawrence and S. Shapin. Chicago, University of Chicago Press: 21-50.

Shapin, S. (2002). "Barbecue of the vanities: a short history of diet books." London Review of Books 16: 21-23 (Selected as the LRB Essay and published online by 'The Guardian Unlimited').

Shendure, J., R. D. Mitra, C. Varma and G. M. Church (2004). "Advanced sequencing technologies: methods and goals." Nature Reviews Genetics 5: $335-344$.

Shinn, T. (1999). "Change or mutation? Reflections on the foundations of contemporary science." Social Science Information 38(1): 149-176.

Shinn, T. (2002). "The triple helix and the new production of knowledge: prepackaged thinking on science and technology." Social Studies of Science 32(4): 599-614.

Shostak, S. (2005). "The emergence of toxicogenomics: a case study of molecularization." Social Studies of Science 35(3): 367-403.

Sider, T. (2007). "Parthood." Philosophical Review 116: 51-91.

Simpson, A. G. B. (2006). Other interests (http://myweb.dal.ca/asimpso2/ otherinterests.htm). 2006.

Sivakumar, A. (2002). "2D Gels and bioinformatics - An eye to the future." In Silico Biology 2: 0045.

Smith, R. W. and J. N. Tatarewicz (1994). "Counting on invention: devices and black boxes in very big science." Osiris, 2nd Series 9: 101-123.

De Solla Price, D. J. (1965). Little science, big science. New York, Columbia University Press.

De Solla Price, D. J. (1986). Little science, big science ... and beyond. New York, Columbia University Press.

Somit, A. and S. A. Peterson (1998). "Biopolitics after Three Decades - A Balance Sheet." British Journal of Political Science 28(3): 559-571.

Spradley, J. P. (1980). Participant observation. Orlando, Florida, Hartcourt Brace Jovanovich.

Star, S. L. and J. R. Griesemer (1989). "Institutional ecology, "translations", and boundary objects. Amateurs and Professionals in Berkeley's Museum of Vertebrate Zoology, 1907 - 1939." Social Studies of Science 19(3): 387420 .

Strauss, A., S. Fagerhaugh, B. Suczek and C. Wiener (1985). Articulation work. Social organization of medical work. Chicago, IL, The University of Chicago Press: 151-190. 
Swartz Rose, M. (1937). "Racial Food Habits in Relation to Health." The Scientific Monthly 44(3): 257-267.

Swiersta, T., M. Korthals and J. Keulartz (2002). You only live twice. Ethische tekortkomingen in het omgaan met genomics. Twente \& Wageningen, University of Twente \& Wageningen University.

Talmud, P. J. and D. M. Waterworth (2000). "In-vivo and in-vitro nutrient-gene interactions." Current Opinions in Lipidology 11(1): 31-36.

Thompson Klein, J. (1990). Interdisciplinarity. History, theory and practice. Detroit, Wayne State University.

Thompson Klein, J. (1998). "Notes toward a social epistemology of transdisciplinarity." Bulletin Interactif du Centre International de Recherches et Études Transdisciplinaires 12.

Thompson Klein, J. (2000). A conceptual vocabulary of interdisciplinary science. Practising Interdisciplinarity. P. Weingart and N. Stehr. Toronto, Buffalo \& London, University of Toronto Press: 3-24.

Toom, V. (2006). "DNA fingerprinting and the right to inviolability of the body and bodily integrity in the Netherlands: convincing evidence and proliferating bodyparts." Genomics, Society and Policy 2(3): 64-74.

Trischler, H. (2002). The "Triple Helix" of Space. German Space Activities in a European Perspective. History Study Reports. R. A. Harris. Noordwijk, European Space Agency.

Tuunainen, J. (2002). "Reconsidering the Mode 2 and the Triple Helix: A critical comment based on a case study." Science Studies 15(2): 36-58.

Vandeberg, L. L. J., E. H. M. Moors and S. Kuhlmann (2007). Proximity and Interactive Learning in the Dutch Nutrigenomics Innovation System. DRUID Winter Conference 2007. Aalborg, Denmark. January 25-27.

Venter, J. C., M. D. Adams, E. W. Myers, P. W. Li, R. J. Mural, et al. (2001). "The sequence of the human genome." Science 291(5507): 1304-1351.

Vermeulen, N. (2008). Supersizing Science. On building large-scale research projects in biology. Faculty of Arts and Social Sciences. Maastricht, Maastricht University: manuscript in preparation.

Vermeulen, N. and B. Penders (2007). Big Science. Encyclopedia of Earth. C. J. Cleveland and K. Vranes. Washington DC, Environmental Coalition, National Council for Science and the Environment: http://www.eoearth. org/article/Big_Science.

Voncken, F., B. Boxma, J. Tjaden, A. Akhmanova, M. Huynen, et al. (2002). "Multiple origins of hydrogenosomes: functional and phylogenetic evidence 
from the ADP/ATP carrier of the anaerobic chytrid Neocallimastix sp." Molecular Microbiology 44(6): 1441-1454.

Vos, R., K. Horstman, H. A. E. Zwart, G. de Wert, W. H. M. Saris, et al. (2002). Nutrigenomics and society in the making: a conceptual empirical analysis of the evolving research practice of an integrated genomics approach towards gut health and nutrition. Maastricht, Maastricht University.

de Vries, G. (2007). "What is political in sub-politics? How Artistotle might help STS." Social Studies of Science 37(5): 781-809.

de Vries, G. and K. Horstman (2008). Learning from the work that links laboratory to society. Genetics from Laboratory to Society. Societal Learning as an Alternative to Regulation. G. de Vries and K. Horstman. Hampshire (UK) \& New York, Palgrave MacMillan: 171-190.

Vrouwe, A. (2007). Complex debat - genomics en maatschappij. Complex debate - genomics and society. The Hague, Netherlands, Netherlands Genomics Initiative.

Wallace, H. (2006). Your diet tailored to your genes: Preventing diseases or misleading marketing?, Genewatch UK.

Watkins, S. M., B. D. Hammock, J. W. Newman and J. B. German (2001). "Individual metabolism should guide agriculture toward foods for improved health and nutrition." American Journal of Clinical Nutrition 74(3): 283286.

Webster, A. (2007). "Crossing boundaries: social science in the policy room." Science, Technology and Human Values 32(4): 458-478.

Weinberg, A. M. (1961). "Impact of Large-Scale Science on the United States: Big science is here to stay, but we have yet to make the hard financial and educational choices it imposes." Science 134(3473): 161-164.

Weinberg, R. A. (2006). "A lost generation." Cell 126(1): 9-10.

Weingart, P. (1997a). "From "finalization" to "Mode 2": old wine in new bottles?" Social Science Information 36(4): 591-613.

Weingart, P. (1997b). „Interdisziplinarität - der paradoxe Diskurs.“ Ethik und Sozialwissenschaften 8(4): 521-529.

Weingart, P. (1997c). ,Interdisziplinarität im Kreuzfeuer: Aus dem Paradox in die Konfusion und zurück." Ethik und Sozialwissenschaften 8(4): 589-597.

Weingart, P. (2000). Interdisciplinarity: the paradoxical discourse. Practising Interdisciplinarity. P. Weingart and N. Stehr. Toronto, Buffalo \& London, University of Toronto Press: 25-41.

Weingart, P. and N. Stehr, Eds. (2000). Practising Interdisciplinarity. Toronto, Buffalo \& London, University of Toronto Press.

Westfall, C. (2003). "Rethinking Big Science." Isis 94: 30-56. 
Williams, R. J. (1956). Biochemical individuality. The basis for the genetotrophic concept. New York, John Wiley \& Sons.

Wolinsky, H. (2007). "The thousand-dollar genome. Genetic brinkmanship or personalized medicine?" EMBO Reports 8(10): 900-903.

Woo Park, H., H. Deug Hong and L. Leydesdorff (2005). "A comparison of the knowledge-based innovation systems in the economies of South Korea and the Netherlands using Triple Helix indicators." Scientometrics 65(1): 327.

Wood, D. (1992). The power of maps. New York and London, The Guilford Press.

Yeretzian, C., P. Pollien, C. Lindinger and S. Ali (2004). "Individualization of flavor preferences: toward a consumer-centric and individualised aroma science." Comprehensive Reviews in Food Science and Food Safety 3(4): 152-159.

Young, V. R. and N. S. Scrimshaw (1979). "Genetic and biological variability in human nutrient requirements." American Journal of Clinical Nutrition 32(2): 486-500.

Zwart, H. A. E. (2000). “A short history of food ethics.” Journal of Agricultural and Environmental Ethics 12(2): 113-126.

Zwart, H. A. E. (2005a). "Food consumption in the genomics era: a foucauldian perspective." Tailoring Biotechnologies 1(2): 31-44.

Zwart, H. A. E. (2005b). "Wat is genomics? Een filosofische profielschets." Filosofie en Praktijk 26(1): 28-37.

Zwart, H. A. E. (2007a). "Genomics and self-knowledge. Implications for societal research and debate." New Genetics and Society 26(2): 181-202.

Zwart, H. A. E. (2007b). Slankheid als beschavingsoffensief: de culturele en maatschappelijke betekenis van obesitas. De obesogene samenleving. Maatschappelijke perspectieven op overgewicht. H. Dagevos and G. Munnichs. Amsterdam, Amsterdam University Press: 43-51. 


\section{ENGLISH SUMMARY}

One of the characteristics of contemporary science it is a large scale endeavour: scientists from many different disciplines and from different parts of the world are cooperating to solve specific scientific problems. To many people this kind of cooperation seems to be a self-evident answer to the complexity of many problems: it is assumed that worldwide cooperation between more disciplines and more institutions makes it easier to solve the research problems at stake. In this book this assumption will be questioned. For, how such cooperation works and which consequences large-scale cooperation may have for the science performed and for the knowledge and norms that co-evolve inside such a cooperation, for the most part remains unclear. This thesis aims to fill in this gap and argues to consider both the technical and normative work accomplished in large scale genomics science.

In this book, contemporary nutrition science is used as an example, and in particular it focuses on the emerging field of nutrigenomics, linking nutrition science with genetic and genomic research practices. It explores the following question: How does large scale nutrition science work? Contained within this central question are two derivative questions. The first one asks how nutrition science is able to construct its problems and solutions and how it gets 'things to work'. How much work and what kind of work does this take and what happens to the character of the problem in the process? The second one deals with the evolution of new norms which are equally important in the working of a scientific practice. It studies nutrigenomics as a normative practice, involving normative work. In particular, how do notions of health and individuality interact with the notion of nutrition in this particular field, how do these conceptualisations coevolve with knowledge production in nutrition science and what are the political effects of these processes. Thus, what sorts of work are necessary for cooperation to succeed and what norms for health or nutrition are being shaped?

Chapter 1 describes how large-scale science was put on the public agenda and subsequently discussed, starting with the introduction of the notion of 'Big Science' in the 1960s and continuing with the notions of 'New Production of Knowledge' and 'Triple Helix' approaches in the 1990s. It reviews the most important critiques on these three approaches and argues for an increased focus on the normative work in science, the work required to determine 'technical' norms such as cut off points in biological parameters, samples, pathways, and statistical and analytical models as well as the 'evaluative' norms such as what counts as 'proper science', 'proper scientific conduct', and 'proper ways of interacting with society at large'. To this end, the inclusion of a biopolitical inquiry into this study 
of large-scale nutrition science is introduced, which implies not only to focus on the dynamics of how knowledge, techniques and norms co-evolve within genomic technologies, but also on their normative and political impact on society. Further, it introduces two nutrition science research programs which have been the subject of this study: the Dutch genomics based Gut Health programme and the EC funded European Nutrigenomics Organisation (NuGO).

In order to study how, in large-scale nutrition science, research problems are articulated, rearticulated and solved, as well as to study which normative work is performed and which effects this work has, the methodology of 'following the actor' has been chosen. The actors followed throughout this book are the norms relating to health, nutrition and individuality. Chapter 2 argues that an ethnographic approach to this study is the most productive method to do so because a deeper understanding of large-scale science practices requires an in-depth and situated study of the multiple sites of such large-scale science practices. The particularities of this approach are presented through the use of a nautical metaphor, in which the researcher sails through uncharted territories alongside the 'fleets' of the different expert fields in nutrigenomics and other stakeholders, e.g. food industry. When using an ethnographic approach, a careful balance of cognitive and normative distance, as well as proximity is important and an approach to uphold this balance is presented. The close interaction which results from this approach, facilitates a reciprocal cognitive and normative influence and appreciation between researcher and researched, a process which this chapter identifies as sensitisation, a concept drawn from biology which helps to understand how expertises may be (partially) exchanged.

When large groups of researchers cooperate, tasks are divided and large problems are spliced into manageable parts. Chapter 3 shows how both problems and the organisations that attempt to solve them are made modular. The Gut Health programme consists of a complex array of geographical and non-geographical sites. This chapter analyses the role of the boundaries that exist inside such a complex setting. How do experiments conducted at one particular site relate to the goals of the whole programme? Scientists pursue doable problems. At every site in the programme, problems are continuously attempted to be made doable. Scientific practice strives to move on, but as ties are forged to enable it to do so, other ties are unmade or made unlikely. The genomics technologies can be identified as an important array of ties, whereas, intriguingly the notion of health also exists at many of these sites. In the process of making modules of the problem doable, elements that are part of that problem are changed. The notion of health is not immune to such change, and so it can be observed that the standard 
of health changes in the Gut Health programme. It is modified according to the characteristics of the research situation and since there are multiple modules of the problem and of the organisation, multiple modifications take place. Influenced by the genomic technology, the notion of health is made molecular and influenced by the modularity of the research situation, health is made situated.

Cooperation in a programme can be very difficult, especially when the partners have different disciplinary backgrounds. A special example of cooperation exists between laboratory practice and computation: 'wet' and 'dry' research. Epistemological differences between 'wet' and 'dry' research result in practical problems in daily cooperation. Chapter 4 introduces 'wet' and 'dry' as different styles of science and demonstrates that next to intentions, interdependence and social relations specific technologies are able to act as 'facilitator devices' for cooperation via identifying a common ground. To illustrate this point I expose the crucial role of the gene pathway map as communication tool in scientific practice. Where 'wet' and 'dry' styles of science meet, this may result in the formation of a new style-in-the-making, the 'moist' style. The emergence of a 'moist' style teaches us about the inner workings of difficult cooperation in large-scale nutrigenomics science and demonstrates how, despite the formation of a 'moist' style, 'wet' and 'dry' styles stabilise and even continue to specialise. Different styles conceptualise elements in the research situation differently, because of material and practical differences between the styles, but also because of a different epistemological rooting. The notion of health is not stable across styles and as a result, 'wet' and 'dry' healths can be identified in which the 'wet' healths can be considered molecular whereas the 'dry' healths can be considered computation-based.

However, there is a limit to the diversification of healths. One of the goals uttered by nutrigenomics was the personalised diet. The personalised diet suggested the individualisation of health. Chapter 5 argues that promises and research practice surrounding the personalised diet interact. Expectations and laboratory practice are important to creating doable research problems, but in different ways. In promises and expectation, personalisation is conceptualised as individualisation, whereas in practice, it is conceptualised as categorisation. In promises and expectations, people abstract from the practical requirements of doing laboratory work. Promises serve the purpose of relating nutrigenomics to the outside world. It can be called rallying, fundraising or creating enthusiasm, or from a constructivist perspective, the gathering of new allies for ones network. Thus, personalisation as individualization and personalisation as categorisation are not at odds with one another and promises and expectation contribute to the construction of doable 
problems. It is, however, imperative for the researchers dealing with the ethical, legal and social issues (ELSI) of nutrigenomics, that they appreciate the difference between them and visit sites at which both personalization proliferate, in order to present an account true to nutrigenomic practice.

In order to produce a doable research problem, all the modules of the problem have to be created doable at a vast array of different sites and in various different disciplines and styles. Furthermore, expectations and promises act upon research practice. In chapter 6 , the insights from chapters 3-5 are combined into a doability network, in which the integration of the local, situated doabilities, as well as the ties between them, results in the doability of the overall research problem. In the process of constructing these doabilities, multiple healths have come into being, some of them molecular, some of them risk-based, but none of them individual. As compared to the 'New Production of Knowledge' and 'Triple Helix', this approach leaves ample room for recognition of the normative work performed in large-scale science.

When considering the construction of multiple co-existing norms for health, in relation to nutrition and the individual, it becomes clear that existing biopolitical theory about normalising and disciplining effects of health can be considered problematic since it presupposes a uniform notion of health. Current biopolitical analyses are not paying enough attention to the pluriformity and diversity of research practice. This thesis shows that investing in biopolitics in practice, may alleviate this blind spot. 


\section{NEDERLANDSE SAMENVATTING}

Een van de kenmerken van hedendaagse wetenschap is dat het een grootschalige onderneming is. Wetenschappers uit vele verschillende disciplines en van over de hele wereld werken samen om specifieke wetenschappelijke problemen op te lossen. Deze manier van samenwerken lijkt voor heel veel mensen een logisch antwoord op de complexiteit van vele problemen: er wordt verondersteld dat het oplossen van de wetenschappelijke problemen in kwestie makkelijker wordt door meer wereldwijde samenwerking tussen meer disciplines en meer instituten. In dit boek wordt deze veronderstelling in twijfel getrokken. Want hoe deze samenwerking precies werkt, en welke consequenties grootschalige samenwerking heeft voor de wetenschap die er wordt bedreven en voor de kennis en normen die zich ontwikkelen, is nog grotendeels onbekend. Om hier verandering in te brengen, beschrijft dit proefschrift zowel het technische als het normatieve werk dat wordt verzet in de grootschalige genoomwetenschappen.

In dit boek wordt de hedendaagse voedingswetenschap als voorbeeldstudie gebruikt. In het bijzonder wordt er aandacht besteedt aan het opkomende gebied 'nutrigenomics', dat voedingswetenschap verbindt met genetische en genomische onderzoekspraktijken. Het boek verkent de vraag: hoe werkt grootschalige voedingswetenschap? Dit zijn eigenlijk twee vragen, namelijk allereerst hoe de voedingswetenschap het voor elkaar krijgt om haar problemen en oplossingen op elkaar aan te passen; hoe voedingswetenschap 'werkt'. Hoe veel werk, en wat voor soort werk is hiervoor nodig en wat gebeurt er met het de kenmerken van het probleem tijdens het hele proces? De tweede vraag gaat over de evolutie van nieuwe normen die van groot belang zijn in het functioneren van een wetenschappelijke praktijk. Deze vraag ziet nutrigenomics als een normatieve praktijk, die zich bezig houdt met normatief werk. In het bijzonder: hoe noties van gezondheid en het individu in dit veld samenhangen met de notie van voeding, hoe deze noties zich samen ontwikkelen met kennisproductie in de voedingswetenschappen en wat de politieke effecten van dit alles zijn. Kortom, welke soorten werk zijn er nodig om samenwerking te laten slagen en welke normen voor gezondheid en voeding worden er gevormd?

Hoofdstuk 1 introduceert hoe grootschalige wetenschap op de publieke agenda is gezet en vervolgens onderwerp van debat werd. Allereerst na de introductie van 'Big Science' in de zestiger jaren van de vorige eeuw en vervolgens met de 'New Production of Knowledge' en de 'Triple Helix' in de negentiger jaren. Hoofdstuk laat de meest belangrijke kritieken op deze drie theorieën zien waaruit duidelijk wordt dat het vruchtbaar is om zich meer te richten op het normatieve werk in de wetenschap. Dit is het werk dat nodig is om technische normen 
vast te stellen, zoals de drempelwaarden van bepaalde biologische parameters, monsters, pathways en statistische en analytische modellen, maar ook evaluatieve normen die beschrijven wat telt als 'goede wetenschap', 'goed wetenschappelijk gedrag' of 'een goede samenwerking van wetenschap en maatschappij'. Daarom behandelt deze studie ook een biopolitieke vraagstelling en stelt dus voor om niet uitsluitend te letten op de dynamiek van hoe kennis, technieken en normen zich in een genomische praktijk samen ontwikkelen, maar ook op de normatieve en politieke gevolgen voor de maatschappij. Ook worden hier twee voedingsw etenschappelijke onderzoeksprogramma's geïntroduceerd die onderwerp zijn geweest van deze studie: het Nederlandse genoomwetenschappelijke Gut Health programma en het door de Europese Commissie gefinancierde NuGO (European Nutrigenomics Organisation).

Om te bestuderen hoe wetenschappelijke problemen in de grootschalige voedingswetenschap telkens opnieuw worden gearticuleerd en vervolgens opgelost en daarom ook hoe het normatieve werk wordt uitgevoerd en welke effecten het heeft, is er voor de methodologie van 'following the actor' gekozen. De actoren die zijn gevolg voor dit boek, zijn de normen die betrekking hebben op gezondheid, voeding en individualiteit. Hoofdstuk 2 laat zien dat een etnografische aanpak hiervoor het meest geschikt is. Inzicht in een grootschalige wetenschappelijke praktijk vereist gedetailleerde studie van de verschillende plekken van de praktijk. Deze aanpak wordt beschreven met behulp van een nautische metafoor waarin de onderzoeker door onbekende wateren zeilt, samen met 'vloten' van verschillende experts uit de nutrigenomics en andere stakeholders, waaronder de voedingsindustrie. Wanneer men gebruik maakt van een etnografische aanpak, is het belangrijk een balans te vinden tussen cognitieve en normatieve afstand en nabijheid. Dit leidt tot een nauwe samenwerking en maakt een wederzijdse cognitieve en normatieve beïnvloeding en waardering tussen onderzoeker en onderzochte mogelijk. In dit hoofdstuk wordt dit proces sensitisering genoemd. Sensitisering is gebaseerd op de gelijknemige term uit de biologie en helpt te begrijpen hoe expertises (gedeeltelijk) kunnen worden uitgewisseld.

Als grote groepen wetenschappers samenwerken, worden taken verdeeld en problemen in kleinere, hanteerbare delen gesplitst. Hoofdstuk 3 laat zien hoe zowel problemen als de organisaties die ze proberen op te lossen modulair worden gemaakt. Het Gut Health programma bestaat uit een ingewikkelde set geografische en niet-geografische plekken. Dit hoofdstuk beschrijft de rol van de grenzen die bestaan tussen de delen van zo'n ingewikkelde organisatie. Hoe houden de experimenten die op de ene plek worden uitgevoerd verband met de doelen van het gehele programma? Wetenschappers streven uitvoerbare 
problemen na en dus wordt op elke plek in het onderzoeksprogramma voortdurend geprobeerd om problemen uitvoerbaar te maken. De wetenschappelijke praktijk probeert verder te komen, maar wanneer nieuwe verbanden worden gelegd om dit mogelijk te maken, worden andere verbanden daardoor ongedaan gemaakt of onwaarschijnlijk gemaakt. De genomische technologieën kunnen worden gezien als een belangrijke set van zulke verbanden tussen plekken. De notie van gezondheid bestaat tegelijkertijd op al deze plekken. In het proces dat modules van het onderzoeksprogramma uitvoerbaar maakt, veranderen delen van het probleem en 'gezondheid' is niet ongevoelig voor zulke veranderingen. We kunnen dan ook zien dat in het Gut Health onderzoeksprogramma de norm voor gezondheid verandert. Deze veranderingen binnen de context van de onderzoekssituatie en angezien er meerdere modules bestaan van zowel het probleem als de organisatie, vinden er dus meerdere veranderingen plaats. Onder invloed van o.a. de genomische technologie, wordt gezondheid moleculair gemaakt en op basis van de modulariteit van de onderzoekssituatie, wordt gezondheid situatieafhankelijk.

Samenwerken in een onderzoeksprogramma kan heel moeilijk zijn, zeker wanneer de partners een verschillende disciplinaire achtergrond hebben. De samenwerking tussen laboratoriumpraktijk en berekeningen, ook wel 'nat' en 'droog' onderzoek genoemd, is een bijzonder voorbeeld van samenwerking. Epistemologische verschillen tussen 'nat' en 'droog' onderzoek resulteren in praktische problemen binnen de dagelijkse samenwerking. Hoofdstuk 4 introduceert 'nat' en 'droog' als verschillende stijlen van wetenschap. Verder laat het zien dat naast bedoelingen, afhankelijkheid en sociale relaties, specifieke technologieën samenwerking kunnen bevorderen. Dit hoofdstuk introduceert de 'gene pathway map' als een voorbeeld van belangrijk hulpmiddel voor de communicatie en uitwisseling binnen de wetenschap. Daar waar 'nat' en 'droog' elkaar overlappen, kan dit leiden tot de ontwikkeling van een nieuwe stijl-in-wording, de 'moist' stijl. Van het ontstaan van deze 'moist' stijl kunnen we over de werking van moeilijke samenwerkingen in grootschalige voedingswetenschap leren. Dit hoofdstuk laat verder zien dat het ondanks het ontstaan van de nieuwe 'moist' stijl, bestaande 'nat' en 'droog' stijlen blijven bestaan en zelfs verder stabiliseren. Verschillende stijlen conceptualiseren elementen in de onderzoekspraktijk op verschillende manieren. Dat gebeurt op basis van verschillende praktische en materiële zaken in de praktijk, maar ook op basis van epistemologische verschillen. De notie van gezondheid is niet stabiel over de stijlen heen, en er kunnen dan ook 'droge' en 'natte' gezondheden worden geïdentificeerd in de praktijk. De 'natte' gezondheden kunnen als moleculair worden opgevat, terwijl de 'droge' gezondheden gebaseerd zijn op berekeningen. 
Er is echter een grens aan de diversiteit van gezondheid. Een van de doelen van nutrigenomics is het gepersonaliseerde dieet.Ditgepersonaliseerde dieet suggereert de individualisering van gezondheid. Hoofdstuk 5 laat zien dat verwachtingen en wetenschappelijke praktijk invloed op elkaar uitoefenen. Verwachtingen en laboratoriumpraktijken zijn allebei van belang bij de constructie van uitvoerbare problemen, maar op een verschillende manier. In beloften en verwachtingen wordt personalisatie uitgelegd als individualisering. In de wetenschappelijke praktijk daarentegen, wordt het uitgelegd als categorisering. Bij beloften en verwachtingen nemen mensen afstand van de praktische vereisten van het doen van laboratoriumwerk. Beloften zijn echter belangrijk om nutrigenomics te verbinden met de buitenwereld. Dit kan enthousiasmeren genoemd worden, of het verzamelen van steun, of vanuit een constructivistisch perspectief: het verwerven van nieuwe bondgenoten. Personalisatie als individualisatie en personalisatie als categorisatie hoeven elkaar niet uit te sluiten. Het is wel van belang van de onderzoekers die zich bezig houden met de ethische, juridische en maatschappelijke aspecten (ELSA) van nutrigenomics dat ze het verschil tussen beiden ter kennis nemen, en plaatsen bezoeken waar beiden voorkomen om een volledigere analyse van de praktijk mogelijk te maken.

Om een uitvoerbaar probleem te produceren moet er rekening worden gehouden met de uitvoerbaarheid van de verschillende modules van het probleem. Deze komen op verschillende plekken voor en bestaan binnen verschillende stijlen van wetenschap. Verder is het van belang om de invloed van beloften en verwachtingen op de praktijk serieus te nemen. In hoofdstuk 6 worden de inzichten verkregen uit de voorgaande hoofdstukken gecombineerd tot het uitvoerbaarheidsnetwerk. In dat netwerk worden lokale, modulaire uitvoerbaarheden samen met de onderlinge verbindingen, samen gevoegd tot de uitvoerbaarheid van het overkoepelende probleem. Tijdens het proces dat deze uitvoerbare problemen heeft opgeleverd, zijn er meerdere gezondheden ontstaan. Sommigen daarvan zijn moleculair, anderen calculatief/risicogebaseerd van aard, maar geen enkele is individueel. Vergeleken met de 'New Production of Knowledge' en de 'Triple Helix' laat deze aanpak ruimte voor het herkennen van het normatieve werk zoals dat wordt verricht in grootschalige wetenschappelijke praktijken.

Wanneer we rekening houden met het bestaan van verschillende normen voor gezondheid, wordt het bestaande biopolitieke denken problematisch. Het maatschappijbrede redeneren in termen van normalisering en disciplinering vooronderstelt namelijk een uniform beeld van gezondheid. Huidige biopolitieke analyses houden onvoldoende rekening met de veelvormigheid en diversiteit van onderzoekspraktijken. Dit proefschrift toont dat een investering in biopolitiek in de praktijk dit gemis kan compenseren. 


\section{CURRICULUM VITAE}

Bart Penders was born on September 26, 1980 in Geleen (the Netherlands). In 1992 he received his VWO diploma (grammar school, A-levels) from the Episcopal College Sittard (currently: Trevianum Sittard, the Netherlands). In the same year, he took up biology at the University of Nijmegen (currently: Radboud University Nijmegen, the Netherlands). After a few years he specialised in evolutionary microbiology and extremophile microbiology, the former at Nijmegen and the latter at Regensburg University (Germany) resulting in two Masters theses. After having fulfilled all requirements for obtaining a Masters degree, he decided to take part in the experimental 'Biology and Communication' curriculum being set up in Nijmegen in 2002. As a part of this additional specialisation he wrote a third thesis before receiving his Master of Science degree cum laude from Nijmegen University at June 24, 2003. Later that year, he started his research as a Ph.D.-student at Maastricht University (the Netherlands) conducted as a part of the Netherlands Organisation of Scientific Research programme 'Societal Component of Genomics' and enlisted in the research school WTMC (Science, Technology and Modern Culture). The research project, under supervision of prof. dr. Rein Vos and prof. dr. Klasien Horstman, resulted in several publications, including this book. As of 2008, he holds positions as post-doctoral research fellow at Maastricht University, Department of Health, Ethics \& Society, and at the Radboud University Nijmegen, Centre for Society and Genomics. 


\section{LIST OF PUBLICATIONS}

Penders, B., Horstman, K. \& Vos, R. (2008). Walking the line between biology and computation: the 'moist' zone. BioScience 58 (8): accepted.

Penders, B., Horstman, K. \& Vos, R. (2008). A ferry between cultures. Crafting a profession at the intersection of science and society. EMBO Reports 9: accepted.

Penders, B. (2008). No man is an island: categorising the individual in contemporary nutrition science. FoodInfo Online Features (Feb): 19.

Van Hoyweghen, I. \& Penders, B. (2007) Research in the Wild. Nature 450 (7169): 478.

Vermeulen, N. \& Penders, B. (2007) Big Science. Encyclopedia of Earth. C. J. Cleveland and K. Vranes. Washington DC, Environmental Coalition, National Council for Science and the Environment.

Penders, B. (2007). Personalised diet: is it doable? Individuality at different sites of nutrigenomic practice. Genes and Nutrition 2(1): 93-94.

Penders, B., Horstman, K. \& Vos, R. (2007) Proper Science in Moist Biology. EMBO Reports 8 (7): 613.

Radstake, M. \& Penders, B. (2007) Inside genomics: the interdisciplinary faces of ELSA. Graduate Journal of Social Science 4 (1): 4-10.

Penders, B. (2007) Aligning Nutrigenomics and ELSA. Towards a politics of classification. Graduate Journal of Social Science 4 (1): 34-49.

Penders, B., Horstman, K., Saris, W.H.M. \& Vos, R. (2007) From individuals to groups: a review of the meaning of 'personalized' in nutrigenomics. Trends in Food Science and Technology 18 (6): 333-338 
